\title{
Computational Weld Mechanics Simulation of Hot Crack Nucleation
}

by

\begin{abstract}
Ahmed Nasser
A Thesis submitted to

the Faculty of Graduate Studies and Research

in partial fulfilment of

the requirements for the degree of

Master of Applied Science

in

Mechanical and Aerospace Engineering

Carleton University

Ottawa, Ontario, Canada
\end{abstract}

April 2012

Copyright (C)

2011 - Ahmed Nasser 
Library and Archives

Canada

Published Heritage

Branch

395 Wellington Street

Ottawa ON K1A ON4

Canada
Bibliothèque et

Archives Canada

Direction du

Patrimoine de l'édition

395 , rue Wellington

Ottawa ON K1A ON4

Canada
Your file Votre référence

ISBN: 978-0-494-91505-9

Our file Notre référence

ISBN: $978-0-494-91505-9$
NOTICE:

The author has granted a nonexclusive license allowing Library and Archives Canada to reproduce, publish, archive, preserve, conserve, communicate to the public by telecommunication or on the Internet, loan, distrbute and sell theses worldwide, for commercial or noncommercial purposes, in microform, paper, electronic and/or any other formats.

The author retains copyright ownership and moral rights in this thesis. Neither the thesis nor substantial extracts from it may be printed or otherwise reproduced without the author's permission.
AVIS:

L'auteur a accordé une licence non exclusive permettant à la Bibliothèque et Archives Canada de reproduire, publier, archiver, sauvegarder, conserver, transmettre au public par télécommunication ou par l'Internet, prêter, distribuer et vendre des thèses partout dans le monde, à des fins commerciales ou autres, sur support microforme, papier, électronique et/ou autres formats.

L'auteur conserve la propriété du droit d'auteur et des droits moraux qui protege cette thèse. $\mathrm{Ni}$ la thèse ni des extraits substantiels de celle-ci ne doivent être imprimés ou autrement reproduits sans son autorisation.
In compliance with the Canadian Privacy Act some supporting forms may have been removed from this thesis.

While these forms may be included in the document page count, their removal does not represent any loss of content from the thesis.
Conformément à la loi canadienne sur la protection de la vie privée, quelques formulaires secondaires ont été enlevés de cette thèse.

Bien que ces formulaires aient inclus dans la pagination, il n'y aura aucun contenu manquant. 


\section{Abstract}

Computational weld mechanics (CWM) is used to estimate the likelihood of hot crack nucleation in a welded joint. CWM predicts that a hot crack will nucleate when the evolution of the local state of stress and strain in the temperature region susceptible to hot cracking reaches a critical value. The local evolution of the stress, strain and temperature state determined by CWM is compared to experimentally measured value for material resistance for each type of hot cracking. This thesis evaluates the susceptibility to ductility dip cracking and solidification cracking, separately, for a single bead-on-plate welds of nickel-based alloys (FM82 and Inconel 600). This capability has the potential to estimate the risk of hot cracking in welded structures and of weld procedures at the design stage. Estimating the risk of hot cracking can aid in minimizing this risk and associated expenses. 
To my family. 


\section{Acknowledgments}

I am grateful for the guidance Prof. John Goldak provided me. Concepts discussed in this thesis are a result of his contribution. I am thankful for the relentless support I received from Prof. A. O. Abd El Halim. I appreciate the assistance Jianguo Zhou, Stanislav Tchernov, Daniel Downey, Mahyar Asadi and Komeil Kazemi have all provided me. I am also thankful for the funding I received from Carleton University and NSERC. 


\section{Table of Contents}

$\begin{array}{ll}\text { Abstract } & \text { ii }\end{array}$

Acknowledgments $\quad$ iv

$\begin{array}{ll}\text { Table of Contents } & \mathbf{v}\end{array}$

List of Tables $\quad$ viii

List of Figures $\quad$ ix

List of Acronyms $\quad$ xiii

List of Symbols $\quad$ xiv

1 Introduction $\quad 1$

1.1 Problem Statement ..................... 1

1.2 Research Objectives ..................... 2

1.3 Main Contributions ... . . . . . . . . . . . . . . 2

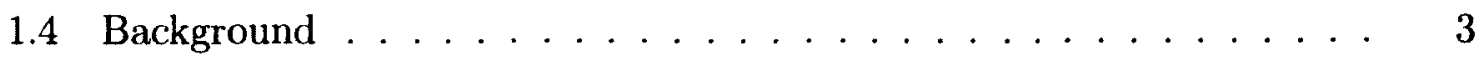

1.4.1 Computational Weld Mechanics ... . . . . . . . . 7

1.4 .2 Welding Process . . . . . . . . . . . . . . . 8

1.4.3 Welding Defects . . . . . . . . . . . . . . 9

1.5 Thesis Outline ........................ 10 
2 Weld Cracking $\quad 11$

2.1 Hot Cracking ...................... 12

2.1.1 Ductility Dip Cracking . . . . . . . . . . . . 13

2.1.2 Liquation Cracking . . . . . . . . . . . . . . . . . 14

2.1.3 Solidification Cracking . . . . . . . . . . . . 15

2.2 Weldabilty Tests . . . . . . . . . . . . . . . 17

2.2 .1 Varestraint Test . . . . . . . . . . . . . . 18

2.2.2 Measurement by Means of In Situ Observation Technique . . . 18

3 Methodology $\quad 21$

3.1 Project Description . . . . . . . . . . . . . . . . . 21

3.1.1 Domain for CWM Models . . . . . . . . . . . . 23

3.1 .2 Parameters ........................ 27

3.1.3 Boundary Conditions . . . . . . . . . . . . . . . . 31

3.1 .4 Initial Conditions . . . . . . . . . . . . . . . . . . 32

3.2 Variation of Design Parameters . . . . . . . . . . . . . 32

3.3 Estimating Risk of Hot Crack Nucleation . . . . . . . . . . . . . . . 33

3.3.1 Susceptible Temperature Range . . . . . . . . . . . . . . 33

3.3.2 Thermal Profile . . . . . . . . . . . . . . . . 34

3.3.3 Tensile Strain Increment and Rate . . . . . . . . . . . . . . 34

3.4 Special Considerations for Material Resistance and Damage Accumu-

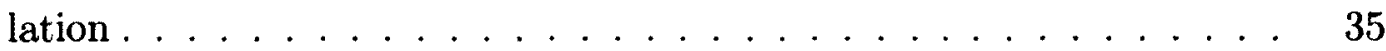

4 Results $\quad 39$

4.1 Ductility Dip Cracking Test . . . . . . . . . . . . . 39

4.1.1 Temperature.................... 39

4.1 .2 Strain ..................... . . 40

4.2 Solidification Cracking Test . . . . . . . . . . . . . . . 54 
4.2 .1 Temperature . . . . . . . . . . . . . . . . 54

4.2 .2 Strain $\ldots \ldots \ldots \ldots \ldots \ldots \ldots \ldots \ldots$

4.3 Discussion . . . . . . . . . . . . . . . . . . 61

5 Conclusion and Recommendations 63

5.1 Summary . . . . . . . . . . . . . . . 63

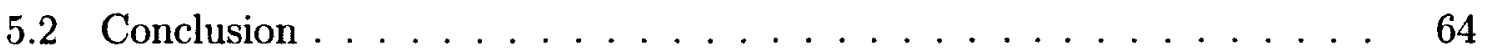

5.3 Reducing Hot Cracking Risk . . . . . . . . . . . . . . 64

5.4 Recommendations and Future Work . . . . . . . . . . . . . 65

$\begin{array}{ll}\text { A Material Properties } & 67\end{array}$

A. 0.1 Young's Modulus . . . . . . . . . . . . . 67

A. 0.2 Yield Stress $\ldots \ldots \ldots \ldots \ldots$

A.0.3 Viscosity . . . . . . . . . . . . . . 69

A.0.4 Thermal Conductivity $\ldots \ldots \ldots \ldots 69$

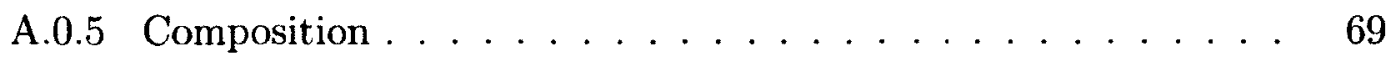

$\begin{array}{ll}\text { B Governing Equations } & \mathbf{7 1}\end{array}$

B.1 Thermal . . . . . . . . . . . . . . . . . . 71

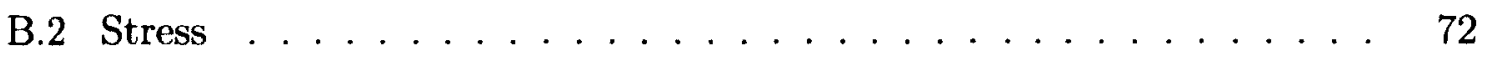

C Effect of Welding Speed on Hot Cracking Susceptibility 73

$\begin{array}{ll}\text { D Viscous Behaviour } & 79\end{array}$

D.1 Yield . . . . . . . . . . . . . . . . . . . . . 79

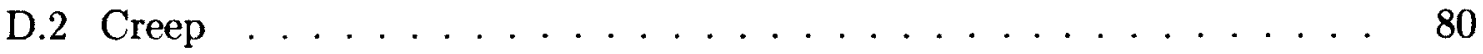

$\begin{array}{ll}\text { List of References } & \mathbf{8 4}\end{array}$ 


\section{List of Tables}

3.1 CWM models for DDC test. . . . . . . . . . . . . . . 23

3.2 CWM models for solidification cracking test. . . . . . . . . . . 23

3.3 DDC test: plate dimensions for CWM model after Chen and $\mathrm{Lu}$ [1] . 24

3.4 Solidification cracking test: plate dimensions for CWM model after Matusda et al. [2]. . . . . . . . . . . . . . . . 24

3.5 DDC test: mesh size of refined section in parent and sub-models. . . 25

3.6 Solidification cracking test: mesh size of refined section in parent and sub-models. . . . . . . . . . . . . . . . 25

3.7 DDC test: number of elements in parent and sub-models projects. . . 25

3.8 Solidification cracking test: number of elements in parent and submodels projects. . . . . . . . . . . . . . 26

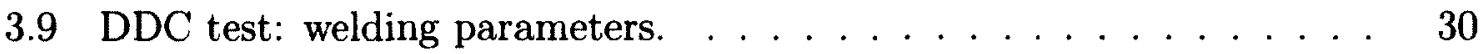

3.10 Solidification cracking test: welding parameters. . . . . . . . 30

3.11 Solidification cracking test: double ellipsoid dimensions. . . . . . . 30

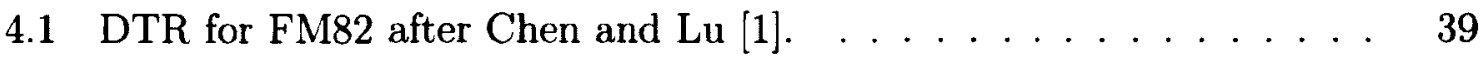

4.2 BTR for Inconel 600 after Matsuda et al. [3] . . . . . . . . . . . 55

A.1 Composition by weight percentage of alloying elements added to the nickel-based Inconel 600 after Matsuda et al. [4] . . . . . . . . 70

A.2 Composition by weight percentage of alloying elements for FM82 after Collins et al. $[5] \ldots \ldots \ldots \ldots \ldots \ldots \ldots$ 


\section{List of Figures}

3.1 DDC test: outline for plate, refined section and submodel. $\ldots \ldots .27$

3.2 Solidification cracking test: outline for plate, refined section and submodel. . . . . . . . . . . . . . . . . . 28

3.3 DDC critical strain at different temperatures with $0.5 \mathrm{~mm} / \mathrm{s}$ cross head speed after Chen and $\mathrm{Lu}[1] \ldots \ldots \ldots \ldots \ldots \ldots$

4.1 DDC test: temperature field and DTR iso-therms with a $2 \mathrm{~mm} / \mathrm{s}$ weld-

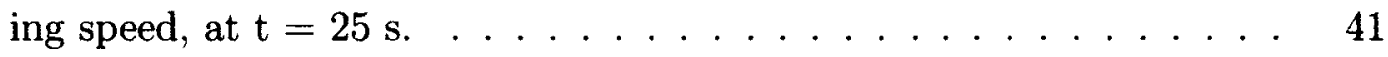

4.2 DDC test: temperature field and DTR iso-therms with a $5 \mathrm{~mm} / \mathrm{s}$ weld-

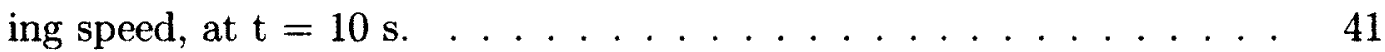

4.3 DDC test: results for temperature and strain are taken at Gauss points that are in between the markers. Shown is their location relative to temperature field in the sub-model with a $2 \mathrm{~mm} / \mathrm{s}$ welding speed, at $\mathrm{t}$

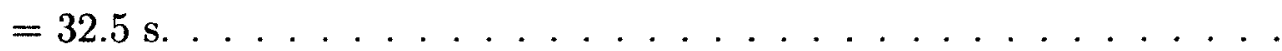

4.4 DDC test: temperature versus time with a $2 \mathrm{~mm} / \mathrm{s}$ welding speed, for Gauss points at the top surface of the plate, halfway across the weld

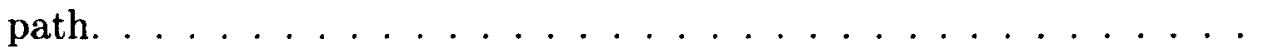

4.5 DDC test: temperature versus time with a $5 \mathrm{~mm} / \mathrm{s}$ welding speed, for Gauss points at the top surface of the plate, halfway across the weld path. . . . . . . . . . . . . . . . 
4.6 DDC test: temperature versus time, at distance of $5 \mathrm{~mm}$ from the weld centre-line, with a $2 \mathrm{~mm} / \mathrm{s}$ welding speed. . . . . . . . . . . . . 44

4.7 DDC test: increment in principal plastic strain 3 versus time, at distance of $5 \mathrm{~mm}$ from the weld centre-line, with a $2 \mathrm{~mm} / \mathrm{s}$ welding speed. 45

4.8 DDC test: sum of the damage parameter, $f_{i}$, versus time, at distance of $5 \mathrm{~mm}$ from weld centre-line, with a $2 \mathrm{~mm} / \mathrm{s}$ welding speed. . . .

4.9 DDC test: eigenvectors for 1st component of principal strain at $t=45$ $\mathrm{s}$, from 0 to $6 \mathrm{~mm}$ from weld centre, for a $2 \mathrm{~mm} / \mathrm{s}$ welding speed. . . .

4.10 DDC test: damage parameter, caused by eigenvalue for 1st component of principal plastic strain increment, versus time, for a $2 \mathrm{~mm} / \mathrm{s}$ welding

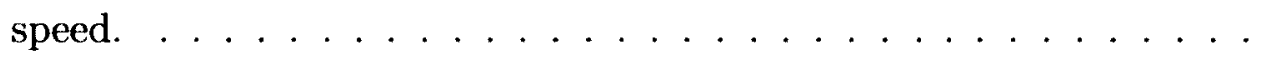

4.11 DDC test: eigenvectors for 2 nd component of principal strain at $\mathrm{t}=$ $45 \mathrm{~s}$, from 0 to $6 \mathrm{~mm}$ from weld centre, for a $2 \mathrm{~mm} / \mathrm{s}$ welding speed .

4.12 DDC test: damage parameter, caused by eigenvalue for 2 nd component of principal plastic strain increment, versus time, for a $2 \mathrm{~mm} / \mathrm{s}$ welding speed.

4.13 DDC test: eigenvectors for 3rd component of principal strain at $\mathrm{t}=$ $45 \mathrm{~s}$, from 0 to $6 \mathrm{~mm}$ from weld centre, for a $2 \mathrm{~mm} / \mathrm{s}$ welding speed. .

4.14 DDC test: damage parameter, caused by eigenvalue for 3rd component of principal plastic strain increment, versus time, for a $2 \mathrm{~mm} / \mathrm{s}$ welding

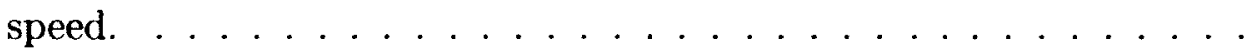

4.15 DDC test: equivalent plastic strain increment versus temperature, for a $2 \mathrm{~mm} / \mathrm{s}$ welding speed. . . . . . . . . . . . . .

4.16 DDC test: eigenvectors for 1 st component of principal strain at $t=18$ $\mathrm{s}$, from 0 to $6 \mathrm{~mm}$ from weld centre, for a $5 \mathrm{~mm} / \mathrm{s}$ welding speed. . . 50 
4.17 DDC test: damage parameter, caused by eigenvalue for 1st component of principal plastic strain increment, versus time, for a $5 \mathrm{~mm} / \mathrm{s}$ welding

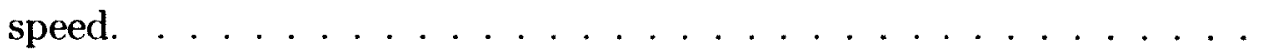

4.18 DDC test: eigenvectors for 2 nd component of principal strain at $t=$ $18 \mathrm{~s}$, from 0 to $6 \mathrm{~mm}$ from weld centre, for a $5 \mathrm{~mm} / \mathrm{s}$ welding speed. .

4.19 DDC test: damage parameter, caused by eigenvalue for 2nd component of principal plastic strain increment, versus time, for a $5 \mathrm{~mm} / \mathrm{s}$ welding

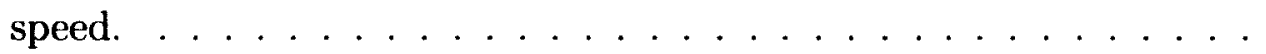

4.20 DDC test: eigenvectors for 3rd component of principal strain at $\mathrm{t}=$ $18 \mathrm{~s}$, from 0 to $6 \mathrm{~mm}$ from weld centre, for a $5 \mathrm{~mm} / \mathrm{s}$ welding speed. .

4.21 DDC test: damage parameter, caused by eigenvalue for 3rd component of principal plastic strain increment, versus time, for a $5 \mathrm{~mm} / \mathrm{s}$ welding

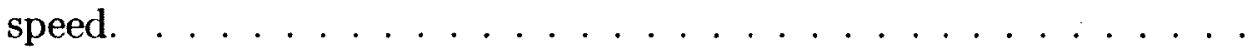

4.22 DDC test: equivalent plastic strain increment versus temperature for $5 \mathrm{~mm} / \mathrm{s}$ welding speed. . . . . . . . . . . .

4.23 Solidification cracking test: temperature versus distance computed from the start to end of the weld path at $t=12.5 \mathrm{~s} . \ldots \ldots \ldots 5$

4.24 Solidification cracking test: temperature versus time computed on the top surface of the weld centre-line and at $\mathrm{d}=16.96 \mathrm{~mm}$ from start of

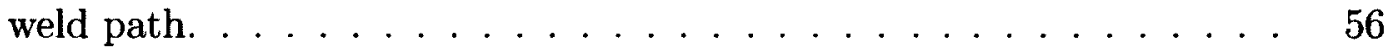

4.25 Solidification cracking test: temperature field at $\mathrm{t}=12.5 \mathrm{~s} \ldots \ldots \ldots 6$

4.26 Solidification cracking test: detailed temperature field with isosurfaces for the solidus and liquidus temperature at $\mathrm{t}=12.5 \mathrm{~s} \ldots \ldots \ldots$

4.27 Solidification cracking test: temperature field with isosurfaces for solidus and liquidus temperature, at $\mathrm{t}=12.5,12.875$ and $13.25 \mathrm{~s} \ldots \quad 58$

4.28 Solidification cracking test: strain versus time for different applied CHS. 59 
4.29 Solidification cracking test: strain versus temperature for different applied CHS. . . . . . . . . . . . . . . . . . . 59

4.30 Solidification cracking test: results from solidification cracking postprocessor for an applied CHS of $20 \mathrm{~mm} / \mathrm{s} . \ldots \ldots \ldots$

A.1 Young's modulus versus temperature after VrSuite $[6] . \ldots \ldots 7$

A.2 Yield stress versus temperature for Inconel 600 after VrSuite [6] . . . 68

A.3 Yield stress versus temperature for FM82 after Chen et al. [7] . . . 68

A.4 Thermal conductivity versus temperature after VrSuite [6] . . . . . 69

C.1 Welding speed test: temperature distribution and DTR iso-therms with a $2 \mathrm{~mm} / \mathrm{s}$ welding speed, at $\mathrm{t}=40 \mathrm{~s} \ldots \ldots \ldots 75$

C.2 Welding speed test: temperature distribution and DTR iso-therms with a $5 \mathrm{~mm} / \mathrm{s}$ welding speed, at $\mathrm{t}=16 \mathrm{~s} \ldots \ldots \ldots 75$

C.3 Welding speed test: temperature distribution and BTR iso-therms with a $2 \mathrm{~mm} / \mathrm{s}$ welding speed, at $\mathrm{t}=40 \mathrm{~s} \ldots \ldots \ldots \ldots$

C.4 Welding speed test: temperature distribution and BTR iso-therms with a $5 \mathrm{~mm} / \mathrm{s}$ welding speed, at $\mathrm{t}=16 \mathrm{~s} \ldots \ldots \ldots \ldots$

C.5 Welding speed test: stress XX (transverse to weld path) field with a 2 $\mathrm{mm} / \mathrm{s}$ welding speed, at $\mathrm{t}=40 \mathrm{~s} . \ldots \ldots \ldots \ldots 77$

C.6 Welding speed test: stress $\mathrm{ZZ}$ (longitudinal to weld path) field with a $2 \mathrm{~mm} / \mathrm{s}$ welding speed, at $\mathrm{t}=40 \mathrm{~s} \ldots \ldots \ldots \ldots 77$

C.7 Welding speed test: stress XX (transverse to weld path) field with a 5 $\mathrm{mm} / \mathrm{s}$ welding speed, at $\mathrm{t}=16 \mathrm{~s} \ldots \ldots \ldots \ldots 78$

C.8 Welding speed test: stress $\mathrm{ZZ}$ (longitudinal to weld path) field with a $5 \mathrm{~mm} / \mathrm{s}$ welding speed, at $\mathrm{t}=16 \mathrm{~s} \ldots \ldots \ldots \ldots$ 


\section{List of Acronyms}

\begin{tabular}{ll}
\hline Acronym & Definition \\
\hline CHS & Cross Head Speed \\
CWM & Computational Weld Mechanics \\
BTR & Brittleness Temperature Range \\
DDC & Ductility Dip Cracking \\
DTR & Ductility Dip Temperature Range \\
HAZ & Heat Affected Zone \\
MISO & Measurement by Means of In Situ Observation \\
PMZ & Partially Melted Zone \\
SEM & Scanning Electron Microscope \\
\hline
\end{tabular}




\section{List of Symbols}

\begin{tabular}{ll} 
Symbol & Definition \\
\hline$e$ & Euler's constant \\
$\epsilon$ & equivalent (von Mises) strain \\
$\dot{\epsilon}$ & equivalent (von Mises) strain rate $\left(\mathrm{s}^{-1}\right)$ \\
$\dot{\epsilon}_{S}$ & minimum creep rate $\left(\mathrm{s}^{-1}\right)$ \\
$f_{i}$ & damage parameter \\
$\Gamma$ & plastic flow rate, plastic strain rate $\left(\mathrm{s}^{-1}\right)$ \\
$J_{2}$ & invariant of second deviatoric stress $(\mathrm{Pa})$ \\
$k$ & Boltzmann constant $\left(\mathrm{m}^{2} \mathrm{~kg} \mathrm{~s}^{-2} \mathrm{~K}^{-1}\right)$ \\
$\kappa$ & extent of work hardening, a positive internal variable \\
$Q$ & activation energy $(\mathrm{J})$ \\
$Q_{\text {input }}$ & heat input rate $\left(\mathrm{J} \mathrm{s}^{-1}\right)$ \\
$R$ & gas constant $\left(\mathrm{J} \mathrm{K}^{-1}\right.$ mol \\
& dynamic flow stress scalar $(\mathrm{Pa})$
\end{tabular}




$\begin{array}{ll}\sigma & \text { equivalent (von Mises) stress (Pa) } \\ T & \text { temperature (K) } \\ t & \text { time (s) } \\ \tau & \text { steady flow stress (Pa) } \\ \mu & \text { viscosity (Pa s) } \\ \xi & \text { work hardening rate }\end{array}$




\section{Chapter 1}

\section{Introduction}

Predicting the risk of hot cracking during welding is of the utmost importance in minimizing the risk of occurrence in the design stage. Eliminating the risk of hot cracking may be an impossible task, but understanding the causes of hot cracking should clarify the options available to reduce the risk of hot cracking. This study of hot cracking is enabled by a computational weld mechanics (CWM) simulation, using VrWeld software [6].

\section{$1.1 \quad$ Problem Statement}

Determining susceptibility to hot cracking has been largely based on comparative assessments of materials. Most research on hot cracking focuses on ranking material resistance to hot cracking. This allows designers to choose materials that are more resistant to hot cracking. However, most of the widely used weldability tests for hot cracking have not been able to estimate the risk of hot cracking in a given real weld. Unfortunately, there are a limited number of weldability tests that provide accurate and quantifiable results for material resistance to hot cracking at the length scale of microstructure and these weldability tests are often complex and costly $[8,9]$. Tests that evaluate resistance to hot cracking use transient measurements of the localized 
strain increment and temperature. Measuring strain at temperatures near melting, which is the case for liquation and solidification cracking, is complicated and often requires expensive equipment and special expertise [8]. The objective of this thesis is to provide the capability to utilize results of experimental tests to predict hot cracking in real welded structures.

\subsection{Research Objectives}

The main objective of this thesis is to provides designers with a technique to design more reliable and more economic structures. More specifically, by better balancing of the risk of hot cracking with the risk of other failure mechanisms. Enabling designers to choose both the material and the welding procedures will expand their design space. The designer will be allowed to choose materials that are less resistant to hot cracking but have better corrosion or mechanical properties.

This research is based a mechanical approach, rather than a metallurgical one, for the analysis of the risk of hot cracking. Cracking is believed to be a local property, not a global property, i.e., a crack nucleates and grows depending only on the evolution of the local state in the neighbourhood of the crack. This local state is of course a function of some global problem. CWM simulation will be used to determine the temperature-stress-strain evolution during welding.

\subsection{Main Contributions}

This thesis attempts to develop a method to estimate the risk of hot cracking nucleation in the design stage using CWM. It should be noted that data for material resistance to hot cracking would normally be determined by experimental tests and are obtained from the literature $[1,3]$. The data for material resistance to hot cracking 
includes hot cracking susceptibility temperature range (i.e., BTR and DTR), critical strain increment and critical strain rate. This .

Furthermore, this thesis demonstrates the potential of CWM simulations as an effective tool for the prediction and consequent minimization of the risk of hot cracking in welded structures. Macroscopic thermal and mechanical analyses are conducted to predict the areas susceptible to hot crack nucleation. CWM simulation tests for two types of hot cracking, ductility dip and solidification cracking, are conducted. The analyses conducted assume that the material is homogeneous. This study does not go beyond the nucleation of hot cracking, i.e., crack propagation is not part of this research.

\subsection{Background}

Before examining the mechanisms of hot cracking, it is useful to show the significance of the issue of hot cracking and, more importantly, define hot cracking. In brief, hot cracking in welds is a material discontinuity that nucleates when material deformation cannot compensate for localized tensile strain at high temperatures. This phenomenon is partly explained by drops in material resistance to cracking that some metallic alloys experience in certain temperature ranges. The combination of high temperature and tensile strain is commonly observed during manufacturing activities, such as fusion welding.

Weld cracking is a significant problem because cracking can affect the integrity or even cause failure of a welded structure. The failure of a welded structure can put lives at risk. Locating and repairing welds can be be costly and can sometimes lead to the nucleation of more hot cracks. Moreover, the shape of a crack affects the stress concentration in the vicinity of the crack. Fusion welding remains a popular fabrication process as it can be cost effective and reliable. However, producing a 
defect free weld joint is not an easy task because of the multiple phenomena involved. These phenomena are residual stress, distortion, metallurgy and the risk of defect occurrence [10].

This research focuses on hot cracking, one of the numerous types of weld defects. The topic of this thesis was driven by the increasing demand from the nuclear, aerospace and other sectors for materials that maintain strength/stiffness at high temperatures and are corrosion resistant [1]. Examples of materials that satisfy these performance needs are nickel (Ni) based super alloys and stainless steels. However, these alloys can also be susceptible to hot cracking [11].

Minimizing the risk of hot cracking is only possible, if the factors that lead to its occurrence are understood. There are numerous methods used to determine susceptibility of and attempts to avoid hot cracking during welding, but most lack a detailed understanding of the physics or mechanism behind cracking. Most research has focused on reducing the risk of cracking based on a metallurgical approach. Limited research has been done using a mechanical approach, such as that conducted by Chihoski [12], Nishimoto et al. [13] and to a lesser extent the work of Chen and Lu [1].

Attempts to evaluate hot cracking susceptibility are often based on weldability tests. However, relating the results of a given weldability test, conducted in a laboratory environment, to the evolution of the temperature-stress-strain state, global mechanics of the welded structure and weld procedure parameters (i.e., weld power, speed, etc.) is difficult. A good example is the case of the Varestraint test for commercial aluminum-magnesium ( $\mathrm{Al}-\mathrm{Mg}$ ) alloys, where susceptibility to hot cracking is deemed higher than that experienced during actual welding applications. The discrepancy is a result of the lack of accurate localized measurements for the strain increment [14]. This thesis assumes that CWM simulation can be developed such that the results of weldability tests can be readily applied to real world welds.

The competition between material resistance and the driving force determines 
whether or not a hot crack nucleates. The tensile strain increment, within a susceptible temperature range, is considered to be the driving force behind hot crack nucleation. The capability of a material to compensate for tensile strain increment necessary for hot crack nucleation has been referred to as deformability or ductility, but the term 'material resistance' is used in this research. A tensile strain increment, within the susceptible temperature range, is localized at the area of reduced material resistance. These areas have a limited ability to transmit strain and consequently strain is accumulated there [2].

Attributing hot cracking to tensile strain was first proposed by the "theory of hot cracking" that was developed in the 1940's [15]. Only by the 1950's, was the critical tensile strain that would cause hot crack nucleation first quantified by Prokhorov [16]. Prokhorov quantified the amount of tensile strain increment necessary for hot crack nucleation. However, results were inaccurate because measurements for strain were not localized. Matsuda et al. [2] developed the Measurement by Means of InSitu Observation (MISO) technique to measure localized evolution of strain in a solid-liquid coexistent region with greater accuracy. The magnitude of the tensile strain increment, in a specific temperature range, is determined by the evolution of temperature-stress-strain state.

Experimental work has determined the evolution of state responsible for hot cracking in tests. Weldability tests have been developed as a first step to address this issue. Weldabilty tests are a means to evaluate the ability to fabricate a weld that maintains its integrity under service conditions. The weldabilty tests can evaluate different aspects of the welded joint, but the type of weldability tests addressed here are those that evaluate hot cracking susceptibility.

Weldability tests are regarded as a viable method, in terms of cost and time, of evaluating some aspects of a weld before actually welding. Certain weldability tests, such as the Varestraint test, have proven their usefulness and, as a result, are widely 
used. Nevertheless, each weldability test is often limited to a specific application. The large number of parameters and the diverse structures involved in welding makes devising a weldability test that can accurately assess weld joints a complex procedure. Similarly, reducing the risk of cracking requires understanding of the causes.

The understanding of hot cracking is facilitated by the work of the likes of Nishimoto et al. [17]. Their research helped in understanding the effects of chemical elements on hot cracking [17]. Nishimoto et al. used a numerical analysis and experimentation to study micro-segregation. It was shown that alloying elements can segregate to the grain boundaries at elevated temperature. The increased concentration of these elements at the grain boundaries alters the local thermal properties of an alloy, which can include having a reduced melting temperature. The risk of ductility dip cracking was decreased by reducing the phosphorus $(P)$ and sulfur $(S)$ content in an Inconel alloy 690 to $30 \mathrm{ppm}[17]$.

Factors affecting susceptibility of austenitic alloys to DDC have been identified by Ramirez et al. [9]. These factors included: chemical composition, segregation, precipitation, recrystallization, grain size and in addition, grain boundary migration and pinning, orientation and tortuosity. Ramirez et al. studied the effect of chemical composition on material resistance to DDC. Resistance to DDC was measured using a scanning electron microscope (SEM), a concept similar to the MISO technique.

Once the experimental results from hot cracking tests for material resistance are obtained, the risk of hot cracking can be reduced. Varying the design and welding parameters controls the evolution of temperature-stress-strain state in the region susceptible to hot cracking. An example of this is research by Chihoski [12] that showed that the risk of hot cracking can be reduced by increasing welding speed. Chihoski explained the cracking phenomenon by observing the strain pattern generated during the welding process. Chihoski used a Moiré fringe method to measure the displacement of material surrounding a weld pool during the welding process. 
An investigation based on Chihoski's [18] concept is shown in Appendix C, where the effect of increasing welding speed on susceptibility to hot cracking is explained. Chihoski [18] asserts that by increasing the welding speed from $6 \mathrm{ipm}$ to $20 \mathrm{ipm}$, he was able to successfully weld 2014-T6 aluminum without hot cracking. The 2014-T6 aluminum alloy is still considered to be 'unweldable' to this day. Chihoski recognized these phenomena by observing interferometric changes on the surface of plates during welding. An alternative to Chihoski's method is the analysis of the mechanical strain responsible for hot cracking by the use computational models, such as that conducted by Feng [11]. CWM has superior capability, yet less associated costs, to perform a similar study $[19$, p. 2]. CWM can provide a three dimensional transient thermal and stress analysis of the laboratory test and of each weld in a real world welded structure.

\subsubsection{Computational Weld Mechanics}

CWM is capable of predicting mechanical response and further weld quality, by providing the evolution of three-dimensional temperature, strain, stress and microstructure fields. A CWM analysis uses the finite element method. In order to conduct an finite element analysis, first, the mechanisms involved are identified and modelled using partial differential equations. By applying appropriate boundary and initial conditions the partial differential equations can be solved $[11$, p. 78].

CWM may be used to study the integrity of welds during the fabrication process. CWM can overcome some of the shortcomings of weldability tests and provide insight in thermo-mechanical conditions that lead to cracking. CWM simulations have been mainly used to predict distortion and residual stress of weld joints. However, the accuracy of behaviour near the weld pool often was limited because material properties at high temperature are difficult to measure and are not readily available. 
Material properties at all required temperatures are usually obtained from experimentation $[11$, p. 10].

The benefit of simulation is in better insight into mechanics of weldability test results by providing information that is not readily observable in practice. CWM analyses allow several variations to be run so that the effect of specific parameters can be effectively analyzed. The use of CWM analyses can minimize the number of experimental tests, resulting in a less costly and time consuming design cycle. A CWM analysis continues to become a better alternative, by aiding the design of more effective laboratory experimentation, considering that computer performance improves and cost decreases [19, p. 2].

\subsubsection{Welding Process}

Fusion welding is a joining method, most commonly used for metals, which relies on localized melting and then fusion on cooling. Various types of welding processes are in use across different industries but certain types of welding are often preferred in specific applications. Welding is used for fabrication in the transportation, power generation and construction industries. Welding remains a widely used joining process but creating a successful weld requires issues associated with the process to be considered.

The welding process induces strain/stress and alters the microstructure and composition. The disadvantages of welded joints are that they permit cracks to propagate between separate sections, have limited low cost and reliable non-destructive tests, result in distortion and residual stress and can contain defects $[10$, p. 2].

During welding, joining of metals is possible by melting the faying surfaces with or without the addition of a filler metal depending on the application. The melting of material occurs by means of a localized heat source. There are numerous kinds of heat sources, such as electric arc, electric resistance, plasma, laser, electron beam, oxy-fuel, 
friction, etc. Immediately after the passing of a heat source, the weld and surrounding metal begin to cool. Heat from the weld pool is conducted to the cooler surrounding material. At the same time, heat from the weld joint convects and radiates to the atmosphere [20].

\subsubsection{Welding Defects}

Alloys subjected to a combination of high temperature and tensile stress are at risk of hot cracking. Hot cracking is classified into three types: ductility dip; liquation; and solidification. Hot cracking affects manufacturing processes, the most common being casting and welding. The use of welding has been deemed unsuitable for various alloys which satisfy high performance requirements in some industries because of their high susceptibility to hot cracking. An example of this is Al-2024 alloy. However, the literature has shown that at least some of these alloys can be welded successfully with appropriately chosen weld procedures [21].

The literature signals a growing yet currently incomplete understanding of the phenomenon of hot cracking. Prevention of hot cracking is not yet fully understood. This might be due to its complex nature. Furthermore, the quality of the weld often relies on keeping the weld free from impurities, i.e., managing the chemical composition. Impurities are reduced by several methods. These methods include cleaning the surface that is to be welded, adding elements that have a higher chemical affinity to the impurities than the weld metal and using a shielding inert gas that reduces the reaction with elements in the surrounding atmosphere during welding. Furthermore, welding modifies the microstructure of the metal [22]. The composition of the metal determines the effect of the high temperature thermal cycles. 


\subsection{Thesis Outline}

The first Chapter briefly introduced the topic of hot cracking, revealed the significance and purpose of this thesis. In Chapter 2, the various types of weld cracking are described with a focus on the characteristics of hot cracking in conjunction with weldability tests. The CWM analyses used to study the localized evolution of the temperature-stress-strain state are described in Chapter 3. The CWM analyses simulate experimental work from the literature. Based on the theory behind hot cracking, causal factors are identified and used to predict elevated risks of hot cracking based on a CWM analysis. Chapter 4 presented the results of CWM analysis. The final chapter provided a summary of this thesis, suggested methods to reduce risk of hot cracks, recommended improvements to the research conducted along with suggestions of future work. 


\section{Chapter 2}

\section{Weld Cracking}

A weld crack is a discontinuity that occurs in a weld during or after welding. The tensile strain increment responsible for weld cracking is often the result of the welding process itself. Welding creates high thermal gradients, which entail localized expansion/contraction of the material. The localized expansion/contraction is opposed by the surrounding material, physical restraints and the geometrical rigidity of the weld piece. The transient tensile strain can be modified by altering welding parameters or restraint conditions [12].

In general, weld cracks can be classified according to the mechanism associated with the nucleation and propagation of a crack. The are several types of weld cracking and associated mechanisms by which they occur. The basic classifications for weld cracking are lamellar tear, cold and hot cracks. Research in this paper is limited to hot cracking. The ability to distinguish between the different types of cracking is the first step to understanding them. Understanding the mechanism behind nucleation and propagation of a certain type of crack provides an opportunity for devising a possible procedure for predicting nucleation. In addition to the previously mentioned types of cracking, cracks could be distinguished according to their location, such as in the parent material, weld fusion zone or heat affected zone (HAZ) and according to the cracks orientation relative to the welding direction. These are different names 
for the same phenomenon.

Lamellar tearing occurs in the vicinity of and sometimes beyond the HAZ, usually in rolled plates. The material separates on non-metallic inclusions. Lamellar tearing is a result of the through-thickness strain transverse to the rolling plane developed from contraction during cooling of the weld joint. The presence of certain plateshaped non-metallic inclusions, often manganese sulfide (MnS) with low cohesive stress, aligned in the thickness direction cause the embrittlement [10]. Cold cracking is likely to occur in the HAZ or fusion zone and develops at low temperatures. These types of cracks can occur at any time after the welding process and provided that three requirements are met. The first requirement for cold cracking is for the material to have a susceptible microstructure, usually martensite in low alloy steels. Secondly, a certain amount of hydrogen is present in the material, which causes embrittlement. Hydrogen diffuses readily in the metal at elevated temperatures experienced during welding. Lastly, a tensile stress in the material can cause nucleation and eventual propagation of cold cracks [23]. Hot cracking is described in greater detail in the following section.

\subsection{Hot Cracking}

Predicting hot crack nucleation is possible by applying concepts from fracture mechanics. The likelihood of cracking can be determined based on the critical rate of damage accumulation and the magnitude of damage [24]. In order to determine the parameters and conditions that increase the risk of hot cracking, a thermal and mechanical analysis is essential. However, a thermal and mechanical analysis alone is not enough unless one can relate it to the mechanism behind the hot cracking phenomenon.

Hot cracking usually occurs in the fusion zone, partially melted zone (PMZ) and 
$\mathrm{HAZ}$. It is a direct result of the combination of reduced material resistance to cracking and an applied tensile strain. Hot cracking can also be classified into different types based on the location and cause of cracking [23]. Hot cracking susceptibility is sensitive to microstructure and composition. The strain that is responsible for hot cracking is caused by expansion/contraction, phase changes or constraints.

Generally, a crack will nucleate when the material damage tolerance for that crack type is exceeded. An accumulation of damage causes material to continue to deteriorate, manifested as a drop in strength or toughness, until.crack nucleation occurs. Prediction of crack nucleation is often based on the assumption that a material is macroscopically homogeneous. The amount of damage a material sustains can be quantified by a parameter [24].

According to Chihoski [12], the localized heating and cooling cause expansion and contraction, which is a result of either the density being temperature dependent or a change in phase. The expansion is restrained by surrounding lower-temperature material. The expansion of material in one region can cause local compressive fields, which in turn creates tensile fields in another region as a reaction [12].

\subsubsection{Ductility Dip Cracking}

Ductility dip cracking (DDC) occurs in the solid phase, i.e. below the true solidus temperature. In other words, DDC can be observed below the temperature for liquation cracking. DDC occurs within the ductility dip temperature range (DTR). For example, the DTR of austenitic alloys often corresponds to 0.5 and 0.7 of the absolute solidus temperature [9]. DDC takes place as part of the grain boundary separates from an adjacent grain boundary, at an atomic/molecular scale. The mechanism of DDC is not fully known, but there are a few theories.

One explanation is that DDC nucleates as an applied shear stress causes voids to pile up and eventually coalesce [7]. DDC is also thought to be caused by grain 
boundary sliding and loss of cohesive strength [7]. Ramirez et al. [25] attributed the drop in inter-granular strength to impurity and interstitial element segregation to grain boundaries, grain size and grain boundary orientation. These material properties are related to applied stress, grain boundary "tortuosity", welding parameters and strain rate [25]. Okauchi et al. [26] also proposed that the reduction of strength at the grain boundaries is as result of the impurity elements segregating to the grain boundaries [26]. This is in agreement with the detection of carbides at the surface of DDC cracks in nickel-chromium ( $\mathrm{Ni}-\mathrm{Cr}$ )alloys by Young et al. [27].

Below the DTR, deformation that of the inter-granular strength. The intragranular is predominately intra-granular, since intra-granular strength is below deformation causes the movement of dislocations that leads to hardening. This means as temperature drops below the DTR, resistance to DDC increases [1]. As temperature increases above the BTR region, the material resistance to DDC increases, which is attributed to the recrystallization that prevents crack nucleation [1].

\subsubsection{Liquation Cracking}

Liquation cracking occurs in the PMZ and is intergranular. This type of cracking occurs as a result of grain boundary melting, while the grain centres remain in a solid state. The grain boundary melts before the solid centre of the grain as a result of segregation, i.e., variation of composition from the grain boundary to the grain centre. Cracking occurs when the grain boundaries cannot accommodate the tensile strain [28].

Alloys with a wide solidification temperature range and high thermal conductivity have larger partially melted zones, which accompanied by contraction due to solidification and temperature dependency of density, are more susceptible to liquation hot cracking [10]. Okauchi et al. [26] propose that material resistance is reduced at 
high temperatures as a result of elements segregating to grain boundaries. The fraction of solid phase, in a mixed solid-liquid region, is one measure of the resistance to cracking. Kou [29] observed that with $\mathrm{Al}$ alloys liquation cracking occurs if the PMZ has a lower solid fraction relative to the adjacent solidifying dendritic structure of the fusion zone. This is applicable when the fraction of solid exceeds $30 \%$ in the PMZ [29].

\subsubsection{Solidification Cracking}

Solidification cracking is inter-granular and occurs in the fusion zone as the liquid solidifies. During the solidification process the crystal structure grows directionally, forming dendrites. The dendrites are surrounded by a liquid phase and these dendrites can be pulled apart by a tensile strain creating a solidification crack. Separation occurs in the inter-dendritic liquid phase. Solidification cracks often contain elements that lower the melting temperature. Solidification cracks that occur near the solidus temperature, propagate in the direction of dendritic growth. On the other hand, solidification cracks that occur near the liquidus temperature do not have a specific direction $[30]$.

Solidification cracking occurs as material resistance drops when within the brittleness temperature range (BTR). The BTR is the temperature range within which material resistance to solidification cracking is reduced. The tensile strain accumulated by material in the BTR is considered as the mechanical driving force. The critical strain that leads to cracking is a function of temperature [2].

Strain accumulates in the region of lower material resistance. In the case of solidification and liquation cracking, the susceptible region also experiences more strain than the remaining part of the weld joint because of both thermal contraction and solidification shrinkage. The temperature gradient across the welded section also causes a difference in the magnitude of contraction/expansion [10]. 
A quantitative measure of material resistance is given in terms of the relation between the temperature and the critical tensile strain increment that causes hot crack nucleation [31]. The curve with this information for solidification cracking is often referred to as a ductility curve. It provides the BTR, minimum critical strain and critical strain rate for temperature drop. These concepts associated with quantifying material resistance are also applicable to the other types of hot cracking [2].

The minimum critical strain is the lowest point on the ductility curve. The minimum critical strain is also the smallest strain increment, at a specific temperature, that causes crack nucleation. It was proposed that the minimum critical strain depends on dihedral angle [3]. The dihedral angle, which is defined as the angle two grains of the solid phase form, to accommodate the liquid phase [32, p. 190-193]. The dihedral angle depends on grain size and wettability. Large wettability means higher susceptibility to solidification cracking because solid grain surrounded by liquid phase, which has less ductility. The critical strain rate is the minimum strain rate below which cracking does not occur.

Material susceptibility to solidification cracking for a given weld procedure and weld joint is dependent on the composition, according to Kou [33]. Certain composition dependent properties are responsible for the difference in susceptibility to cracking. The properties in question are solidification temperature range, the distribution and amount of interdentritic liquid during solidification, the phase of the solidifying material, the surface tension of the grain-boundary liquid, the dendrite grain structure, composition distribution and the material resistance of the solidifying weld metal [33].

The solidification temperature range controls the size the mixed solid-liquid region. A wider solidification temperature range translates into a larger mixed solid-liquid region where the possibility of cracking is greater. It must be noted that solidification in welds is usually too fast to achieve equilibrium, thus the solidification temperature 
range obtained from an equilibrium phase diagram is not usually applicable. Segregation of elements cause the liquidus and solidus temperatures to change, resulting in a larger temperature range than that obtained from an equilibrium phase diagram. The phase that forms during solidification determines the solubility of alloying elements. A solidifying phase with low solubility rejects elements to the liquid phase. The BTR for solidification cracking is a better approximation of the true solidification range [34].

The distribution and amount of interdentritic liquid during solidification affect the likelihood of solidification crack nucleation and propagation. A large amount of interdendritic liquid could fill in any cracks that initiate. On the other hand, a limited amount of liquid might not reduce the ductility sufficiently. A material is most susceptible to solidification cracking when a thin liquid film covers a large region of dendrites [33].

The surface tension of the grain-boundary liquid affects the tendency to form continuous films on grains and is related to the dihedral angle. A large dihedral angle would reduce the tendency for a continuous film to form. Alloys with finer equiaxed grains are less susceptible to solidification cracking. Liquid more readily fills cracks. There are less segregating elements of low melting points at the grain boundary due to larger ratio of grain boundary area to grain size. The material resistance of the solidified phase is a factor in the susceptibility to cracking [33].

\subsection{Weldabilty Tests}

Weldabilty tests provide information regarding the effects of material composition, welding parameters or restraint. Weldabilty tests can provide comparative assessments of material susceptibility to defects. Numerous weldabilty tests have been developed over the years [35], but the most successful and popular of these tests are 
often cost effective, simple (user friendly) and repeatable. For example the Varestraint test provides a good indicator of the effect of certain design variables on the behaviour of a weld. The weldabilty tests conducted by Matsuda et al. [2] provide a quantitative analysis of a material's susceptibility to hot cracking.

\subsubsection{Varestraint Test}

The Varestraint test is used to determine susceptibility to solidification and liquation cracking [36]. In the Varestraint weldability test the weld joint is subjected to a variable restraint, either in the longitudinal or transverse direction relative to the welding direction, which is known as the Trans-Varestraint test [37].

Both the Varestraint and Trans-Varestraint tests require fixing the plate being welded as a cantilever, while a bending force is applied on the edge. A die block underneath the cantilever controls the radius of curvature.

The timing of the application of the force should coincide with a specific position of the weld pool [10]. The radius of the die block controls the strain to which the bar is subjected. As indicated previously, hot cracking typically occurs at the surface near the $\mathrm{HAZ}$ or the fusion zone [27].

\subsubsection{Measurement by Means of In Situ Observation Tech- nique}

The purpose of the Measurement by Means of In Situ Observation (MISO) technique is to measure the strain increment during the solidification process. Matsuda et al. [2] used the MISO technique to determine susceptibility to solidification cracking. The MISO technique provided the relationship between the critical strain increment and temperature, in the form of a 'ductility curve'. The MISO technique is used to determine material resistance to solidification cracking, based on the local strain 
increment and strain rate that are measured behind a weld pool [2].

The MISO technique uses high-speed photography to measure the local strain and strain rate that leads to crack nucleation and propagation. Measurements are made behind the weld pool, where the material is a combination of liquid and solid phase. During welding the area behind weld pool is filmed with a high speed camera that moves with the heat source. Strain is determined by visually measuring the distance between any two distinguishable surface marks in the desired direction. The surface marks used, appear naturally, as a result of the welding process [2].

Two methods are used to measure the strain across a propagating crack. The first, the moving gauge method, involves measuring the strain at the crack tip and following it as it propagates. The second, or fixed gauge method, measures the strain only across the crack nucleation point and assumes it is the same at the propagating crack tips. The corresponding temperatures at the crack tips are computed based on its distance from the solidification front. The moving gauge method theoretically produces more accurate results but the difference between the results of the two methods is minimal and only obvious with alloys that are less susceptible to solidification cracking. The difference in the results obtained from moving versus fixed gauge was attributed to the sudden increase in strain before crack nucleation due to accumulation of strain at the propagating crack tip [2].

Measuring the localized strain using the MISO technique on the Trans-Varestraint test yielded values for minimum critical strain higher than those measured using the ordinary Trans-Varestraint test. The cause of this difference in results is the measurement of strain. Matsuda et al. [2] used the MISO technique on the TransVarestraint and tensile hot cracking test yielding similar results. The measurement of strain from the ordinary Trans-Varestraint test does not account for peaks in strain in the vicinity of the solidification front, i.e., it averages strain over a longer gauge length. The peak in strain at the solidification front is explained by the stress 
concentration at the weld pool. The variation of strain over a plate is caused by temperature gradient [2].

The MISO technique offers accurate results but not the true value, as shown by the minimum critical strain dependence on gauge length [2]. The minimum critical strain was shown to increase as the gauge length decreased. A gauge length smaller than a certain limit produced results that were not repeatable. At small scales the strain becomes less uniform due to concentration of strain at the columnar grain boundaries. Matsuda et al. [2] showed that a gauge length 0.9 to $1.7 \mathrm{~mm}$ provided the largest value for minimum critical strain with good repeatability. 


\section{Chapter 3}

\section{Methodology}

A computational weld mechanics (CWM) simulation was developed for the purposes of this thesis, in order to determine the localized evolution of the transient temperature-stress-strain state for hot crack nucleation. During the time any Gauss point in the hot crack temperature region the strain increment exceeds the material hot crack resistance, it is assumed a hot crack will nucleate. The evolution of the temperature-stress-strain state determines the susceptibility of weld joints to hot cracking. A CWM simulation, using VrWeld software [6], computes temperature and stress, at all temperatures up to melting temperature. Obtaining 3D transient temperature and strain fields in such a temperature range, would otherwise be difficult to physically measure. Several issues were considered, while developing the CWM model, to depict the behaviour of the weld joint. These issues include meshing, stress boundary conditions, welding parameters and material properties.

\subsection{Project Description}

The CWM simulation of welding begins by conducting a transient three-dimensional thermal analysis. The transient temperature results, from this thermal analysis, are 
used to compute the thermal strains in the stress analysis that follows. In this research, two CWM models were developed to simulate two tests described in the literature $[1,2]$. In particular the susceptibility to ductility dip cracking (DDC) and the susceptibility to solidification cracking were determined separately using CWM models of single pass bead-on-plate welds, i.e., with no added filler metal.

The first CWM model emulates the CWM simulation conducted by Chen and $\mathrm{Lu}[1]$, to determine susceptibility to DDC of a weld. Chen and Lu measured the strain to DDC nucleation versus temperature for filler metal 82 (FM82). FM82 is a nickel-based alloy often used as filler metal during the welding of Inconel alloys. The results were obtained by conducting multiple tensile tests with a constant cross head speed of $0.5 \mathrm{~mm} / \mathrm{s}$. Each tensile test was conducted at a different temperature within the ductility dip temperature range (DTR). Chen and Lu followed these hot tensile tests by CWM analyses of two welds with different welding speeds. Chen and $\mathrm{Lu}$ used the computed localized equivalent strain increment and temperature to determine the risk of DDC at different distances from the weld centre-line [1].

The second CWM model was designed to emulate the solidification cracking tests conducted by Matsuda et al. [2]. In Matsuda et al.'s test, a displacement rate, referred to as cross head speed (CHS), was applied to the edges of the plate that are parallel to the weld. The applied CHS causes a localized tensile strain transverse to the welding direction [21]. The CHS was varied to analyze the effect of localized strain rate and increment on the risk of solidification cracking. The localized strain increment behind the weld pool was measured by the Measurement In-Situ Observation (MISO) technique, which Matsuda et al. [2] pioneered.

The two CWM analyses presented in this thesis determine hot cracking susceptibility by comparing the computed strain increment and temperature to curves that quantify material resistance to hot cracking. The CWM models used in each analysis are shown in Tables 3.1 and 3.2. It must be noted that the actual cracking mechanism 
is not modelled. Only the evolution of temperature-stress-strain state is simulated, based on which the susceptibility to crack nucleation is determined. Curves for material resistance were obtained from existing literature $[1,3]$. The material resistance curves quantify the strain increment necessary to cause hot cracking nucleation at different temperatures within a susceptible range. CWM simulation is a step towards predicting the risk of hot crack nucleation in real welds, using the experimentally measured curves for material resistance to hot cracking.

Table 3.1: CWM models for DDC test.

\begin{tabular}{|c|c|c|}
\hline Variable & \multicolumn{2}{|c|}{ Project } \\
\hline weld speed & parent & sub 1 \\
\hline $2 \mathrm{~mm} / \mathrm{s}$ & ddc_ws1_prnt & ddc_ws1_sub1 \\
\hline $5 \mathrm{~mm} / \mathrm{s}$ & ddc_ws2_prnt & ddc_ws2_sub1 \\
\hline
\end{tabular}

Table 3.2: CWM models for solidification cracking test.

\begin{tabular}{|c|c|c|c|}
\hline Variable & \multicolumn{3}{|c|}{ Project } \\
\hline cross head speed & parent & sub 1 & sub 2 \\
\hline $0.1 \mathrm{~mm} / \mathrm{s}$ & sc_chs1_prnt & sc_chs1_sub1 & sc_chs1_sub2 \\
\hline $0.2 \mathrm{~mm} / \mathrm{s}$ & sc_chs2_prnt & sc_chs2_sub1 & sc_chs2_sub2 \\
\hline $2 \mathrm{~mm} / \mathrm{s}$ & sc_chs3_prnt & sc_chs3_sub1 & sc_chs3_sub2 \\
\hline $20 \mathrm{~mm} / \mathrm{s}$ & sc_chs4_prnt & sc_chs4_sub1 & sc_chs4_sub2 \\
\hline
\end{tabular}

\subsubsection{Domain for CWM Models}

The dimensions of the plates for the DDC and solidification cracking CWM models are presented in Table 3.3 and 3.4, respectively. The weld path is along the dimension given for the length of the plate. The transverse dimension is perpendicular to the welding direction. The dimensions of the plate for the DDC CWM model are the 
same as those used by Chen and $\mathrm{Lu}[1]$. The solidification cracking CWM model used dimensions for the plate that are comparable to those used by Matsuda et al. [3]. However, in the solidification cracking CWM model the length of the plate in the welding direction was modified slightly for the convenience of the user.

Table 3.3: DDC test: plate dimensions for CWM model after Chén and Lu [1]

\begin{tabular}{|l|l|}
\hline Width & $100 \mathrm{~mm}$ \\
\hline Length & $100 \mathrm{~mm}$ \\
\hline Thickness & $2 \mathrm{~mm}$ \\
\hline
\end{tabular}

Table 3.4: Solidification cracking test: plate dimensions for CWM model after Matusda et al. [2].

\begin{tabular}{|l|l|}
\hline Width & $300 \mathrm{~mm}$ \\
\hline Length & $50 \mathrm{~mm}$ \\
\hline Thickness & $2 \mathrm{~mm}$ \\
\hline
\end{tabular}

In each CWM model the domain of the plate was meshed with eight-node hexahedron or brick elements using a $2 \times 2 \times 2$ distribution of Gauss points. The mesh was refined at and in the vicinity of the fusion zone as required particularly for the expected high thermal gradients and the resulting high stress/strain gradients. The width of the section to be refined was chosen to be $20 \mathrm{~mm}$ in width for the CWM models for both the DDC and the solidification cracking tests.

The difference in element size between adjacent elements was limited. The desired mesh size was based on Matsuda et al.'s [2] recommendation for a gauge length between $0.9 \mathrm{~mm}$ and $1.7 \mathrm{~mm}$. A range for the gauge length was spccified, instead of a single length, because the MISO technique uses distinguished marks that randomly and naturally appear. The element width is less than $1.0 \mathrm{~mm}$ so that gauge length would contain at least a single element. In order to use a fine mesh, while reducing computational cost, 'sub-models', which are discussed in the next section, were used. 
The mesh was refined using sub-models, such that the difference in mesh size between consecutive mesh refinements is limited.

The dimensions of the elements in the meshes are given in Tables 3.5 and 3.6, for the DDC and solidification cracking tests, respectively. The numbers for fine and coarse correspond to the element size in the refined section and the coarse section of the plates. A single dimension is given for the brick elements, because they are cubic in shape, also known as a regular hexahedron. The number of elements used in the DDC and solidification cracking tests are shown in Tables 3.7 and 3.8.

Table 3.5: DDC test: mesh size of refined section in parent and sub-models.

\begin{tabular}{|l|c|}
\hline Project & $\begin{array}{c}\text { Element Size } \\
\text { fine / coarse }\end{array}$ \\
\hline parent & $1 / 2 \mathrm{~mm}$ \\
\hline sub 1 & $0.5 / 2 \mathrm{~mm}$ \\
\hline
\end{tabular}

Table 3.6: Solidification cracking test: mesh size of refined section in parent and sub-models.

\begin{tabular}{|l|c|}
\hline Project & $\begin{array}{c}\text { Element Size } \\
\text { fine / coarse }\end{array}$ \\
\hline parent & $1 / 2 \mathrm{~mm}$ \\
\hline sub 1 & $0.5 / 2 \mathrm{~mm}$ \\
\hline sub 2 & $0.25 / 1 \mathrm{~mm}$ \\
\hline
\end{tabular}

Table 3.7: DDC test: number of elements in parent and sub-models projects.

\begin{tabular}{|c|c|}
\hline Project & Number of Elements \\
\hline parent & 6000 \\
\hline sub 1 & 2880 \\
\hline
\end{tabular}

The time step size is defined by the user. In the CWM simulations conducted, the size of each time step was set such that the heat source moves one element in the 
Table 3.8: Solidification cracking test: number of elements in parent and sub-models projects.

\begin{tabular}{|c|c|}
\hline Project & Number of Elements \\
\hline parent & 5500 \\
\hline sub 1 & 1920 \\
\hline sub 2 & 15360 \\
\hline
\end{tabular}

welding direction for every time step. This means that the time step size equals the total welding time divided by the number of elements in the welding direction.

\section{Sub-models}

The sub-model feature in the VrWeld software [6] allows for an analysis of a small section of a larger model. The sub-model feature permits mesh refinement in any section of choice. This feature provides more accurate results than a coarse mesh, while maintaining low computational time. Results from a parent project are mapped onto the boundary of the sub-model. Nodes from the sub-model boundary, that do not have corresponding nodes from the parent projects, have values that are an interpolation of the values from adjacent parent master nodes. In order to obtain a certain degree of accuracy the difference in mesh size between the parent and the sub-model was limited. The sub-model geometry was defined by specifying multiple half-spaces, i.e., oriented planes. This type of sub-model is referred in the VrWeld software as 'CutPlaneBox'.

The stress analysis for the DDC test was performed using the sub-model feature. The sub-model was from the centre of the plate and made large enough so that the susceptibility to DDC of multiple points, at various distances from the weld centreline, could be studied. The sub-model in the DDC test measures $18 \mathrm{~mm}$ across the weld path, $10 \mathrm{~mm}$ along the weld path and includes the entire thickness of the plate. The stress analysis, for the solidification cracking test, was also performed using the 
sub-model feature. In the solidification cracking test, the location of the sub-model is focused on the trailing end of weld pool during the time when the CHS is applied. The CHS is applied when the heat source reaches the midpoint on the weld path. The size of the sub-model encompasses the trailing edge of the weld pool during the period of time at which the CHS is applied to the sides of the plate. As in the DDC test the sub-model in the solidification cracking test measures $18 \mathrm{~mm}$ across the weld path, $10 \mathrm{~mm}$ along the weld path and through the thickness of the plate. The location of the sub-model relative to the parent model is shown in Figures 3.1 and 3.2, for the DDC test and solidification cracking test, respectively.

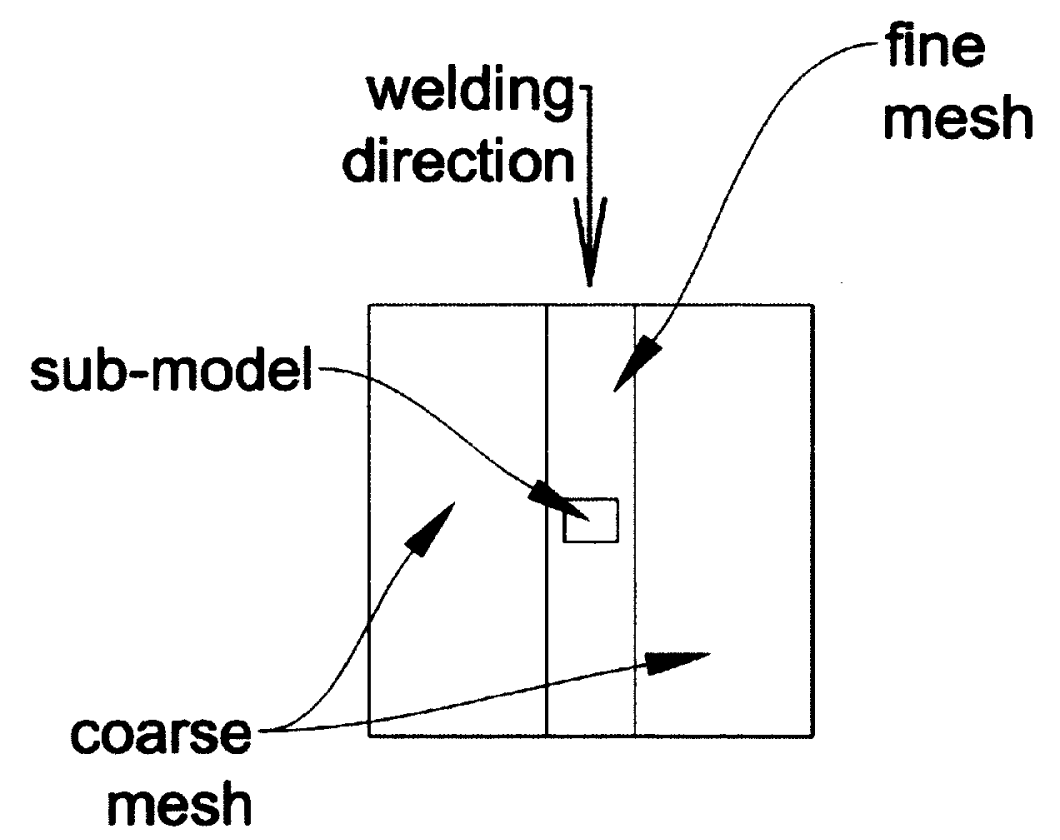

Figure 3.1: DDC test: outline for plate, refined section and submodel.

\subsubsection{Parameters}

The thermal and stress analyses are based on governing equations for the conservation of energy, mass and momentum. The solution of the equations requires certain parameters, which are material properties. Although the properties are often dependent on the material state, composition and temperature, their values are readily 


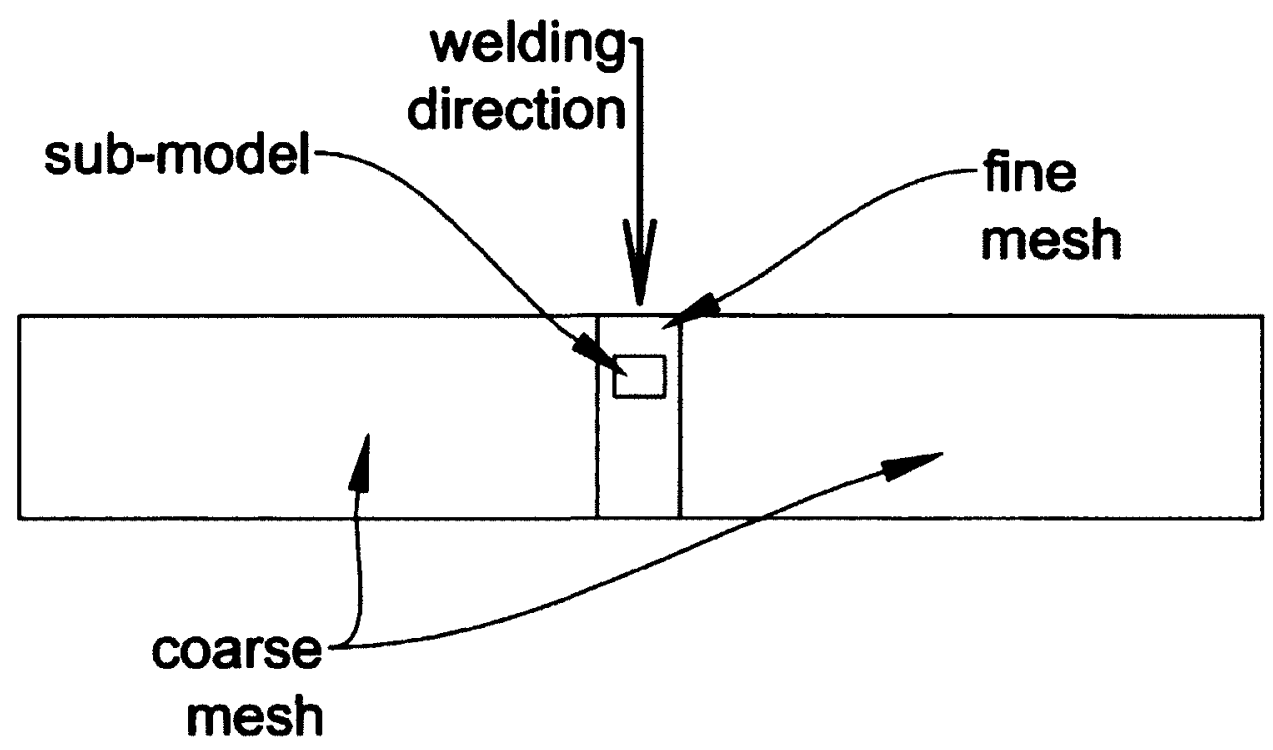

Figure 3.2: Solidification cracking test: outline for plate, refined section and submodel.

available.

\section{Thermal Analysis Parameters}

The thermal analysis uses the heat equation, based on the fundamental principle of energy conservation. Heat input from a welding process is given in terms of a power density distribution applied to the domain defined by the double ellipsoid heat source model [38]. The thermal analysis parameters used in the heat governing equation in this welding simulation were: thermal conductivity, specific heat, solidus and liquidus temperatures and latent heat of melting. The values of the thermal parameters are temperature dependent and are presented in Appendix A.

\section{Stress Analysis Parameters}

The parameters, in the governing equation used in the stress analysis, were: Young's modulus, Poisson's ratio, viscosity, yield stress, hardening modulus and coefficient of thermal expansion. The values for these temperature-dependent material properties 
that were used in this CWM analysis are in Appendix A. The viscosity used in this CWM analysis is for stress relaxation. Viscosity defines the relationship between strain rate and stress, as shown in Equation 3.1.

$$
\sigma=\mu \dot{\varepsilon}
$$

Metals in the solid state can exhibit viscous behaviour under certain circumstances. While elastic behaviour leaves the topology of the network of atomic bonds unchanged, viscous behaviour changes the network of atomic bonds. The viscous behaviour should be accounted for in a computational model to better represent actual material response to stress. Viscous behaviour exhibited during creep was omitted in the simulation conducted for this research but would be a more significant factor for projects with larger time frames. Viscosity is discussed in greater detail in Appendix D.

\section{Heat Source}

The welding parameters include: welding speed, weld current, weld voltage, arc efficiency and dimensions of the double ellipsoid heat source model to emulate the power density distribution in the weld pool. The dimensions of the double ellipsoid heat source model are chosen to be as close as possible to the dimensions of the weld pool. The maximum temperature in the weld pool is usually in the range of $300 \mathrm{~K}$ greater than the liquidus temperature. The magnitude of the power and the welding speed will affect the amount of energy transferred to the weld joint. The depth of the double ellipsoid is set such that the weld fully penetrates the plate thickness.

The DDC test used two different welding speeds, which were the same as those used by Chen and $\mathrm{Lu}[1]$. The current and voltage for the $2 \mathrm{~mm} / \mathrm{s}$ weld were taken from Chen and Lu's paper [1]. The welding parameters of the test, with a welding 
speed of $5 \mathrm{~mm} / \mathrm{s}$, were chosen such that the weld pool size would be almost the same as in the test with a $2 \mathrm{~mm} / \mathrm{s}$ welding speed, as specified by Chen and Lu [1]. The welding parameters for the two DDC tests are shown in Table 3.9. On the other hand, for the solidification cracking test, a single set of welding parameters, shown in Tables 3.10 and 3.11 , were used with separate stress analyses.

Table 3.9: DDC test: welding parameters.

\begin{tabular}{|l|c|c|c|}
\hline Voltage & \multicolumn{2}{|c|}{$10 \mathrm{~V}$} \\
\hline \multicolumn{2}{|l|}{ Arc efficiency } & \multicolumn{2}{|c|}{0.6} \\
\hline \multicolumn{2}{|l|}{ Welding speed } & $2 \mathrm{~mm} / \mathrm{s}$ & $5 \mathrm{~mm} / \mathrm{s}$ \\
\hline \multirow{2}{*}{ Current } & $100 \mathrm{~A}$ & $180 \mathrm{~A}$ \\
\hline \multirow{3}{*}{$\begin{array}{l}\text { Double } \\
\text { ellipsoid }\end{array}$} & front $\left(\mathrm{a}_{2}\right)$ & $3 \mathrm{~mm}$ & $2 \mathrm{~mm}$ \\
\cline { 2 - 4 } & rear $\left(\mathrm{a}_{1}\right)$ & $15 \mathrm{~mm}$ & $8 \mathrm{~mm}$ \\
\cline { 2 - 4 } & width (b) & $8 \mathrm{~mm}$ & $10 \mathrm{~mm}$ \\
\cline { 2 - 4 } & depth (c) & $4 \mathrm{~mm}$ & $4 \mathrm{~mm}$ \\
\hline
\end{tabular}

Table 3.10: Solidification cracking test: welding parameters.

\begin{tabular}{|l|c|}
\hline Weld speed & $2 \mathrm{~mm} / \mathrm{s}$ \\
\hline Voltage & $19.5 \mathrm{~V}$ \\
\hline Current & $35 \mathrm{~A}$ \\
\hline Arc efficiency & 0.7 \\
\hline
\end{tabular}

Table 3.11: Solidification cracking test: double ellipsoid dimensions.

\begin{tabular}{|l|c|}
\hline front $\left(\mathrm{a}_{2}\right)$ & $6 \mathrm{~mm}$ \\
\hline rear $\left(\mathrm{a}_{1}\right)$ & $12 \mathrm{~mm}$ \\
\hline width $(\mathrm{b})$ & $6 \mathrm{~mm}$ \\
\hline depth $(c)$ & $2 \mathrm{~mm}$ \\
\hline
\end{tabular}




\section{Material Properties}

The material properties that are used in the governing equations determine the behaviour of the model. The analysis conducted is a macro analysis, because the scales dealt with are larger than grain size. As such, material properties are based on bulk values for sufficiently large sampling volumes. These large sampling volumes are not sensitive to local variations at smaller length scales, i.e., the microstructure length scale.

\subsubsection{Boundary Conditions}

In an initial value problem, boundary conditions are a function of time. In both the DDC and solidification cracking tests rigid body motion was constrained. In the solidification cracking test the plate was constrained along both edges, to prevent movement in the direction transverse to the weld path. The constraints, in the solidification cracking test, simulate the effect of the pins, used to apply the CHS in the Matsuda et al. experiment [2]. The same constraints at the plate edges are used to apply the CHS, when the heat source reaches midway of the weld path.

\section{Cross Head Speed}

A CHS was used in the solidification cracking test in order to simulate the effect of the load applied halfway through the welding process. A prescribed displacement was applied over a specified period of time, to obtain the displacement rate defined in terms of CHS, by Matsuda et al. [2]. The starting time for the CHS was set to the point in time at which the heat source has reached the midpoint on the plate. The CHS generates a localized strain that can cause cracking. The rate of the applied displacement is varied because it affects the risk of hot cracking.

The localized strain is computed in the solidification cracking CWM model by 
a virtual gauge positioned across the weld centre-line, halfway along the weld path. Since the mechanics of crack propagation are beyond the scope of this thesis, the CWM model will be used to measure the strain increment that may lead to solidification crack nucleation. Matsuda et al. [2] were able to produce ductility curves because strain is measured before crack nucleation and during propagation. Displacement in the simulation was applied at both sides in opposite directions to preserve symmetry of displacements across the weld path. The applied strain is evenly distributed over the nodes on opposite sides of the plate. The duration for which the CHS is applied, is a minimum of $1 \mathrm{~s}$ and such that the ending time corresponds to a time step.

\subsubsection{Initial Conditions}

Initial conditions are required if it is an initial value problem that evolves in time. The initial temperature for the weld and the ambient temperature was set to $300 \mathrm{~K}$. Before welding begins the material is subject to zero stress and strain. The CWM analysis is conducted without consideration of the microstructure of the material.

\subsection{Variation of Design Parameters}

The DDC test used two different sets of welding parameters. The welding parameters were varied by Chen and $\mathrm{Lu}$ [1] to show the effect of welding speed on susceptibility to DDC. In the solidification cracking test, the variable in the cases that are analyzed was cross head speed (CHS). The different cases determine the effect of CHS on the localized strain rate, thus susceptibility to solidification cracking. A sufficiently low CHS will not cause cracking as the resultant localized strain rate will be below the critical value. The critical strain rate, obtained from material resistance plots, is the rate of strain with respect to temperature. 


\subsection{Estimating Risk of Hot Crack Nucleation}

The competition between the driving force and material resistance determines the likelihood of hot crack nucleation. This competition can be interpreted as criteria, which when they coincide at a material point result in the nucleation of a hot crack. These criteria are:

1. the temperature is within a specific range;

2. has a certain thermal profile;

3. and is subject to a tensile strain increment and strain rate greater than critical values.

Based on these criteria, the risk of hot cracking may be evaluated using 3D transient thermal and stress analyses based on CWM.

\subsubsection{Susceptible Temperature Range}

Hot cracking at a point occurs within specific temperature ranges, within which the material resistance to cracking is reduced. Each type of hot cracking occurs within a specific temperature range. This temperature range is a material property that is composition dependent. The temperature range at which DDC occurs is known as the ductility dip temperature range (DTR). Solidification cracking occurs in the brittleness temperature range (BTR). While liquation cracking occurs within the same temperature range as the BTR but liquation cracking necessitates that the temperature does not exceed the local liquidus temperature. However, if the temperature only exceeds the susceptible temperature range before crack nucleation, then damage caused by the strain will likely be reduced. The hot cracking susceptible temperature range is measured experimentally. 


\subsubsection{Thermal Profile}

Any cracks that could form in the area directly ahead of the weld pool will be 'healed', once transformed into a liquid phase. However, this phenomena depends on availability of sufficient quantity of liquid to fill the discontinuity. At temperatures below the local liquidus, there is a risk of nucleation of DDC during cooling and heating. Similarly, there is also a risk of liquation cracking, at temperatures below the local liquidus, during cooling and heating. Liquation cracking will not occur after the temperature exceeds the local liquidus temperature. The reason is, in liquation cracking, the centre of the grains must have remained in a solid phase. In contrast, solidification cracking can initiate only during cooling from a liquid phase. This cooling may be interpreted as a temperature drop over time. Based on this criterion, during welding the region susceptible to solidification cracking is behind the weld heat source.

\subsubsection{Tensile Strain Increment and Rate}

A magnitude for the localized strain increment and strain rate above critical values in the susceptible temperature ranges, BTR or DTR, will lead to hot crack nucleation [11]. Ideally, measurements of the strain and strain rate would be made in each of the directions of the principal axes of tensile stress. The magnitudes of the critical strain increment and the strain rate are proportional, material specific and may be obtained from a material resistance curve [4].

The relation between strain and strain rate for DDC is explained by grain boundary sliding, which occurs at temperatures within the DTR. A high strain rate in a fixed time increment generates a greater amount of strain for crack nucleation. The effect of strain rate is more apparent for materials that are less susceptible to cracking [39]. Plastic deformation, due to grain boundary sliding, cannot compensate for a strain applied at a high rate, which increases hot cracking susceptibility. The reason 
being that grain boundary sliding is based on a diffusion process, which is time dependent [39]. On the other hand, using a low strain rate prevents cracking. Matsuda et al. [39] were able to quantify the grain boundary sliding, which was used to study the effect of strain rate. As a result, Matsuda et al. determined that the amount of grain boundary sliding is proportional to the total strain increment.

\subsection{Special Considerations for Material Resistance and Damage Accumulation}

Hot cracking is an irreversible process and the damage that leads to crack nucleation is similarly irreversible. The plastic component of the tensile strain is the likely cause of the damage that leads to cracking. The plastic component of strain is significantly greater than the elastic component, in the susceptible temperature ranges [16].

The transient thermal analysis provides the temperature at each Gauss point at the end of each time step over the welding time period. The time steps for the stress analysis match those of the thermal analysis.

The computed strain in the principal directions is used in order to determine the direction of the maximum tensile strain. A hot crack will nucleate as a result of the maximum principal tensile strain and eventually propagate in the direction perpendicular to the maximum principal tensile strain.

As stated earlier, the materials used for the CWM models are FM82 for the DDC test and Inconel 600 for the solidification cracking test. Ni-based materials are chosen for two reasons. The first reason is simply a consequence of the limited availability of data for resistance to hot cracking. The second and more significant reason, for the choice of nickel-based materials, is that a macroscopic analysis alone can provide an adequate approximation for the material behaviour. This is justified 
by Wei Zhang [40], "For austenitic stainless steels and nickel alloys, they largely stay in the face-centered cubic (FCC) crystal structure in the solid state. Many models for predicting weld residual stresses do not include any solid-state transformation for those materials."

The values of the FM82 material resistance to DDC are obtained from the work of Chen and $\mathrm{Lu}$ [1]. Material resistance to solidification cracking for the Inconel 600 is taken from the work of Matsuda et al. [3]. Based on the thermal analysis, the area with reduced resistance to hot cracking, at any instant in time, can be identified by the isotherms for the maximum and minimum of the hot cracking susceptible temperature range. The computed localized strain increment is compared to the data for material resistance. Values for localized strain increment exceeding the material resistance curves indicate an increased risk of hot cracking, computed at each Gauss point in the mesh.

Material resistance to DDC was based on the results of the tensile tests, conducted by Chen and Lu [1], which are shown as a curve in Figure 3.3. Chen et al. [7] also used the tensile tests to create stress-strain curves for FM82 at different temperatures. The strain at which fracture occurs is significantly higher than the strain at which DDC nucleates. In addition, the maximum temperature at which a tensile test was conducted is approximately $1473 \mathrm{~K}$ but the DTR upper limit for FM82 was specified as $1623 \mathrm{~K}$. Material resistance at temperatures between 1473 and $1623 \mathrm{~K}$ has been extrapolated from the material resistance exhibited at $1473 \mathrm{~K}$, based on a conservative assumption that the strain to DDC nucleation remains at least constant.

The evolution of state on the constant temperature tensile tests, conducted by Chen and $\mathrm{Lu}$ [1], is quite different from the evolution of state in a weld, which is subject to a thermal cycle. A method is required to relate or map the evolution of state in the high temperature tensile tests to the evolution of state at a point in a weld. The solution conjectured here is to measure the accumulated damage at a point 


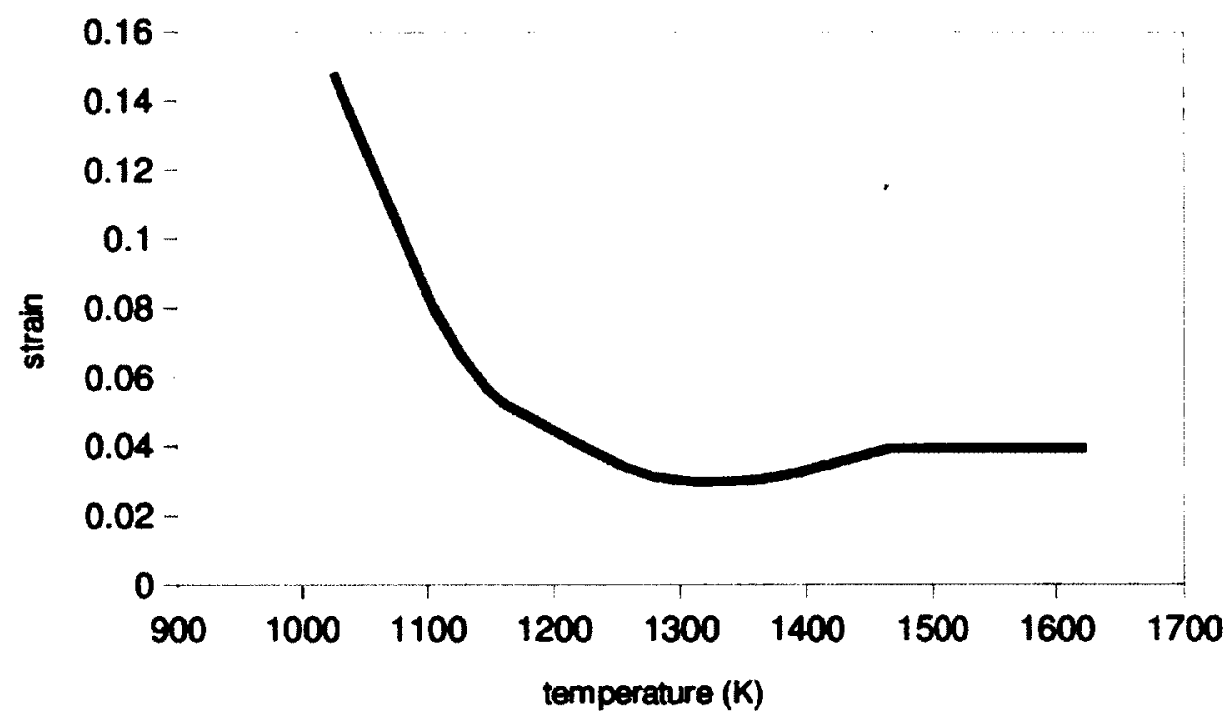

Figure 3.3: DDC critical strain at different temperatures with $0.5 \mathrm{~mm} / \mathrm{s}$ cross head speed after Chen and $\mathrm{Lu}$ [1].

in the weld, using a concept similar to Miner's rule. Miner's rule is used to determine the fatigue life of a part subjected to cyclic loads at different stress levels. Miner's rule computes the fraction of the fatigue life for each stress level. When the fractions sum to 1.0, the specimen is assumed to have reached the end of its fatigue life.

A similar idea can be used to determine the amount of damage caused by the plastic strain increment at different temperatures for any point $(x, y, z)$ in a weld joint. Accumulated damage at a point in the weld is computed at $n$ time intervals or time steps within the duration of the weld thermal cycle. The sum of the increments in the damage parameter determines the likelihood of hot crack nucleation. The contribution to the damage parameter is measured by the plastic strain increment in the weld, within each temperature interval, normalized with the experimentally detcrmined strain to DDC nucleation in hot tensile tests. This is interpreted in Equation 3.2 for $n$ time steps.

$$
\sum_{i=1}^{n} \frac{\Delta \epsilon_{f}\left(T\left(\Delta t_{i}\right)\right)}{\epsilon_{f}\left(T\left(\Delta t_{i}\right)\right)}=\sum_{i=1}^{n} f_{i}\left(\Delta t_{i}\right)
$$




$$
\sum_{i=1}^{n} f_{i}\left(\Delta t_{i}\right) \geq 1.0
$$

where $\epsilon_{f}\left(T\left(\Delta t_{i}\right)\right)$ is the experimentally measured strain to DDC nucleation in hot tensile tests, at temperature $T\left(\Delta t_{i}\right)$ and $\Delta \epsilon_{f}\left(T\left(\Delta t_{i}\right)\right)$ is the increment in the computed principal strain in a given time interval, $\Delta t_{i}=t_{i+1}-t_{i}$, with an average temperature, $T\left(\Delta t_{i}\right)=\left(T\left(t_{i+1}\right)+T\left(t_{i}\right)\right) / 2$.

Clearly, this criterion for estimating the risk of hot crack nucleation needs experimental verification. For this thesis, it is assumed that a hot crack nucleates when the sum of the damage parameter increments, $f_{i}$, is 1.0. Before utilizing this technique, the role of negative (compressive) strain increment on the accumulated damage must be addressed.

There are four possible assumption that can be made to account for the effect of a negative strain increment:

1. a negative strain increment causes as much damage as a positive strain increment, thus the absolute value of the strain increment is used;

2. a negative strain is irrelevant to the damage, therefore a negative damage increment is set to zero;

3. a negative strain reduces damage or, in other other words, heals;

4. or some weighting factor can be assigned to above options.

The method that best represents reality can be determined by conducting appropriate experiments. The most conservative conjecture for the role of negative strain increment is used, that is it causes as much damage as the positive strain increment, even though this is improbable. Figure 4.8 will show how these options compare in use. 


\section{Chapter 4}

\section{Results}

\subsection{Ductility Dip Cracking Test}

The CWM analyses for the DDC test required two separate thermal analyses for the two different welding speeds and a separate stress analysis for each thermal analysis. The CWM analyses for DDC test were conducted on a plate with restraints to prevent rigid body motion only. The susceptibility of several points on the top surface of the plate was analyzed. The temperatures at which FM82 is susceptible to DDC, also known as the DTR, is shown in Table 4.1 [1]. The isotherms for the DTR, at any instant of time, bound the region at risk of DDC.

Table 4.1: DTR for FM82 after Chen and Lu [1].

\begin{tabular}{|l|l|}
\hline Maximum & $1623 \mathrm{~K}$ \\
\hline Minimum & $1173 \mathrm{~K}$ \\
\hline
\end{tabular}

\subsubsection{Temperature}

The visualizations for thermal results with isotherms for the DTR are shown for the two welding speeds, $2 \mathrm{~mm} / \mathrm{s}$ and $5 \mathrm{~mm} / \mathrm{s}$, in Figures 4.1 and 4.2 , respectively. These 
results are at the time the heat source reached the midpoint of the designated weld path.

For the DDC test, the temperature is recorded at the top of the plate on the midpoint of weld path and at six other positions, $1 \mathrm{~mm}$ apart, computed along the axis transverse to the welding direction. The locations at which the strain and temperature results were taken from relative to the heat source, at time of $32.5 \mathrm{~s}$ from the start of welding, are shown in Figure 4.3 for the sub-model.

The plots of the temperature results for the two welding speeds are shown in Figures 4.4 and 4.5. The temperature for the liquidus was assumed to be $1655 \mathrm{~K}$. The welding current and double ellipsoid dimension were modified such that the weld pool dimensions would be the same for both welding speeds, as specified by Chen and Lu [1].

\subsubsection{Strain}

The damage caused by the maximum tensile component of the plastic principal strain increment is used to study susceptibility to DDC cracking. The principal components are used, because it is the maximum tensile strain that causes the separation of the grains. The equivalent plastic strain at Gauss points is also shown for the purposes of comparing the results of Chen and $\mathrm{Lu}[1]$. The strain increment was recorded when the temperature reached the minimum of the DTR. However, where the temperature exceeded the maximum of the DTR, $1623 \mathrm{~K}$, the plastic strain increment was recorded at the point when the temperature dropped back to the maximum of the DTR. Once the temperature exceeds the DTR, recrystallization is expected to occur reducing the damage accumulated during heating. In the tests conducted, damage accumulated during heating was minor and not sufficient to cause cracking. The temperature exceeded $1623 \mathrm{~K}$ at distances up to and including $3 \mathrm{~mm}$ from the weld centre-line for both welding speeds. 


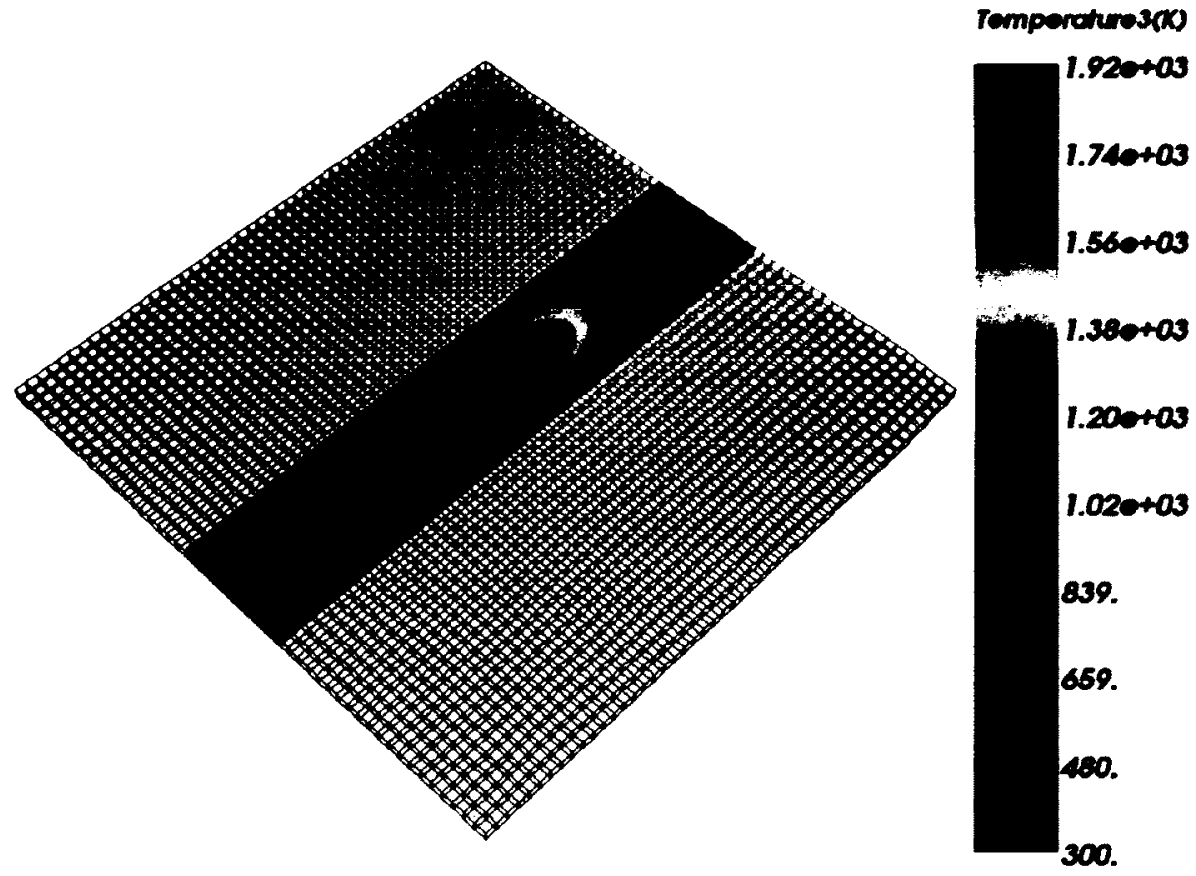

Figure 4.1: DDC test: temperature field and DTR iso-therms with a $2 \mathrm{~mm} / \mathrm{s}$ welding speed, at $\mathrm{t}=25 \mathrm{~s}$.

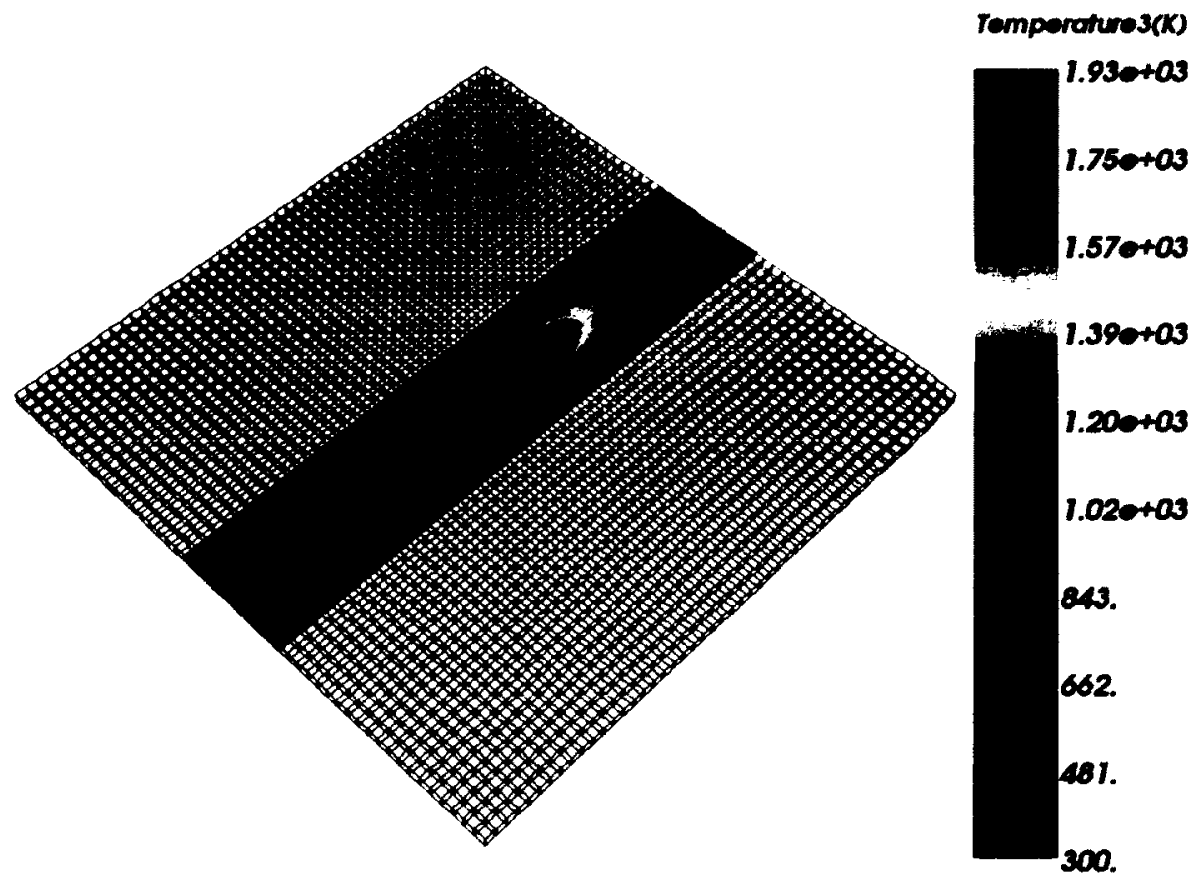

Figure 4.2: DDC test: temperature field and DTR iso-therms with a $5 \mathrm{~mm} / \mathrm{s}$ welding speed, at $\mathrm{t}=10 \mathrm{~s}$. 


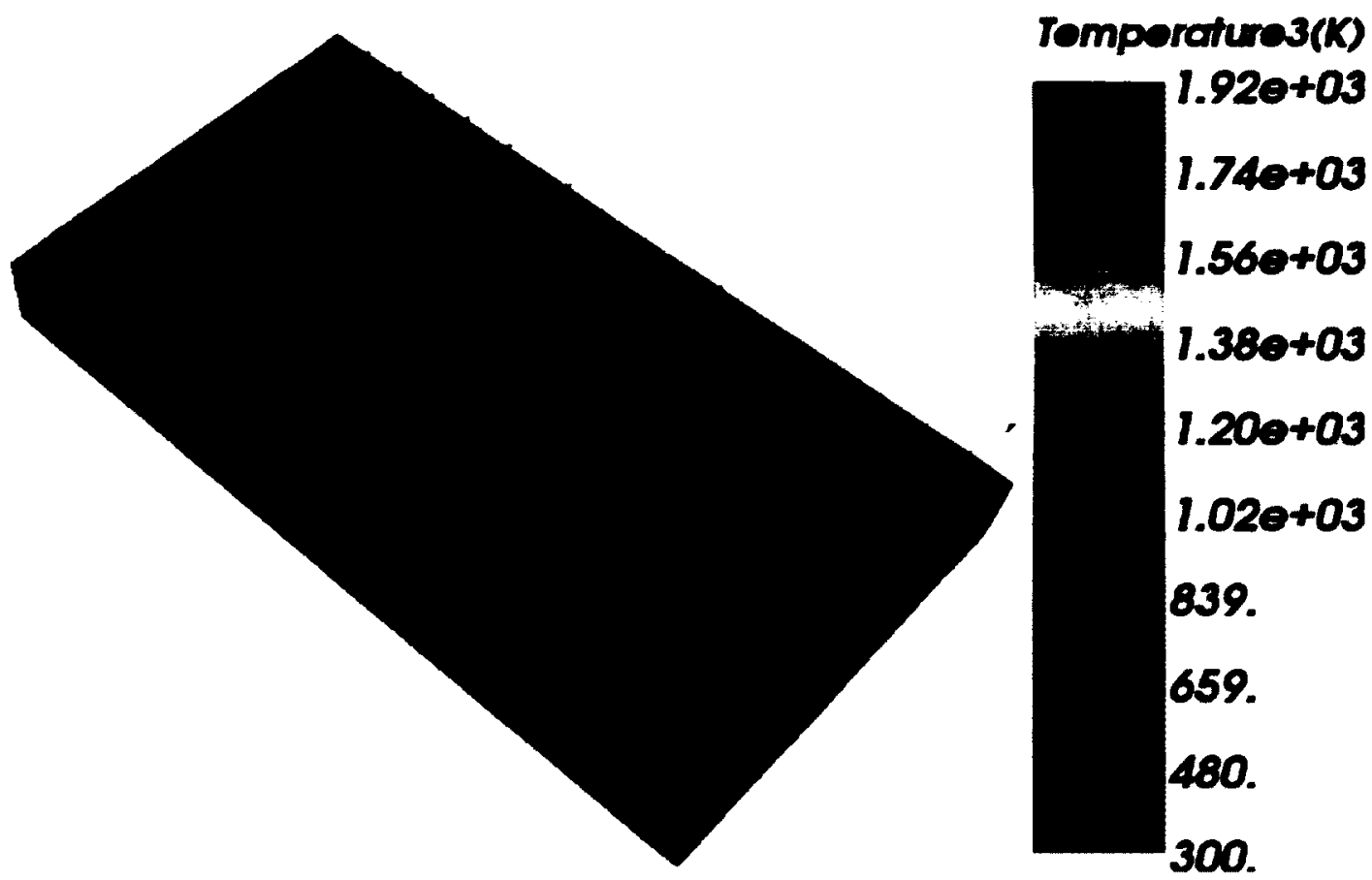

Figure 4.3: DDC test: results for temperature and strain are taken at Gauss points that are in between the markers. Shown is their location relative to temperature field in the sub-model with a $2 \mathrm{~mm} / \mathrm{s}$ welding speed, at $\mathrm{t}=32.5 \mathrm{~s}$.

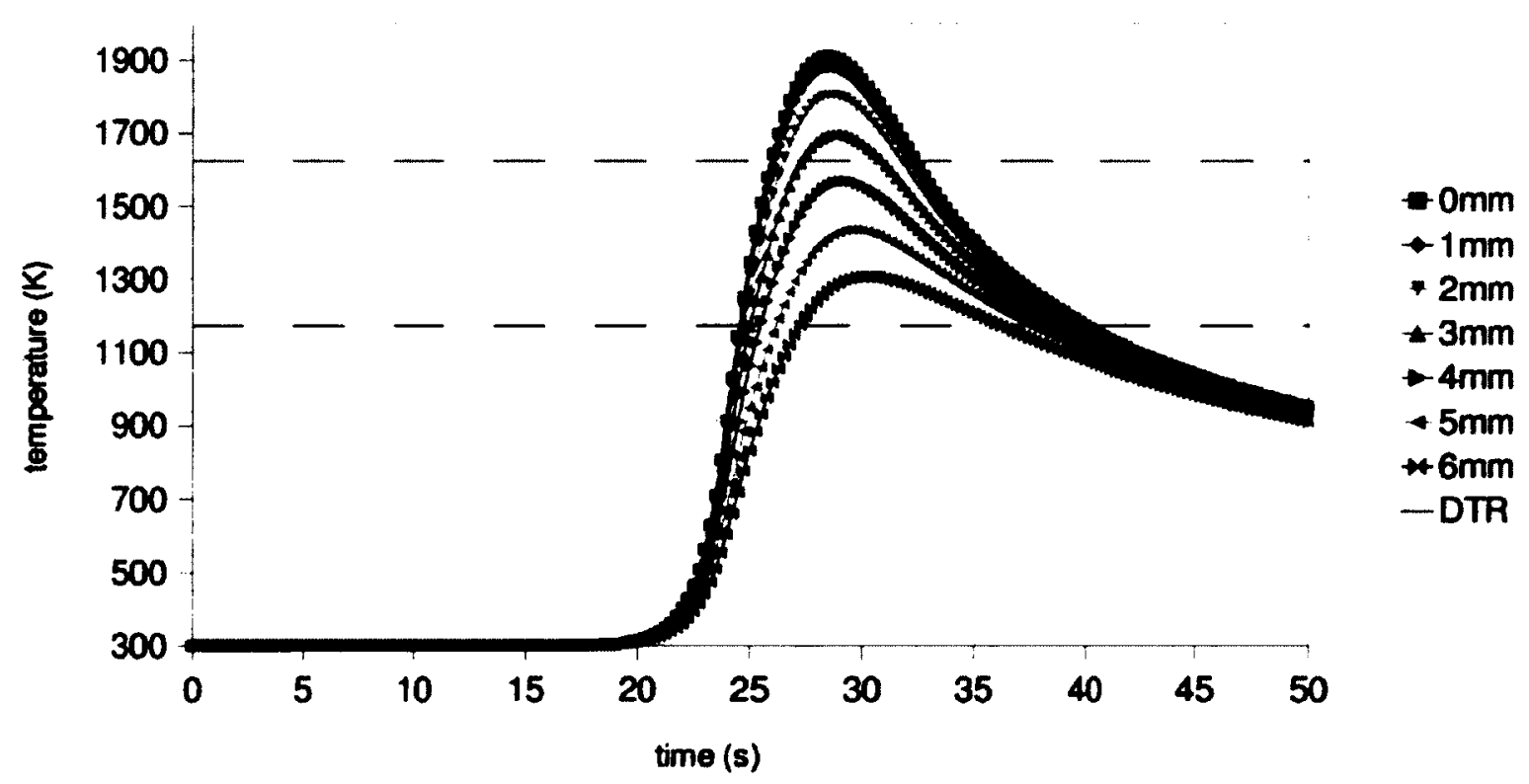

Figure 4.4: DDC test: temperature versus time with a $2 \mathrm{~mm} / \mathrm{s}$ welding speed, for Gauss points at the top surface of the plate, halfway across the weld path. 


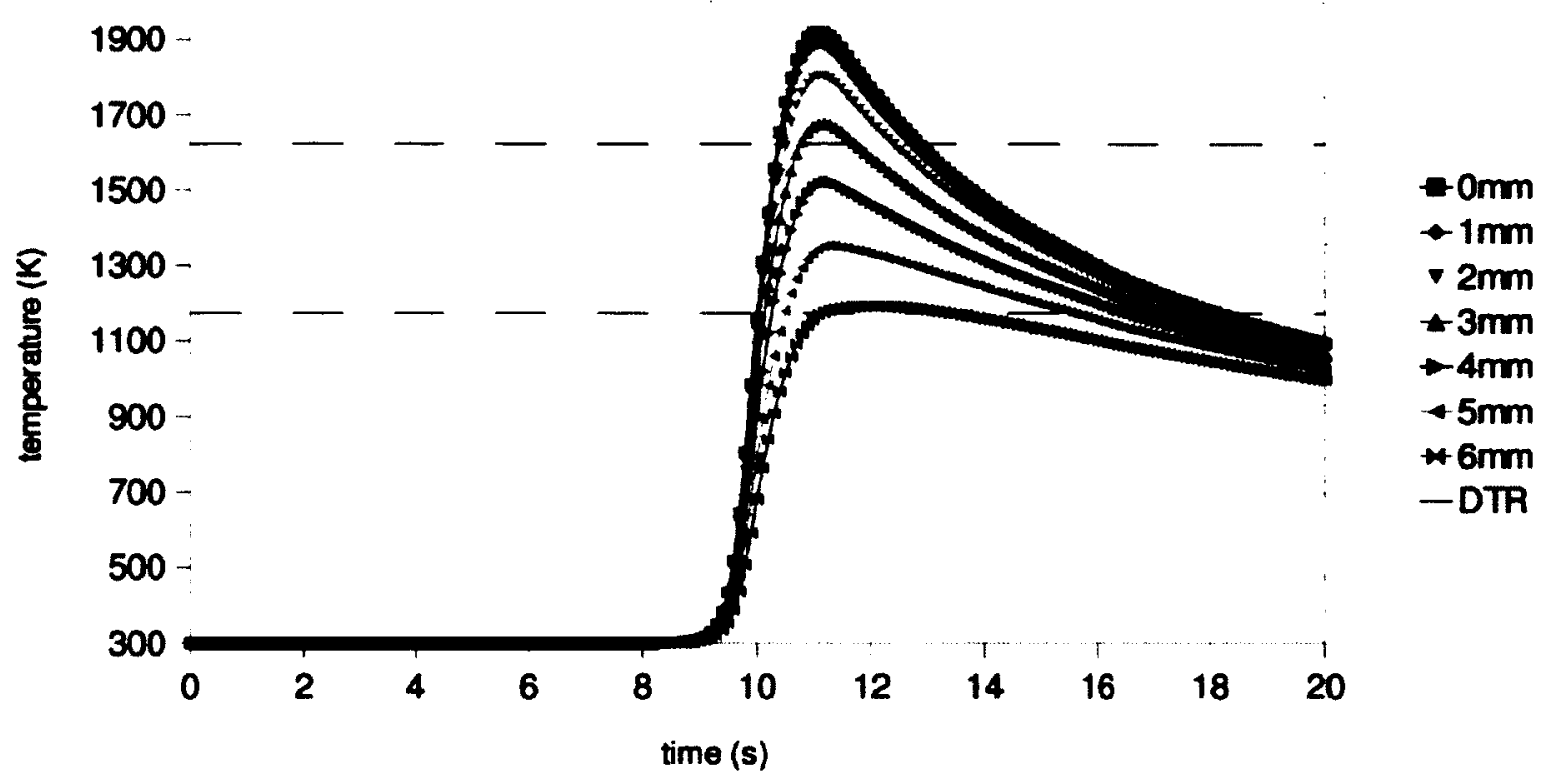

Figure 4.5: DDC test: temperature versus time with a $5 \mathrm{~mm} / \mathrm{s}$ welding speed, for Gauss points at the top surface of the plate, halfway across the weld path.

In order to better illustrate the details of the method outlined above and the effect of negative (compressive) plastic strain increment, the likelihood of DDC nucleation at a point, $5 \mathrm{~mm}$ from the weld centre-line and at the midpoint of the weld path is determined. In Figure 4.6 the temperature profile at the specified point is shown. Results at the same point for the tensile principal plastic strain increments are shown in Figure 4.7 and the sum of damage parameter is shown in Figure 4.8.

In the CWM model for DDC, plastic strain increment is computed in all principal directions at Gauss points. The sum of the damage parameter, which leads DDC, is computed at the same points, for which temperature is shown in Figures 4.4 and 4.5. The sum of the damage parameter, caused by the increment of the components of principal plastic strain, versus time curves, for a welding speed of $2 \mathrm{~mm} / \mathrm{s}$, are shown in Figures 4.10, 4.12 and 4.14. In the test with a welding speed of $2 \mathrm{~mm} / \mathrm{s}$, eigenvectors for the plastic strain are shown in Figures 4.9, 4.11 and 4.13. In the test with a welding speed of $5 \mathrm{~mm} / \mathrm{s}$, eigenvectors for the plastic strain are shown in Figures 4.16, 4.18 and 4.20. The equivalent plastic strain increment versus temperature curve, for a welding 
speed of $2 \mathrm{~mm} / \mathrm{s}$, is shown in Figure 4.15. Figures 4.17, 4.19 and 4.21 show the curves for the sum of the damage parameter, caused by the components of principal plastic strain increment, versus time, for a welding speed of $5 \mathrm{~mm} / \mathrm{s}$. The equivalent plastic strain increment versus temperature curve, for a welding speed of $5 \mathrm{~mm} / \mathrm{s}$, is shown in Figure 4.22.

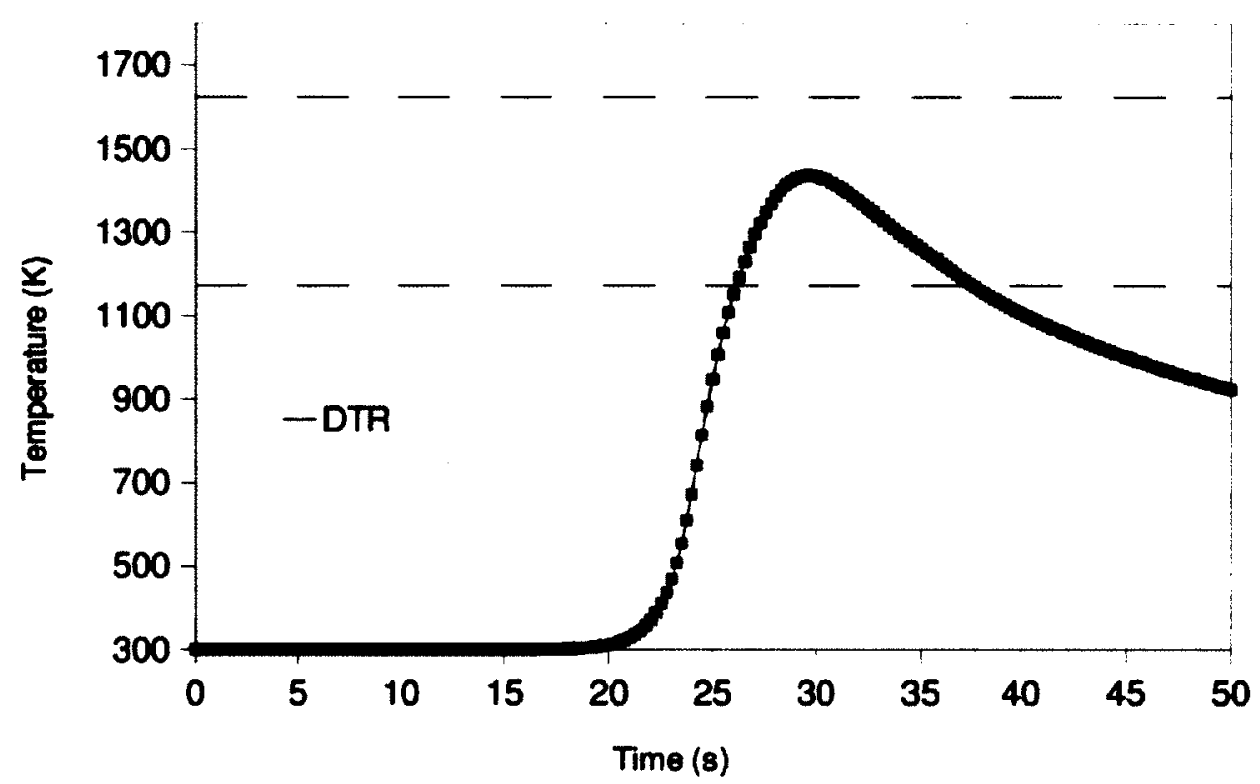

Figure 4.6: DDC test: temperature versus time, at distance of $5 \mathrm{~mm}$ from the weld centre-line, with a $2 \mathrm{~mm} / \mathrm{s}$ welding speed. 


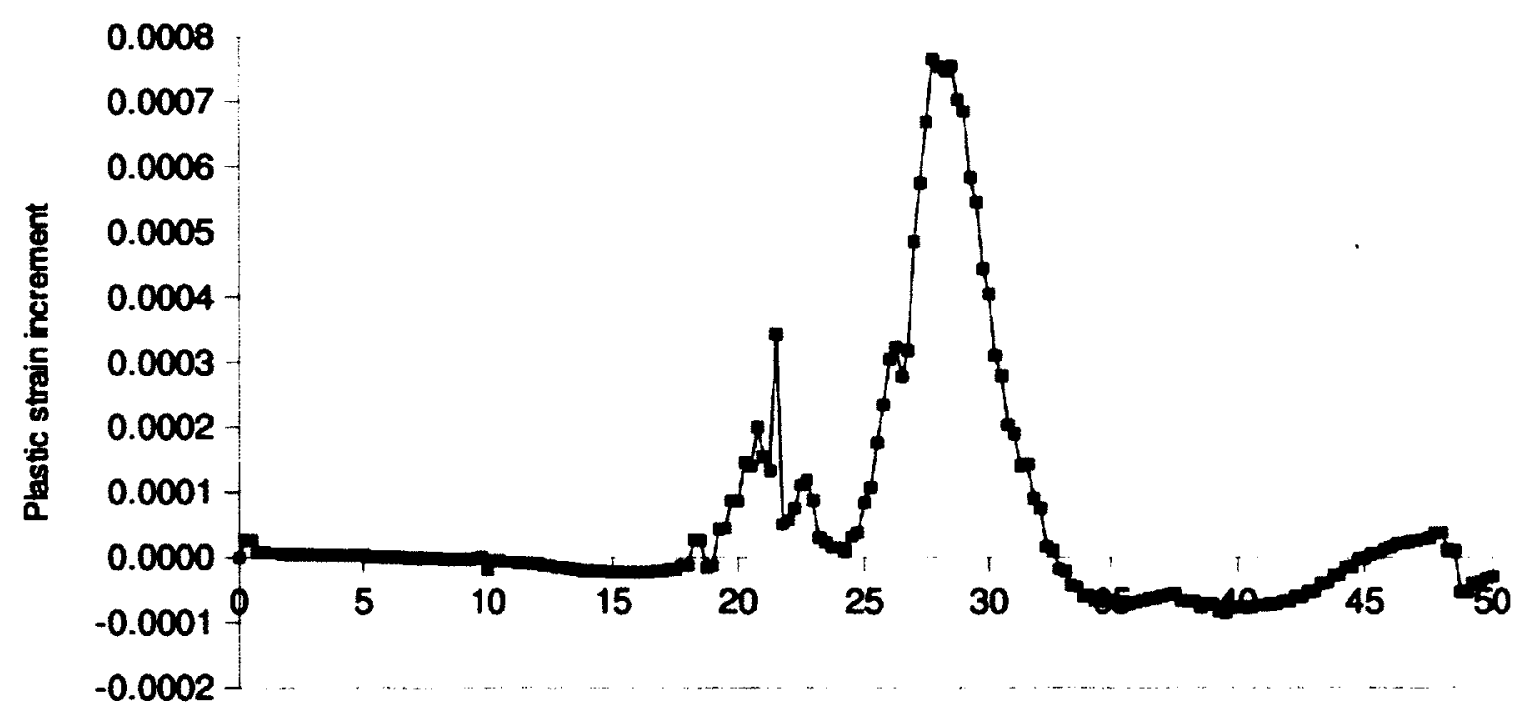

Time (s)

Figure 4.7: DDC test: increment in principal plastic strain 3 versus time, at distance of $5 \mathrm{~mm}$ from the weld centre-line, with a $2 \mathrm{~mm} / \mathrm{s}$ welding speed.

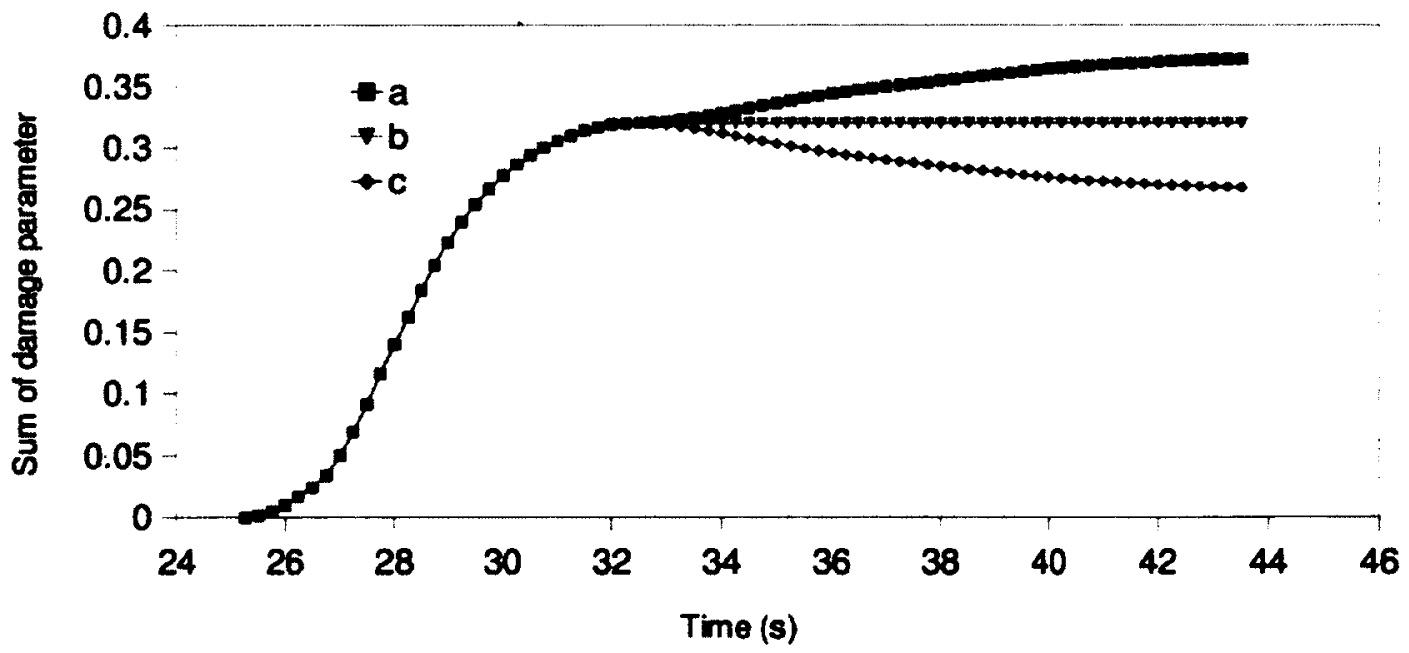

Figure 4.8: DDC test: sum of the damage parameter, $f_{i}$, versus time, at distance of $5 \mathrm{~mm}$ from weld centre-line, with a $2 \mathrm{~mm} / \mathrm{s}$ welding speed.

(a) assumes the absolute value of the strain increment causes damage; (b) assumes the negative strain increment causes no damage; and (c) assumes the negative strain increment heals. 


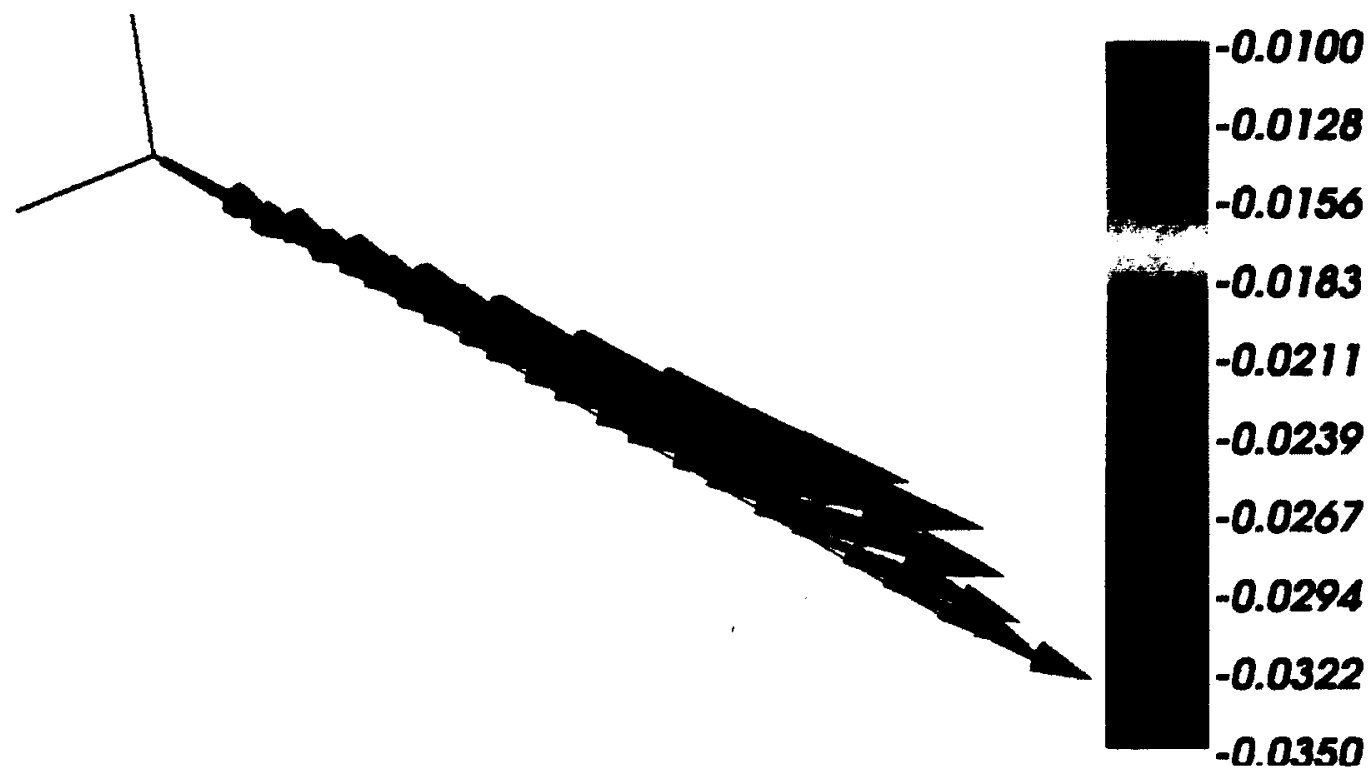

Figure 4.9: DDC test: eigenvectors for 1st component of principal strain at $t=45$ $\mathrm{s}$, from 0 to $6 \mathrm{~mm}$ from weld centre, for a $2 \mathrm{~mm} / \mathrm{s}$ welding speed.

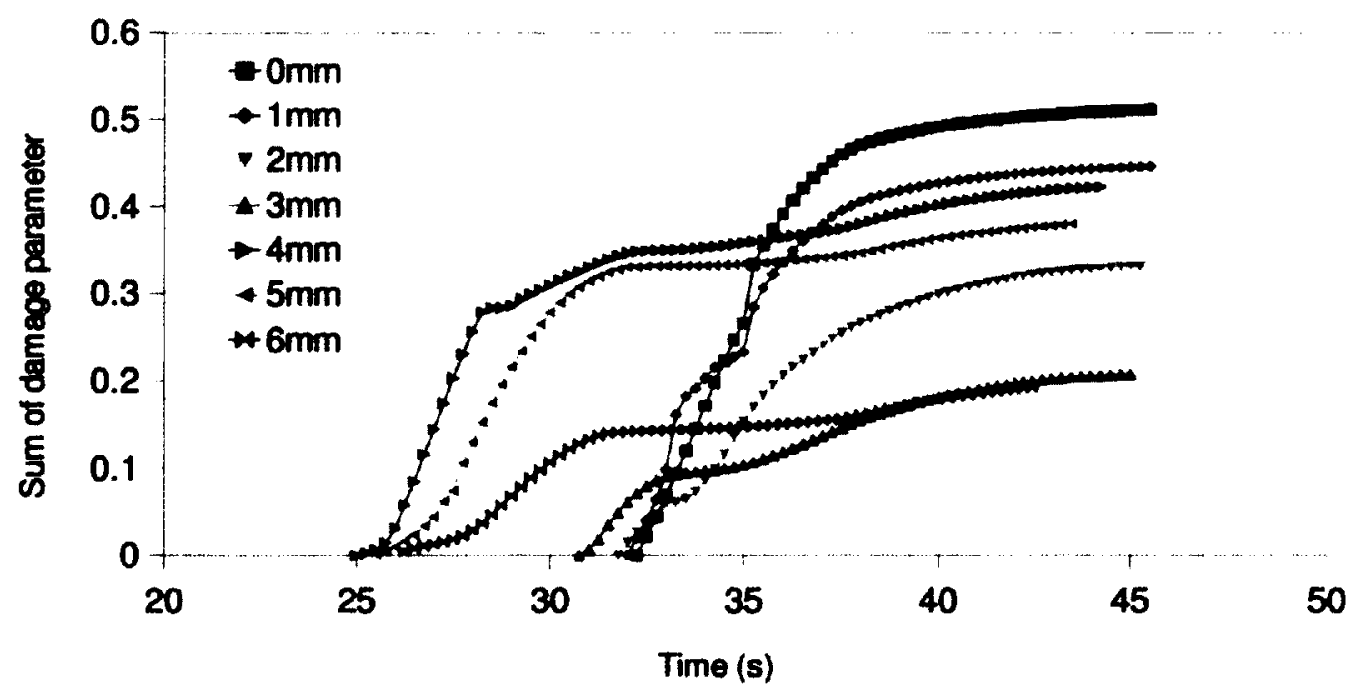

Figure 4.10: DDC test: damage parameter, caused by eigenvalue for 1 st component of principal plastic strain increment, versus time, for a $2 \mathrm{~mm} / \mathrm{s}$ welding speed. 


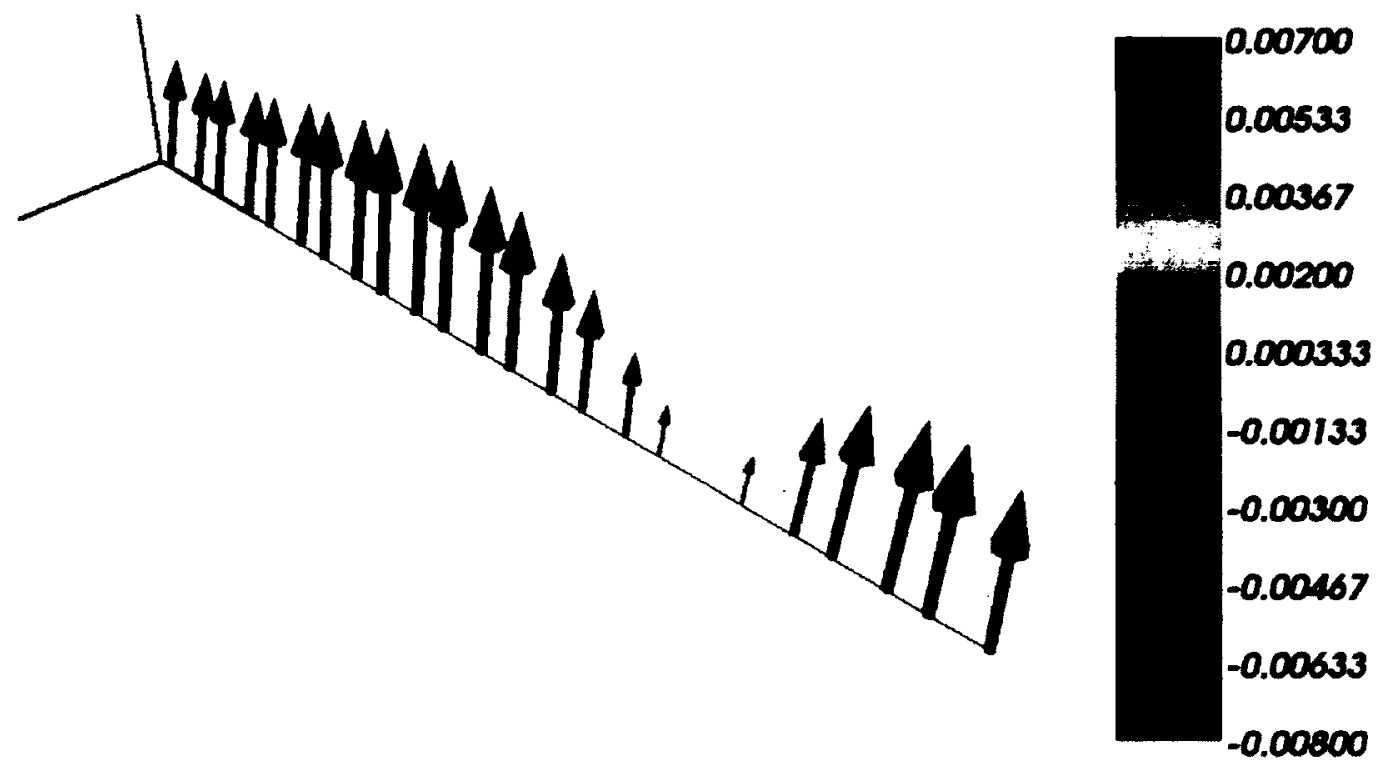

Figure 4.11: DDC test: eigenvectors for 2 nd component of principal strain at $\mathrm{t}=$ $45 \mathrm{~s}$, from 0 to $6 \mathrm{~mm}$ from weld centre, for a $2 \mathrm{~mm} / \mathrm{s}$ welding speed

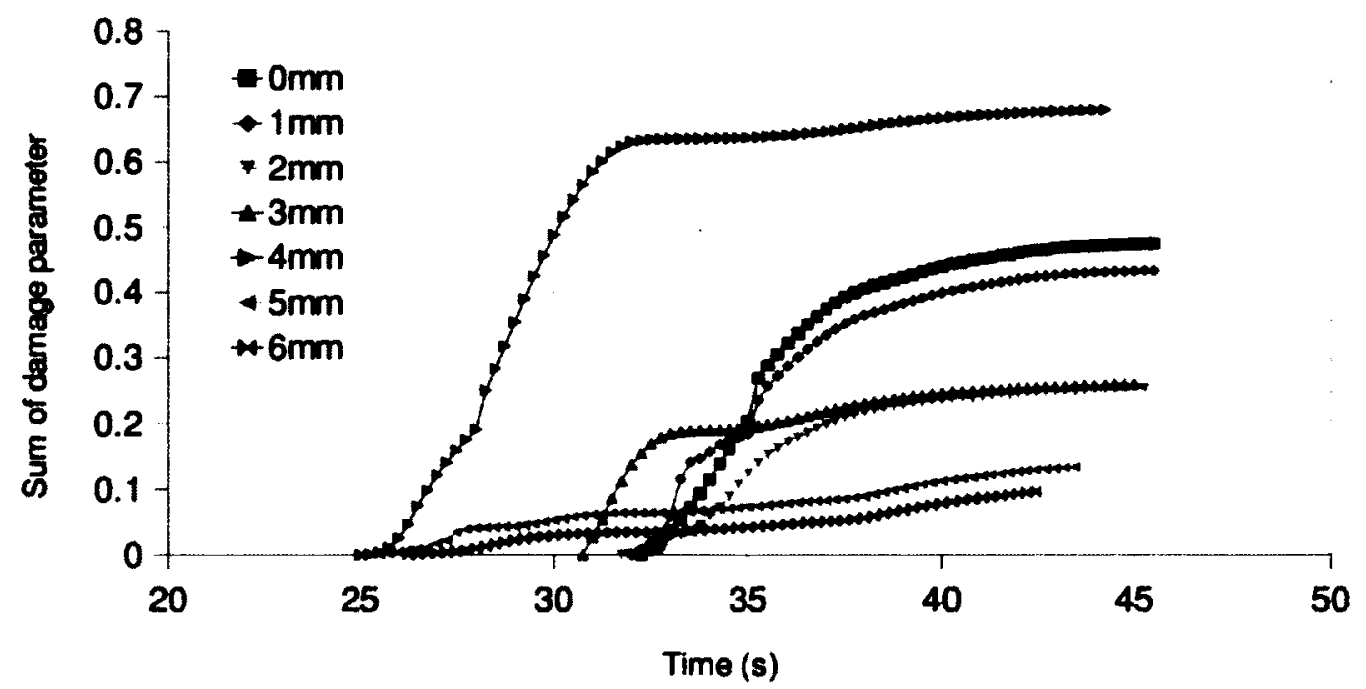

Figure 4.12: DDC test: damage parameter, caused by eigenvalue for 2 nd component of principal plastic strain increment, versus time, for a $2 \mathrm{~mm} / \mathrm{s}$ welding speed. 


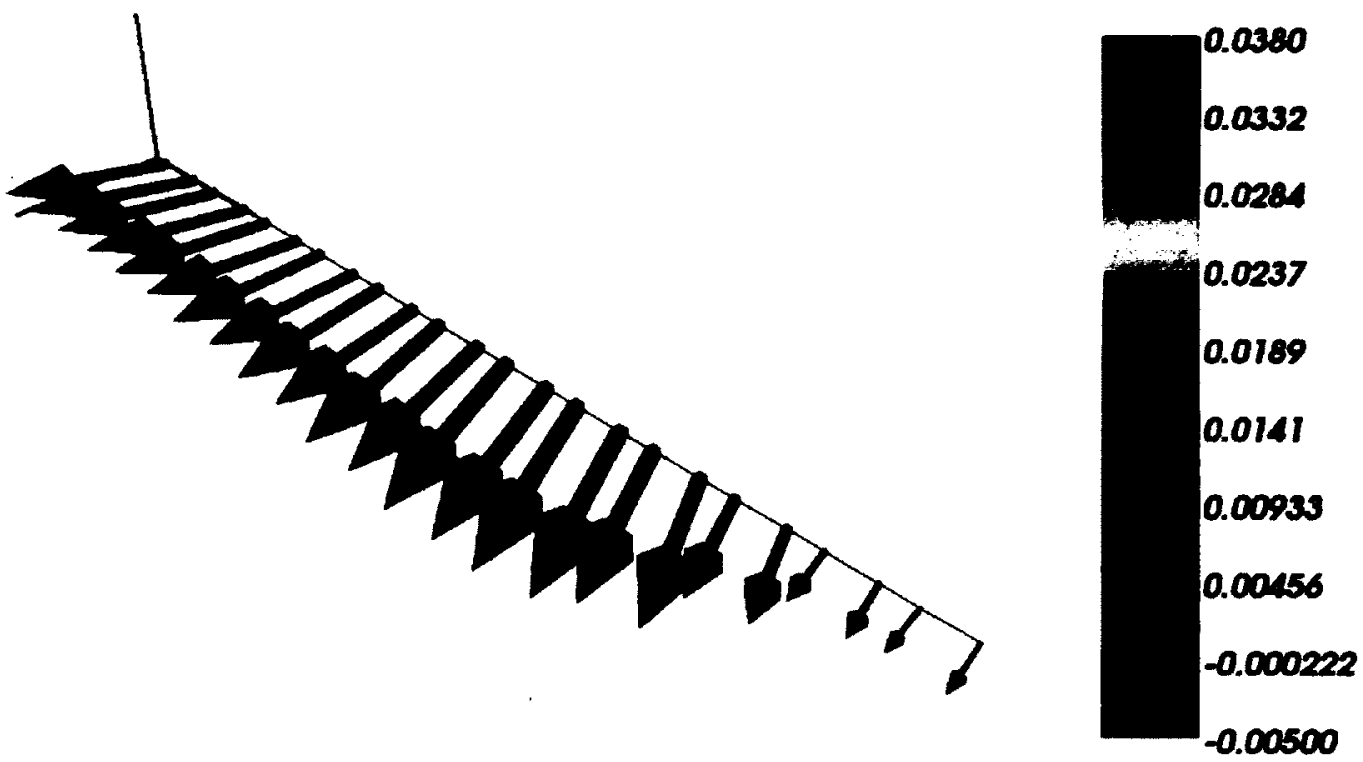

Figure 4.13: DDC test: eigenvectors for 3rd component of principal strain at $t=$ $45 \mathrm{~s}$, from 0 to $6 \mathrm{~mm}$ from weld centre, for a $2 \mathrm{~mm} / \mathrm{s}$ welding speed.

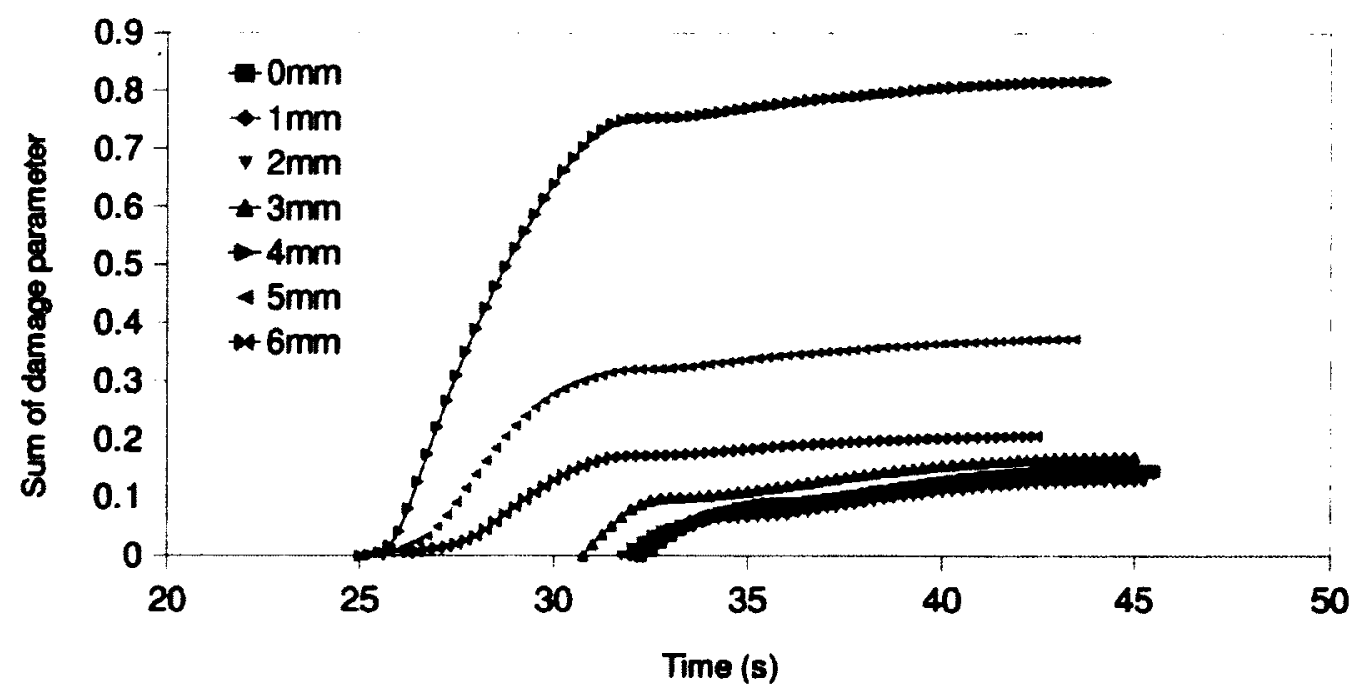

Figure 4.14: DDC test: damage parameter, caused by eigenvalue for 3rd component of principal plastic strain increment, versus time, for a $2 \mathrm{~mm} / \mathrm{s}$ welding speed. 


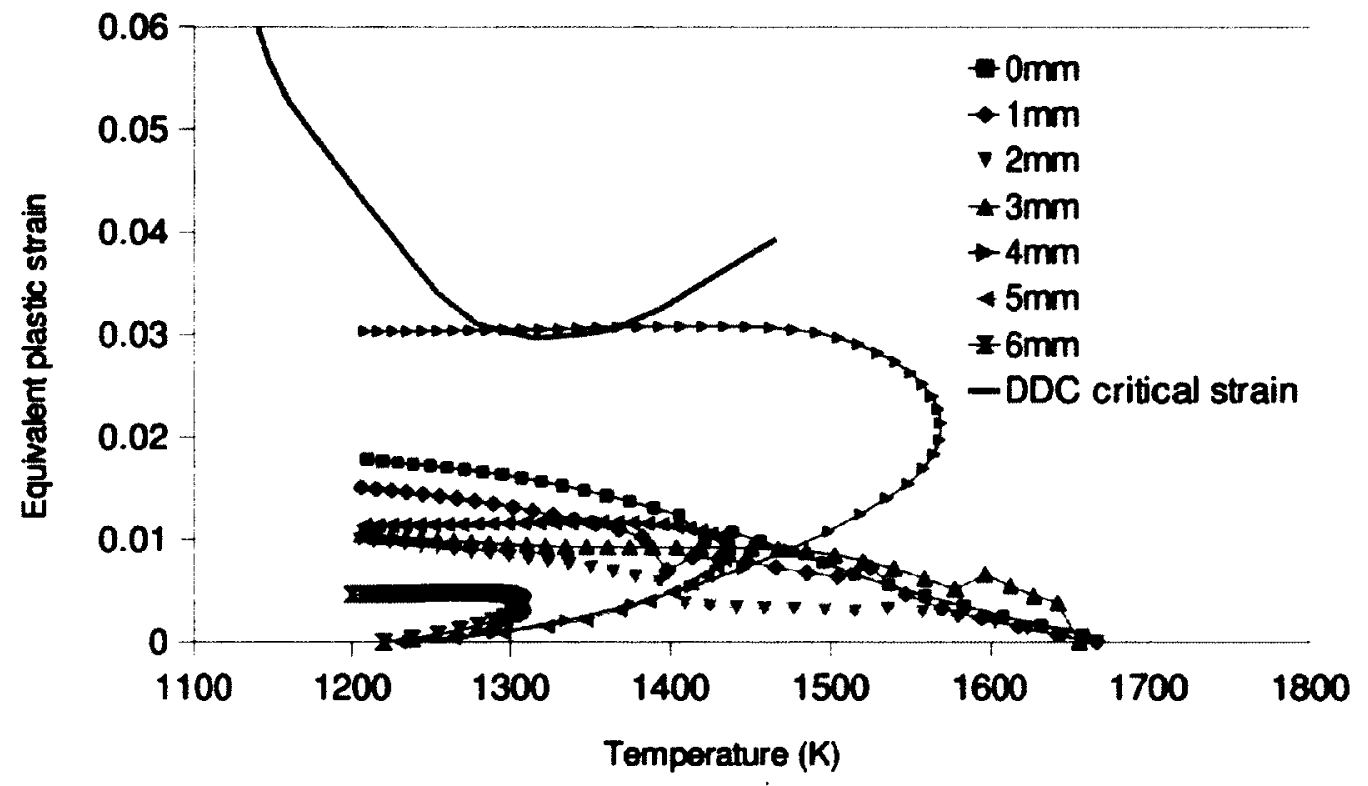

Figure 4.15: DDC test: equivalent plastic strain increment versus temperature, for a $2 \mathrm{~mm} / \mathrm{s}$ welding speed. 


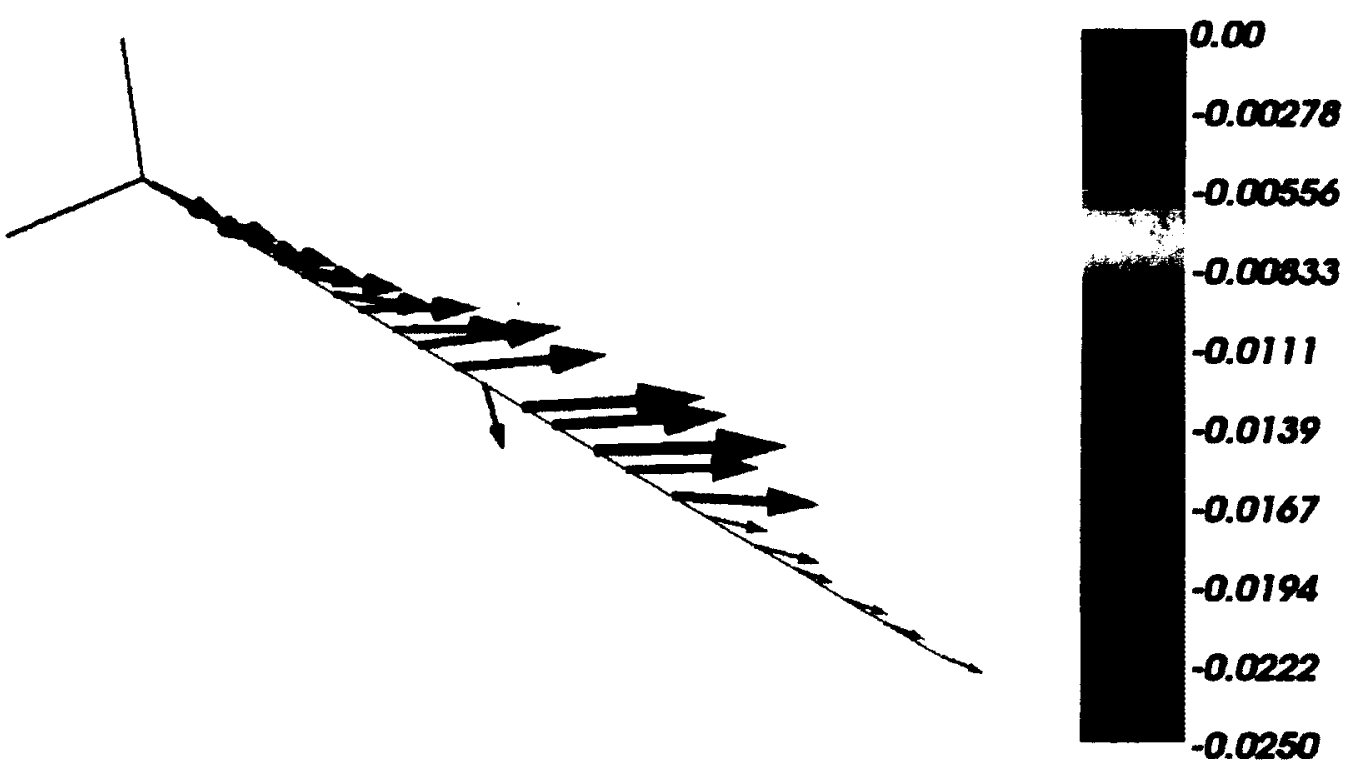

Figure 4.16: DDC test: eigenvectors for 1st component of principal strain at $\mathrm{t}=$ $18 \mathrm{~s}$, from 0 to $6 \mathrm{~mm}$ from weld centre, for a $5 \mathrm{~mm} / \mathrm{s}$ welding speed.

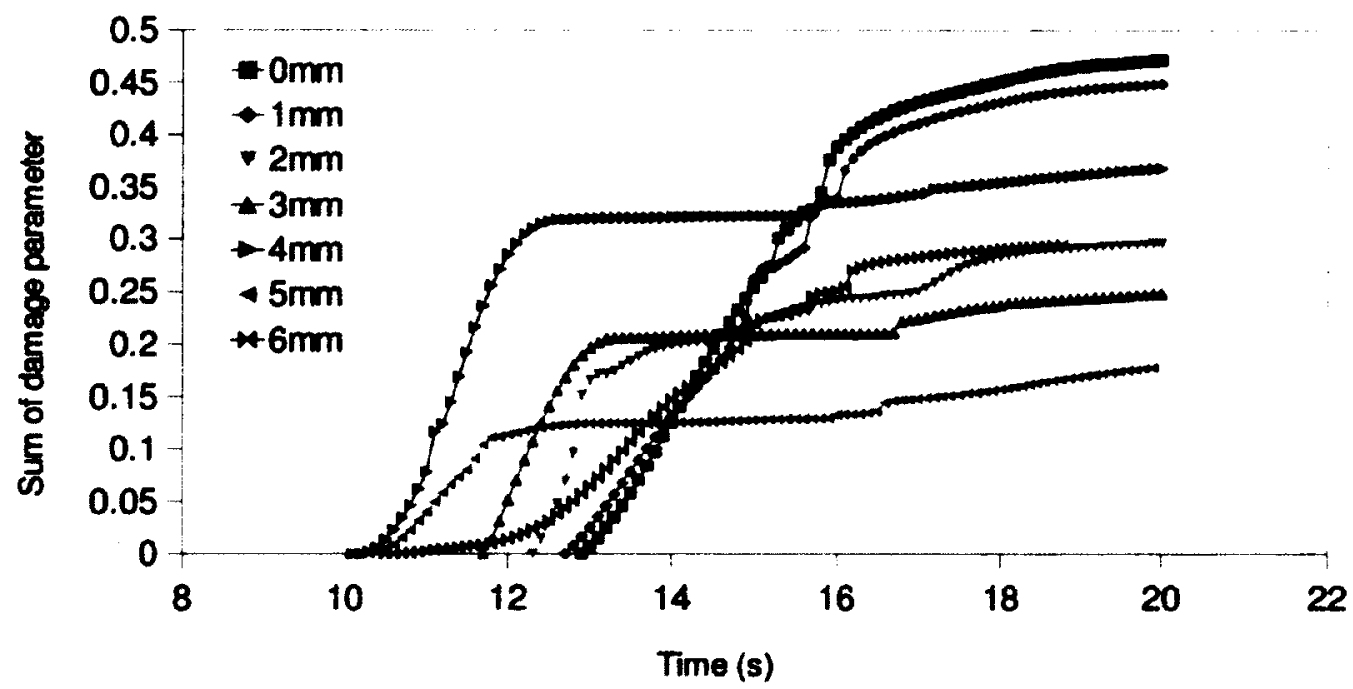

Figure 4.17: DDC test: damage parameter, caused by eigenvalue for 1st component of principal plastic strain increment, versus time, for a $5 \mathrm{~mm} / \mathrm{s}$ welding speed. 

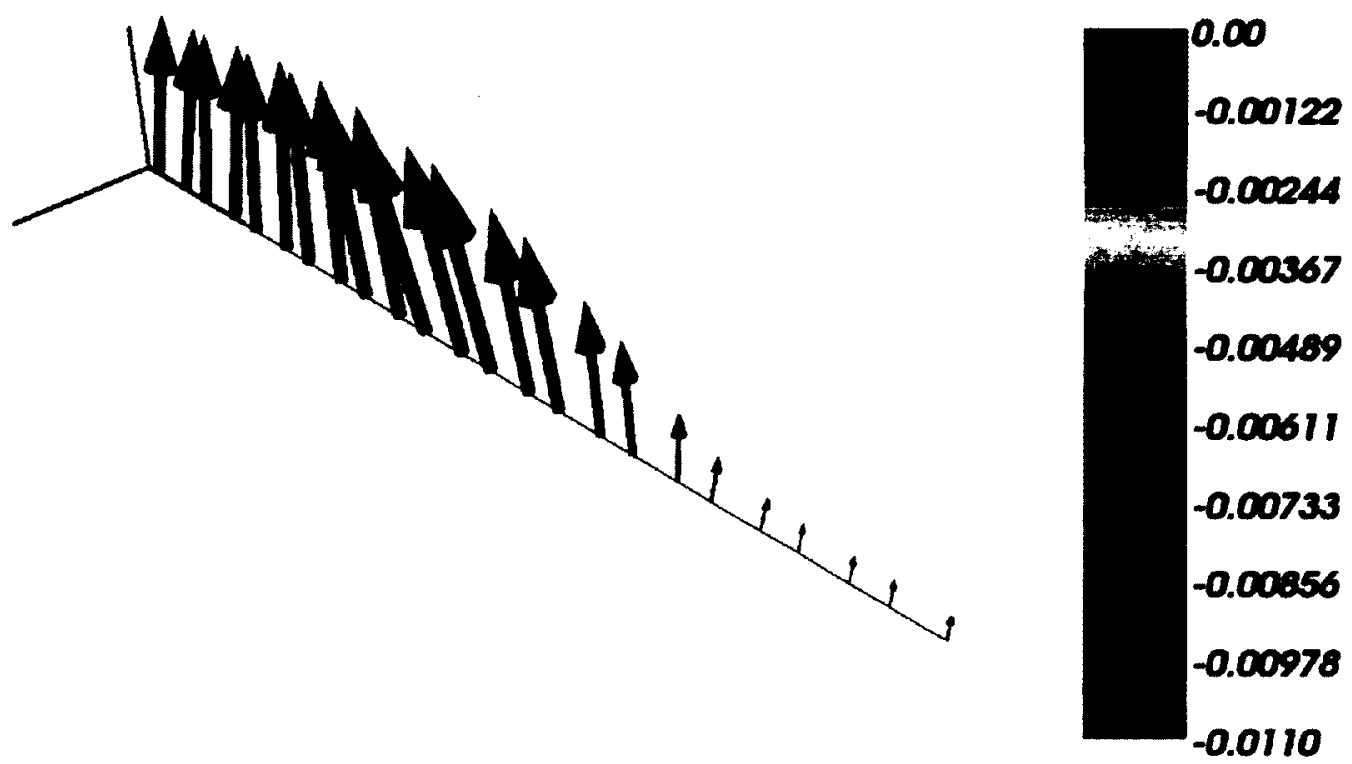

Figure 4.18: DDC test: eigenvectors for 2 nd component of principal strain at $t=$ $18 \mathrm{~s}$, from 0 to $6 \mathrm{~mm}$ from weld centre, for a $5 \mathrm{~mm} / \mathrm{s}$ welding speed.

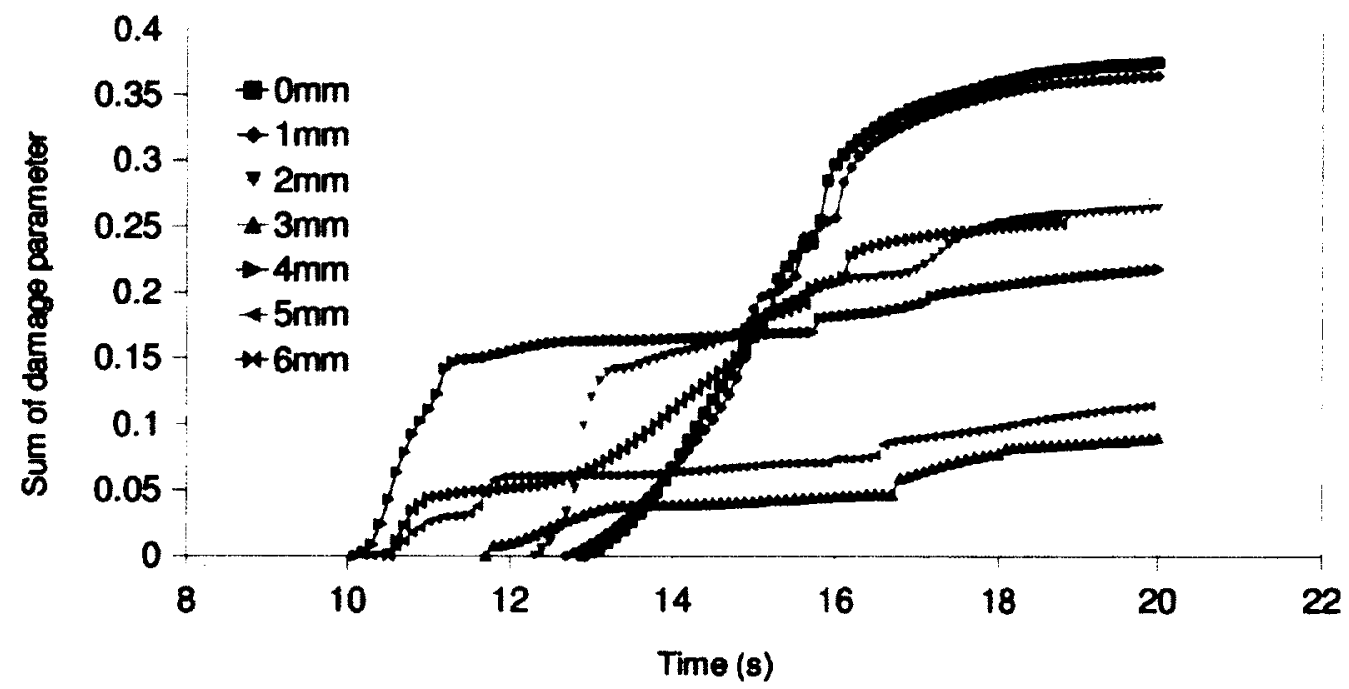

Figure 4.19: DDC test: damage parameter, caused by eigenvalue for 2 nd component of principal plastic strain increment, versus time, for a $5 \mathrm{~mm} / \mathrm{s}$ welding speed. 

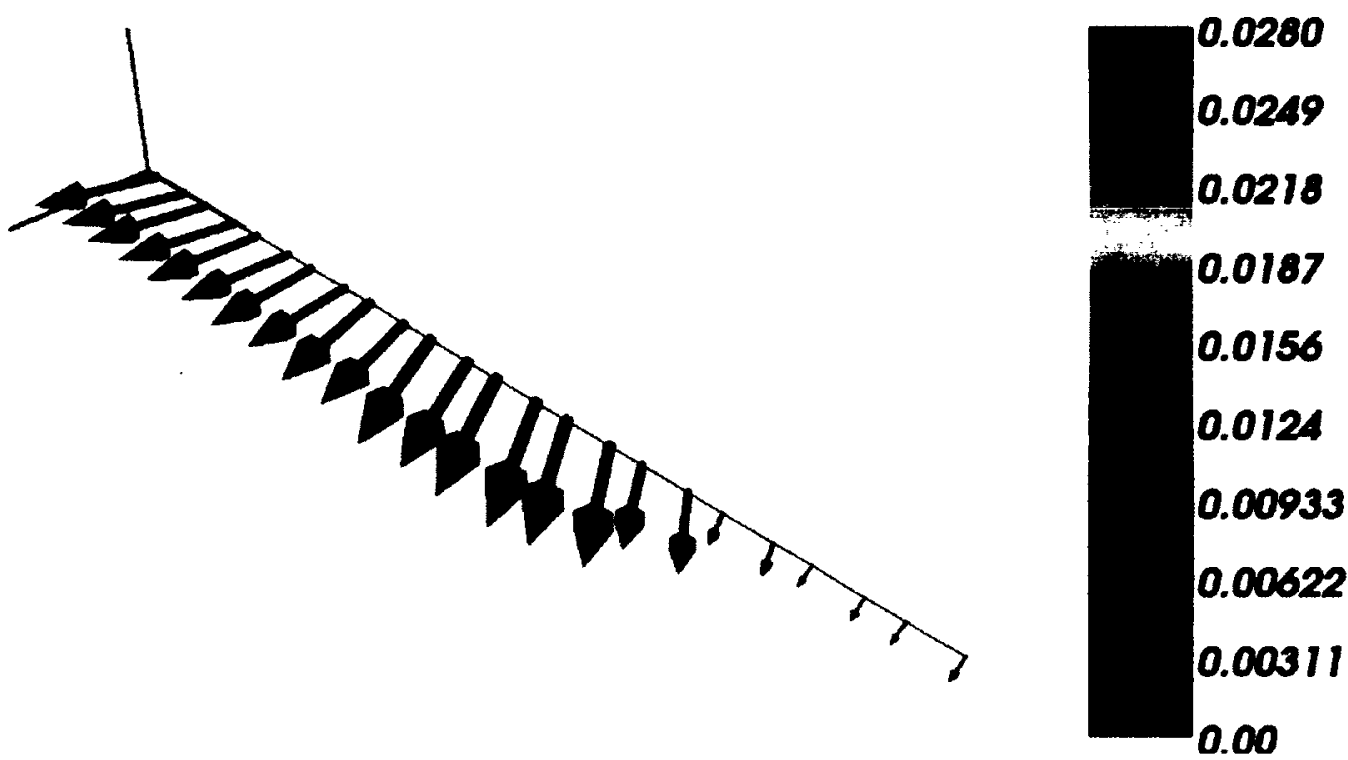

Figure 4.20: DDC test: eigenvectors for 3rd component of principal strain at $\mathrm{t}=$ $18 \mathrm{~s}$, from 0 to $6 \mathrm{~mm}$ from weld centre, for a $5 \mathrm{~mm} / \mathrm{s}$ welding speed.

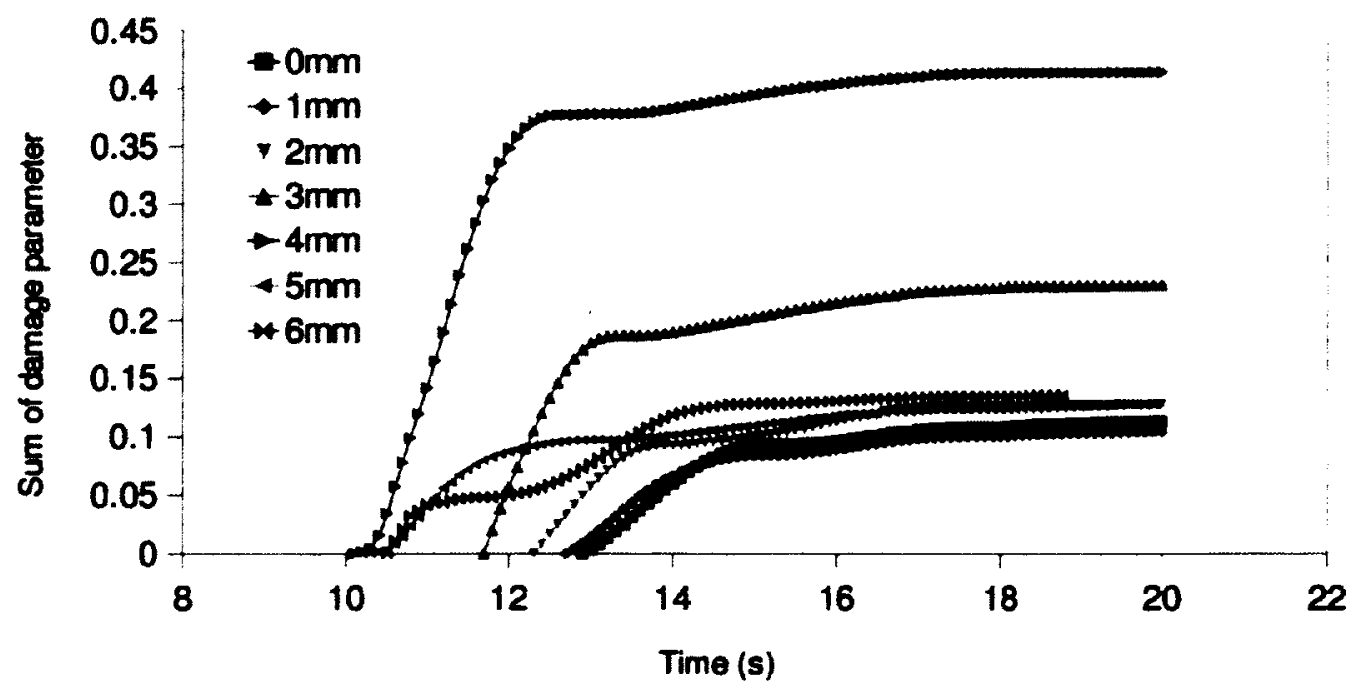

Figure 4.21: DDC test: damage parameter, caused by eigenvalue for $3 \mathrm{rd}$ component of principal plastic strain increment, versus time, for a $5 \mathrm{~mm} / \mathrm{s}$ welding speed. 


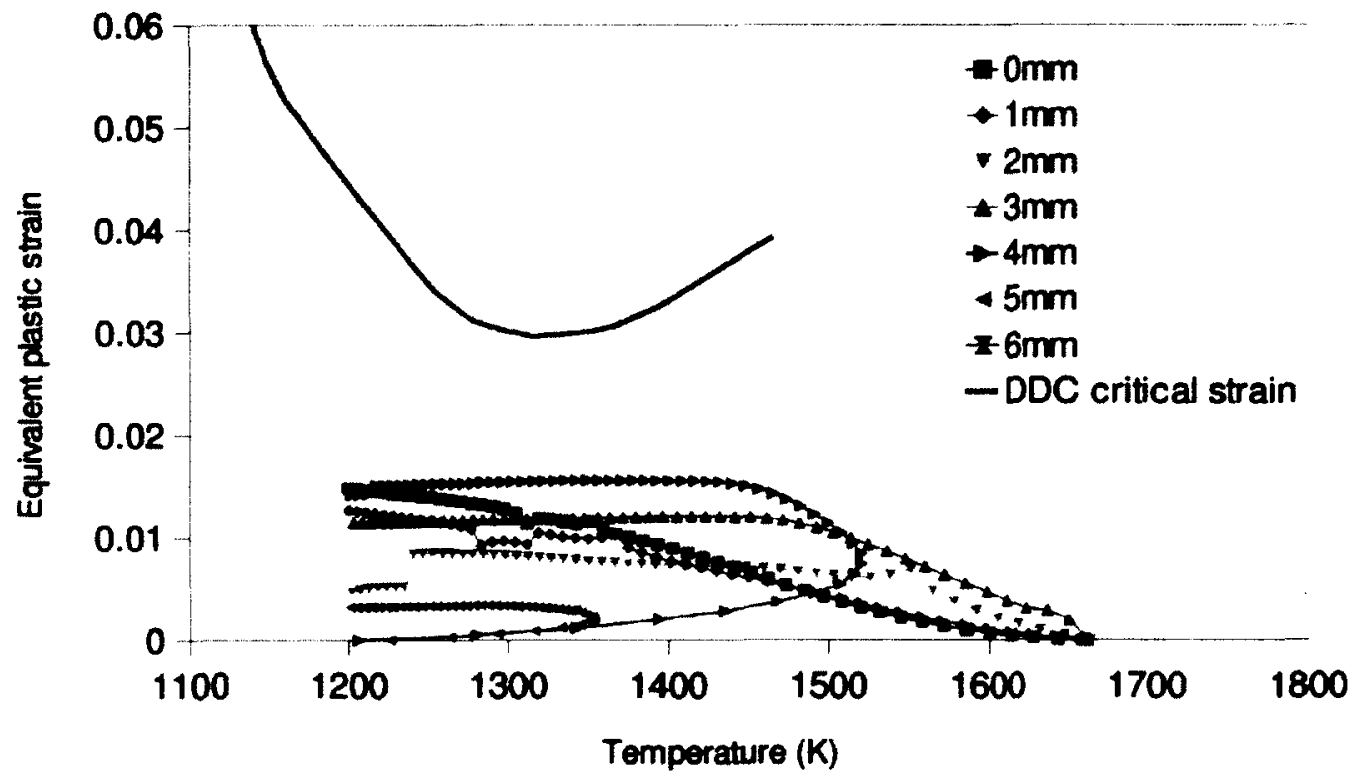

Figure 4.22: DDC test: equivalent plastic strain increment versus temperature for $5 \mathrm{~mm} / \mathrm{s}$ welding speed. 


\subsection{Solidification Cracking Test}

The CWM simulation of solidification cracking used the results of a single thermal analysis, because the welding parameters were constant. The CWM analysis of solidification cracking relied on applying a rate of displacement, referred to as cross-head speeds (CHS), at the opposite edges of the plate to nucleate solidification cracking. The CHS was applied once the weld heat source reached the midpoint of the designated weld path, at $12.5 \mathrm{~s}$ from the start of welding. Consequently, a separate stress analysis is necessary for each different CHS that was applied. The likelihood of solidification cracking is determined by comparing the tensile strain increment in the susceptible region to the ductility curve.

\subsubsection{Temperature}

In the solidification cracking CWM model, the location of the virtual strain gauge is determined by the the thermal analysis. The strain increment is computed during the time the CHS is applied. The virtual strain gauge is located behind the heat source, where the temperature reaches the maximum of the solidification cracking susceptible temperature range, also known as the brittleness temperature range (BTR), which is a material specific property. However, an appropriate approximation for the BTR, shown in Table 4.2, is based on the limits of the ductility curve used [3].

The location of the virtual strain gauge is determined by computing the temperature along the weld path at the starting time of the applied CHS, which is shown in Figure 4.23. The position for the virtual stain gauge is on the centre-line and at 16.96 $\mathrm{mm}$, measured from the start of the weld path. The temperature profile over time at the location of the strain gauge is shown in Figure 4.24. The temperature limits of the BTR are shown in Figure 4.26 for the solidification cracking test. The maximum temperature for the BTR is most commonly associated with the local liquidus 
temperature. The values for the liquidus temperature may vary as local composition changes during the solidification process. The liquidus temperature happens to be the trailing edge of the weld pool.

Table 4.2: BTR for Inconel 600 after Matsuda et al. [3].

\begin{tabular}{|l|l|}
\hline Maximum & $1655 \mathrm{~K}$ \\
\hline Minimum & $1557 \mathrm{~K}$ \\
\hline
\end{tabular}

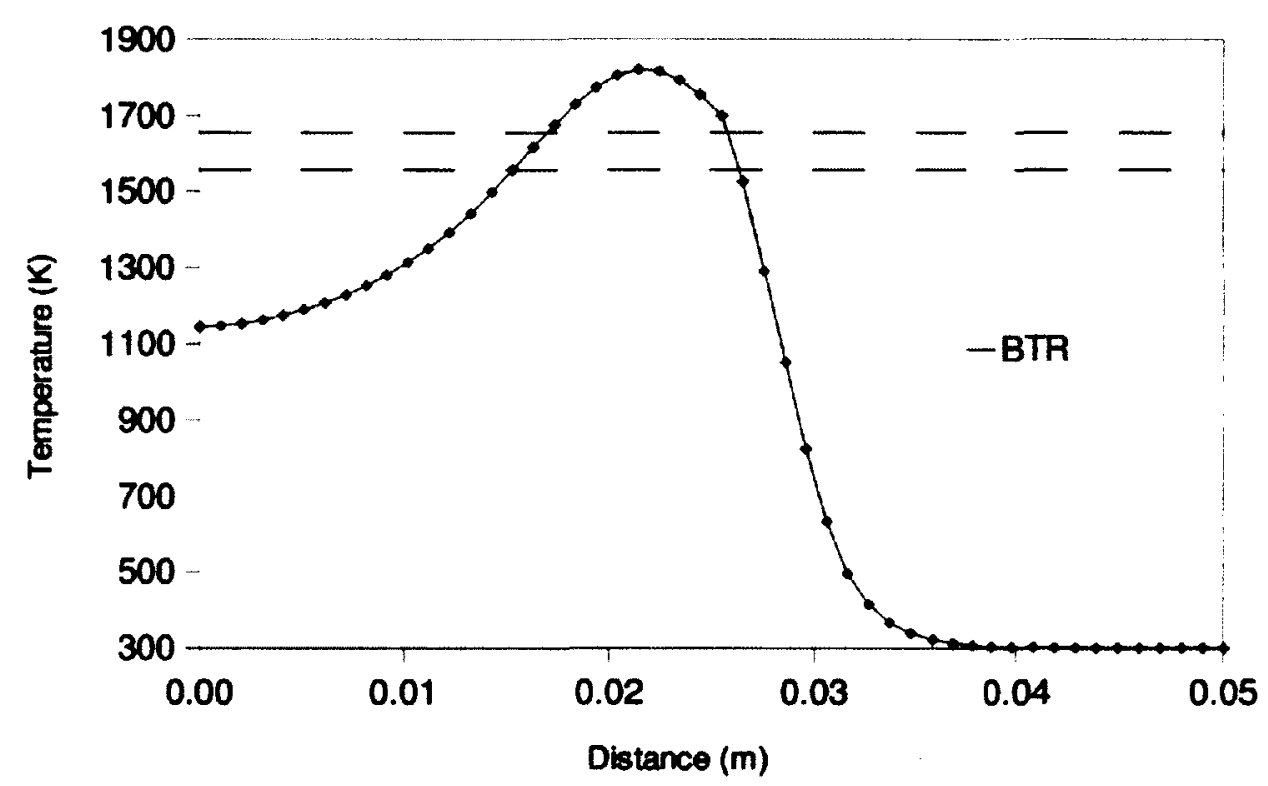

Figure 4.23: Solidification cracking test: temperature versus distance computed from the start to end of the weld path at $t=12.5 \mathrm{~s}$.

\subsubsection{Strain}

In the CWM simulation for solidification cracking, a virtual strain gauge to compute strain increment, transverse to the welding direction and in the direction of the applied cross-head speed (CHS), is positioned across the weld path on the top surface of the plate. The purpose is to determine the risk of solidification cracking at the specified location. The edges of plate are pulled at three different CHSs and the resulting 


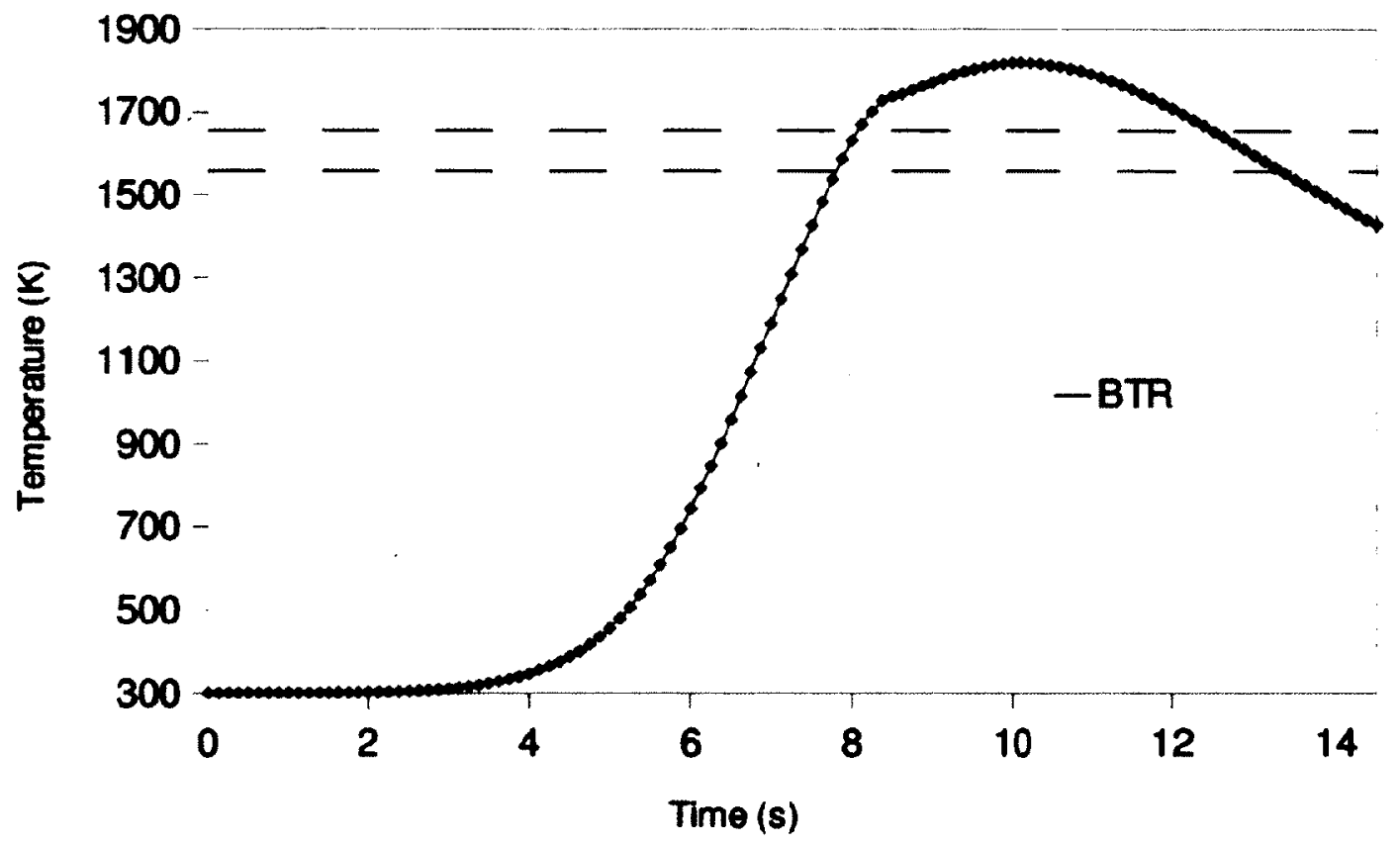

Figure 4.24: Solidification cracking test: temperature versus time computed on the top surface of the weld centre-line and at $\mathrm{d}=16.96 \mathrm{~mm}$ from start of weld path.
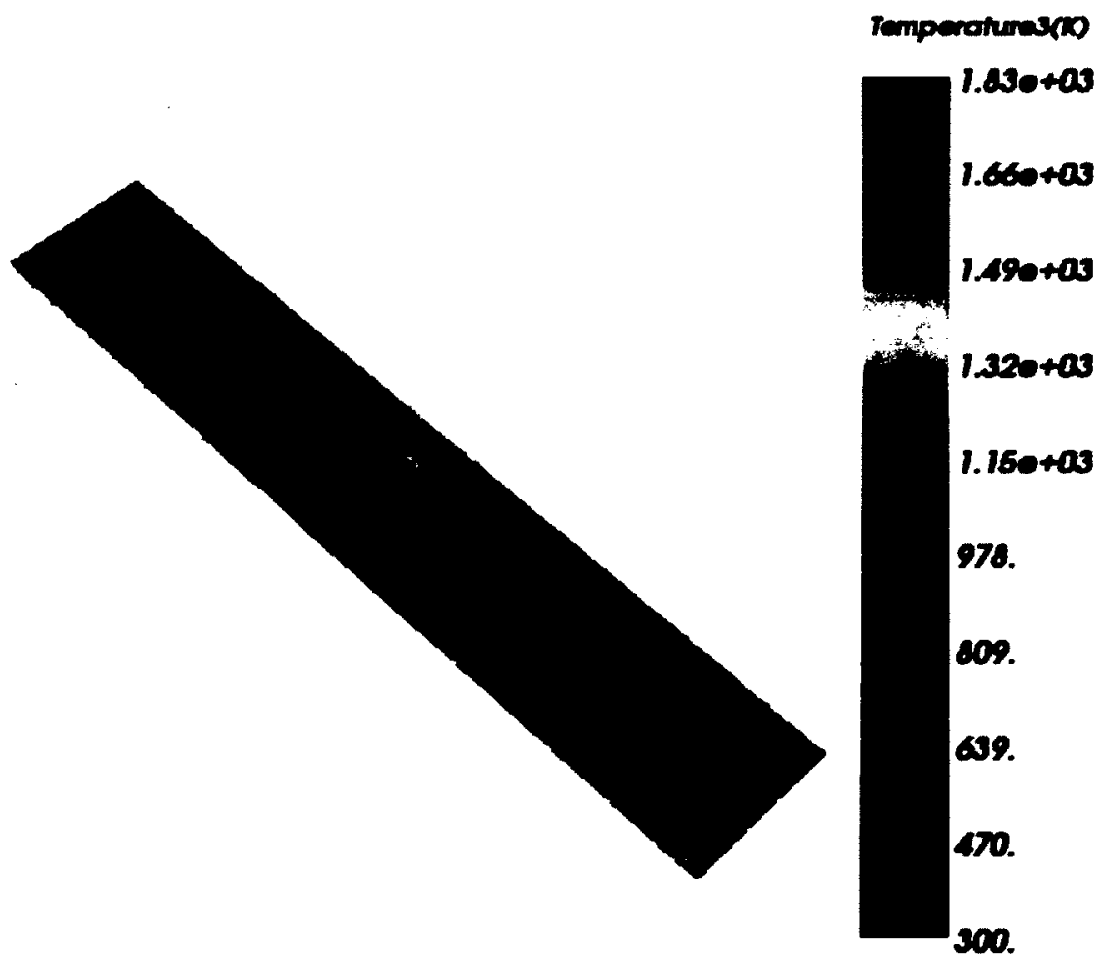

Figure 4.25: Solidification cracking test: temperature field at $t=12.5 \mathrm{~s}$. 


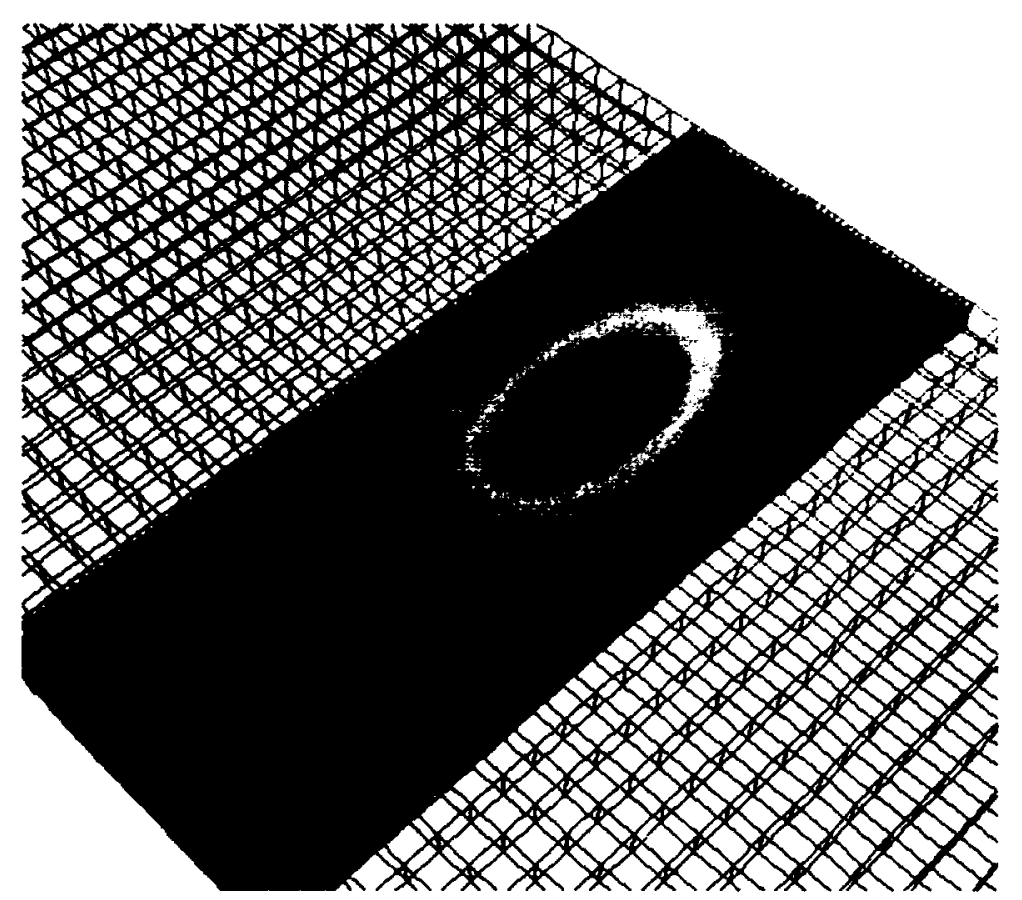

Figure 4.26: Solidification cracking test: detailed temperature field with isosurfaces for the solidus and liquidus temperature at $\mathrm{t}=12.5 \mathrm{~s}$.

localized strain is computed while the strain gauge is within the BTR. The movement of the weld pool relative to the strain gauge over time is shown in Figure 4.27.

The effect of the three different CHSs on localized strain and strain rate is revealed in Figure 4.28. Figure 4.29, for the localized strain versus temperature, compares experimental values for critical strain rate and ductility curves, obtained from the literature [3], with values computed with CWM simulation. An intersection of the computed strain-temperature curve with the ductility curve indicates an increased risk of solidification crack nucleation.

In addition, an algorithm, available in the VrWeld software [6], was used to identify Gauss points susceptible to hot cracking in the CWM analysis. The algorithm evaluated susceptibility to hot cracking based on the plastic strain increment in the susceptible temperature range. This post-processor was used for the solidification cracking test with a $20 \mathrm{~mm} / \mathrm{s}$ CHS. The Gauss points at risk of solidification crack 


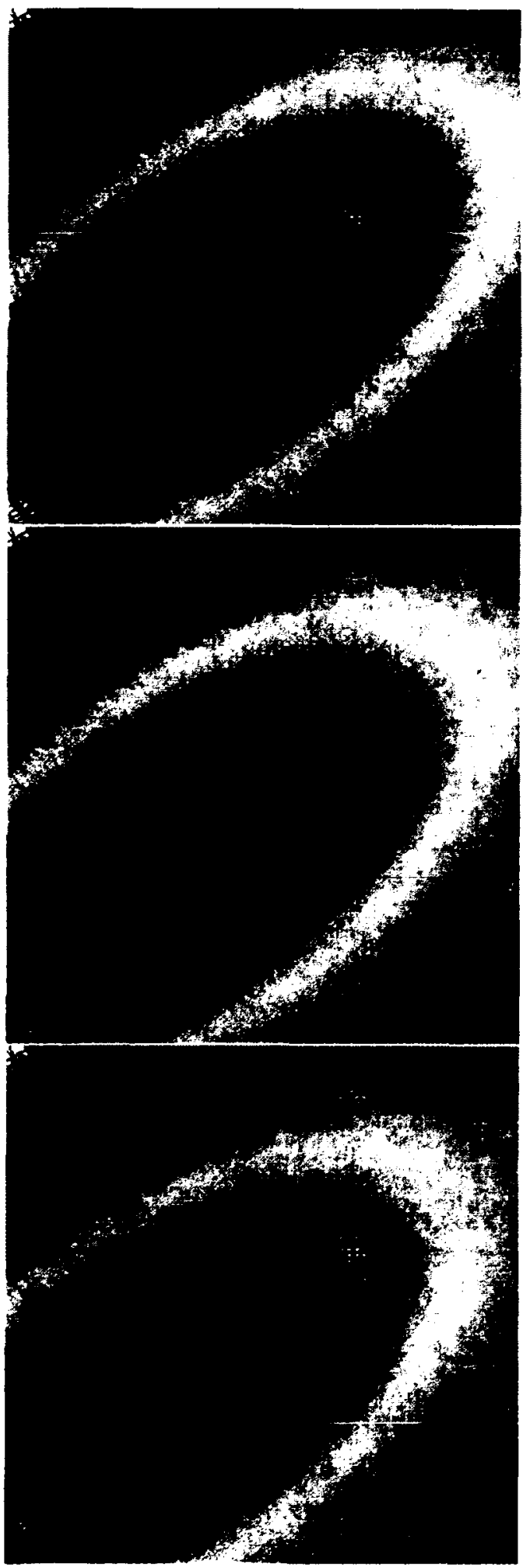

Figure 4.27: Solidification cracking test: temperature field with isosurfaces for solidus and liquidus temperature, at $\mathrm{t}=12.5,12.875$ and $13.25 \mathrm{~s}$.

The strain gauge is between the two circular markers. 


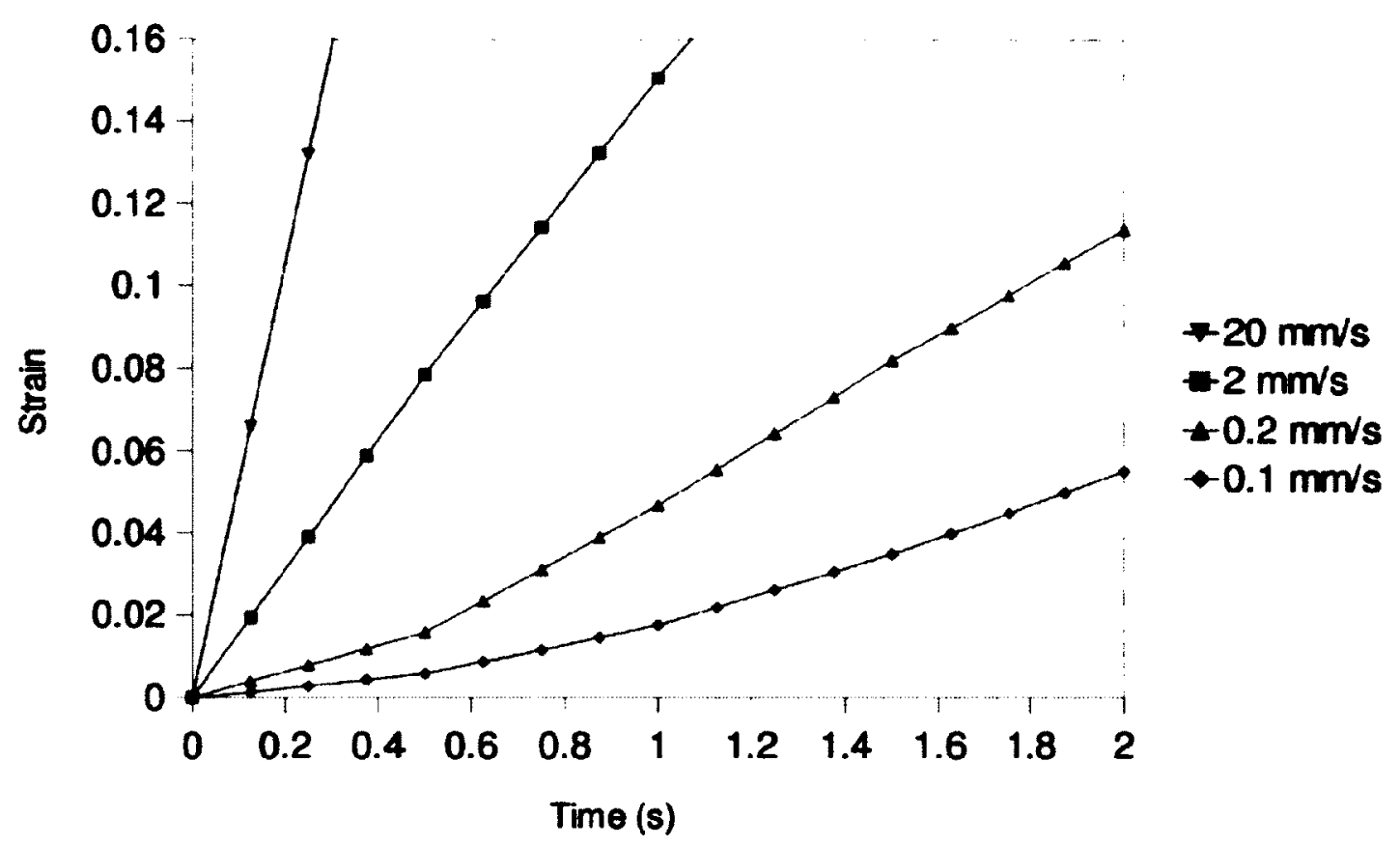

Figure 4.28: Solidification cracking test: strain versus time for different applied CHS.

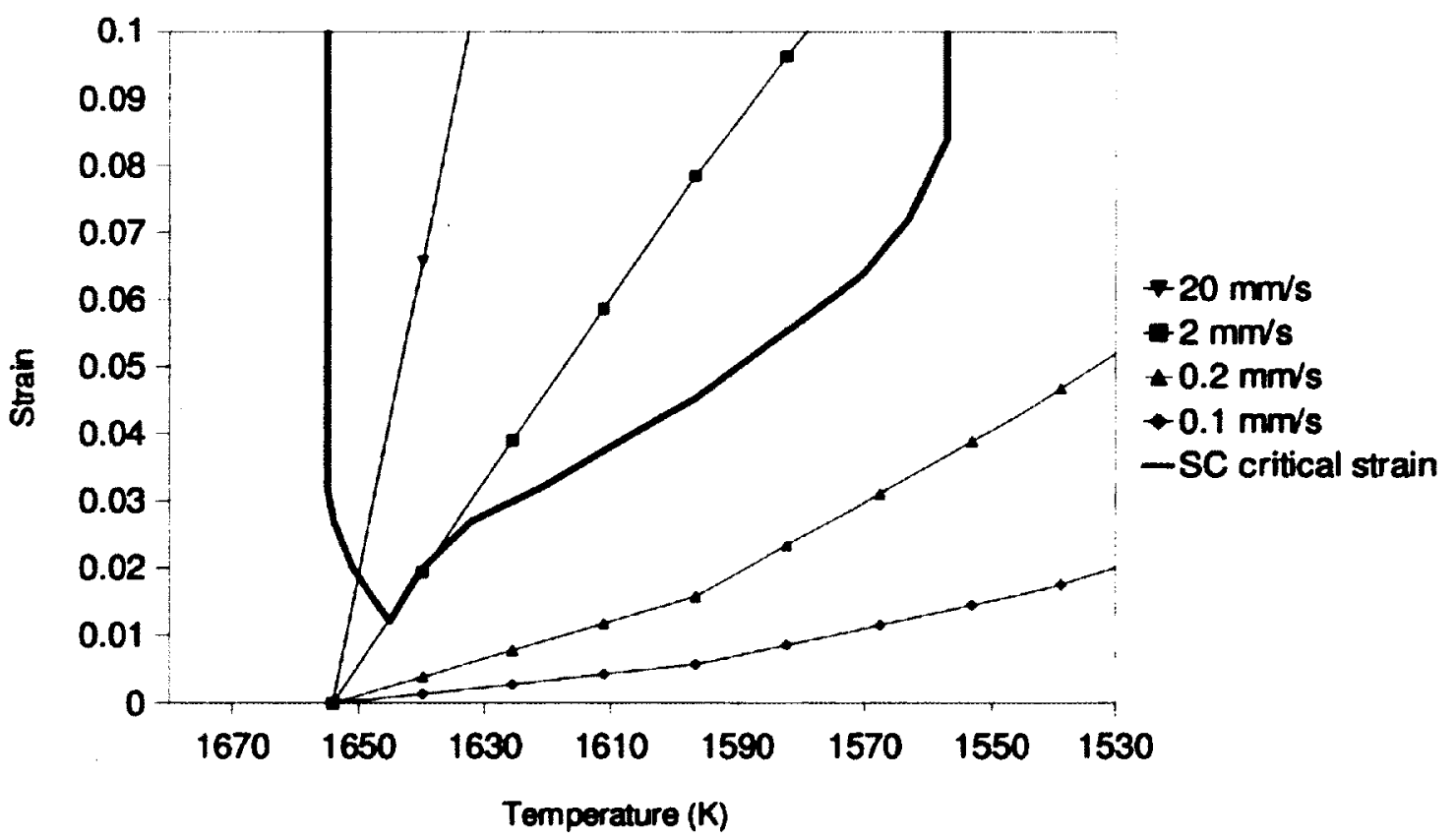

Figure 4.29: Solidification cracking test: strain versus temperature for different applied CHS. 
nucleation are shown in Figure 4.30. The region likely to experience solidification cracking is shown to be behind the weld pool. This region is at temperatures within the BTR, during the time at which the CHS is applied.

The magnitude of the plastic strain increment is used as an indicator of the relative risk of solidification cracking at each Gauss point. The post-processor has automated the tedious process of determining the risk of cracking at each Gauss point or node. However, the data for experimentally measured material resistance to the different types of hot cracking must be available in the software library for material properties.

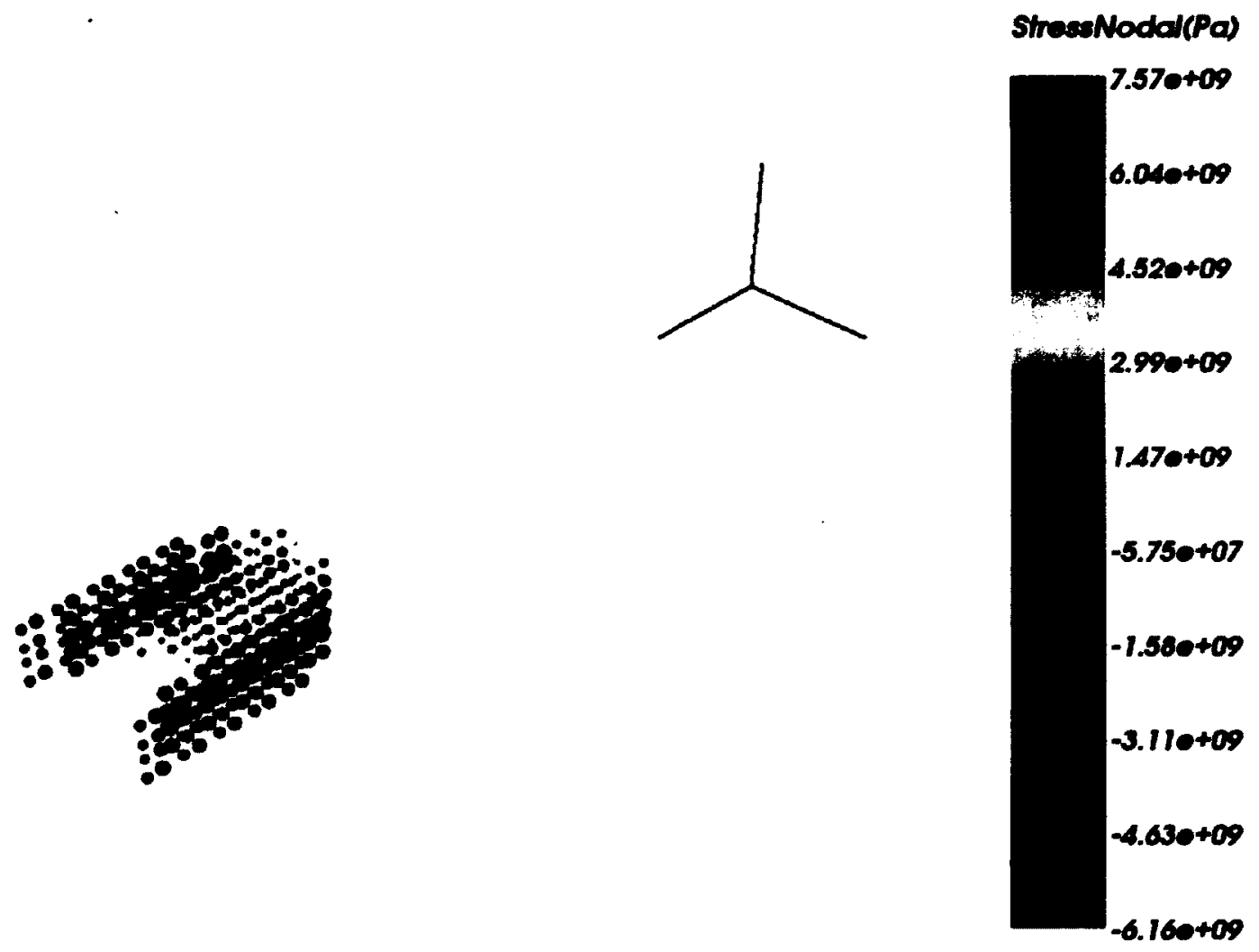

Figure 4.30: Solidification cracking test: results from solidification cracking postprocessor for an applied CHS of $20 \mathrm{~mm} / \mathrm{s}$. 


\subsection{Discussion}

There are some differences between the results of the DDC test for the equivalent plastic strain increment versus temperature with respect to the results of Chen and $\mathrm{Lu}$ [1]. The point with the maximum tensile plastic strain increment was at $4 \mathrm{~mm}$ from the centre-line, rather than the $3 \mathrm{~mm}$ observed by Chen and Lu [1]. The most probable cause of these apparent discrepancies is the lack of detail in the Chen and Lu [1] paper. The locations, at which strain and temperature were recorded, were not clearly identified. In addition, the restraints applied to welded plate were not specified. The lack of values for arc efficiency and the size of the weld pool or heat source are also a concern.

According to the results obtained from the DDC test, cracking is not likely to occur with either welding speed. However, with a welding speed of $2 \mathrm{~mm} / \mathrm{s}$, there is relatively higher risk of DDC nucleation at distance of $4 \mathrm{~mm}$ from the centre-line on the top surface of the plate. In addition, the results show that increasing the welding speed did reduce the likelihood of DDC nucleation, as observed by Chen and Lu in their work [1].

The effect of welding speed on the risk of hot cracking is explained by Chihoski's [12] work. Chihoski showed that 2014-T6 aluminum (Al) can be welded and crackfree. 2014-T6 Al has been and until this day generally, but wrongfully, regarded as impossible to weld without hot cracking. Chihoski showed that, during the welding of a plate, a deformation pattern will appear. As a result, the area behind the weld pool is subject to a tensile strain from solidification and thermal shrinkage. The deformation pattern, hence the location of the tensile strain, is affected by the welding speed. Increasing the welding speed can increase the distance between the tensile strain and the weld pool. Moving the tensile strain beyond the susceptible temperature range greatly reduces the risk of hot cracking [12]. The effect of welding 
speed on hot crack susceptibility is better illustrated in Appendix C.

In the solidification cracking test, as anticipated and apparent from the strain versus temperature plots, increasing the applied CHS with the same welding parameters will increase susceptibility to cracking. According to the results of the computational analysis, an applied CHS of 0.2 and $0.1 \mathrm{~mm} / \mathrm{s}$ does not cause solidification cracking during the welding of Inconel 600 . A CHS of $2 \mathrm{~mm} / \mathrm{s}$ caused solidification cracking with the lowest magnitude of strain, also referred to as minimum ductility, which is at $1.2 \%$ strain and a temperature of $1645 \mathrm{~K}$. Moreover, solidification cracking initiates at a strain of $2 \%$ with an applied CHS of $20 \mathrm{~mm} / \mathrm{s}$. 


\section{Chapter 5}

\section{Conclusion and Recommendations}

\section{$5.1 \quad$ Summary}

This thesis has shown that computational weld mechanics (CWM) can be successfully used to estimate the risk of hot cracking in welding a structure. The methodology to use CWM to estimate the risk of hot crack nucleation is provided. The methodology is based on the transient localized values computed during the evolution of the temperature-stress-strain state. Once these values reach material specific thresholds, hot crack nucleation is likely to occur. Furthermore, a design driven CWM analysis can be used to assess and optimize the design of the weld procedure and welded structure, so that the risk of hot cracking is minimal. This thesis has also shown that altering the weld procedure can affect the risk of hot cracking. Subsequently, the main conclusion is that a CWM analysis can be used as a weld design tool in the early design stage. As a result, modifications can be made to a structure at the design stage, which are less time consuming and less costly than at any later stage of a project life cycle. 


\subsection{Conclusion}

The major tasks of the CWM analyses in this thesis were

1. defining the domain

2. meshing the domain

3. optimizing weld procedure and boundary conditions

4. post-processing and interpretation of the results

In addition to this CWM analysis, three novel concepts were proposed. Firstly, principal tensile plastic strains were used to estimate damage that leads to hot crack nucleation. Secondly, an algorithm was used to identify the risk of hot cracking at all Gauss points in an entire domain. Thirdly, the material resistance to hot cracking obtained using constant temperature tensile tests was applied to welding using an equation inspired by Miner's rule, which yet remains a conjecture that will have to be tested by experiments to determine it's validity.

In concept, the methods used to estimate the risk of solidification cracking and ductility dip cracking (DDC) are similar. A notable difference is that in the solidification test strain accumulation was measured during cooling only, as cracks that form before the heat source will be removed once melted. On the other hand, in the DDC test the strain increment was measured during heating and cooling only if the temperature did not exceed the DTR. At points where the temperature did exceed the DTR, the strain increment was measured during cooling only.

\subsection{Reducing Hot Cracking Risk}

In order to reduce the strain increment and strain rate, within the hot cracking susceptible temperature ranges, below critical values, will reduce the risk of hot cracking. 
The fluctuations in the strain fields can be changed by altering the welding parameters. For example, the tensile region that follows the heat source, can be reduced in size or shifted beyond a susceptible temperature range by varying welding speed, while maintaining constant power per unit length, reducing the risk of hot cracking. This approach is quite different from the overwhelming majority of researchers in the field who have focused on the effect of composition and the associated metallurgy, examples of which were presented at the International Hot Cracking Workshops convened to this day [41-43].

The requirement of a tensile strain for hot cracking to nucleate is in line with Matsuda et al.'s [21] observation that cracking would occur if the weld edge appeared to expand. In contrast, a crack would not occur if the weld edge appeared to contract. Matsuda et al. [21] also observed that the magnitude of deformation increases with a reduced rigidity of the weld joint. The reduced rigidity could be a result of decreasing the specimen thickness, increasing the specimen width or lower material hardness [21].

\subsection{Recommendations and Future Work}

A few aspects that may affect the accuracy of the results obtained from the CWM analyses are discussed below. In the solidification test, the cross head speed (CHS) was applied at the edges of the plate in opposite directions. However, Matsuda et al. [2] applied the load with pins going through the plate and by fixing one end and moving the other. There are also two notches length wise at the beginning and ending of the weld path that were not included in the simulation. It is anticipated that simulating these conditions will not result in much difference in results, since the region, where the results were taken, is far from differences that may arise due to stress concentrations at the pins or the notches. 
Describing the hot cracking propagation mechanism by solid state fracture mechanics is not sufficient, because neither the properties of the material in solid-liquid state nor the mechanism observed experimentally are simulated [31]. The behaviour of the liquid phase, found in the mixed solid-liquid zone and the weld pool, is not accounted for in the simulation conducted in this research. This limitation is expected to affect results, specifically for solidification cracking and liquation cracking. The liquid phase may flow into cracks and repair them.

A suggestion for future work would be coupling a microscopic analysis to the macroscopic constitutive equations used in the CWM analysis conducted here [11]. A microscopic analysis should take into account the composition gradient across grains. Composition varies as a result of solidification segregation and grain boundary segregation [17]. It is also suggested that the shape and flow of the liquid film on solidifying grains may also be part of the microscopic analysis. Finally, the relative motion of grains and the change in grain morphology should be considered in a microscopic analysis [11].

In the near future, it should be possible to determine the susceptibility of a material to the different types of hot cracking at the same time and for different applications at risk of hot cracking. However, the current obstacle to this is the lack of data for material resistance to the different types of hot cracking. The work of Matsuda et al. [3] provides the resistance to solidification cracking of several materials. It is likely that the Measurement by means of In-Situ Observation (MISO) technique, developed by Matsuda et al. [2], can be used to determine material resistance to DDC and liquation cracking. 


\section{Appendix A}

\section{Material Properties}

The material used in the CWM simulations conducted were Inconel 600 and Filler Metal 82 (FM82). With the exception of the yield stress, the mechanical and thermal properties available for the Inconel 600 was used for the FM82.

\section{A.0.1 Young's Modulus}

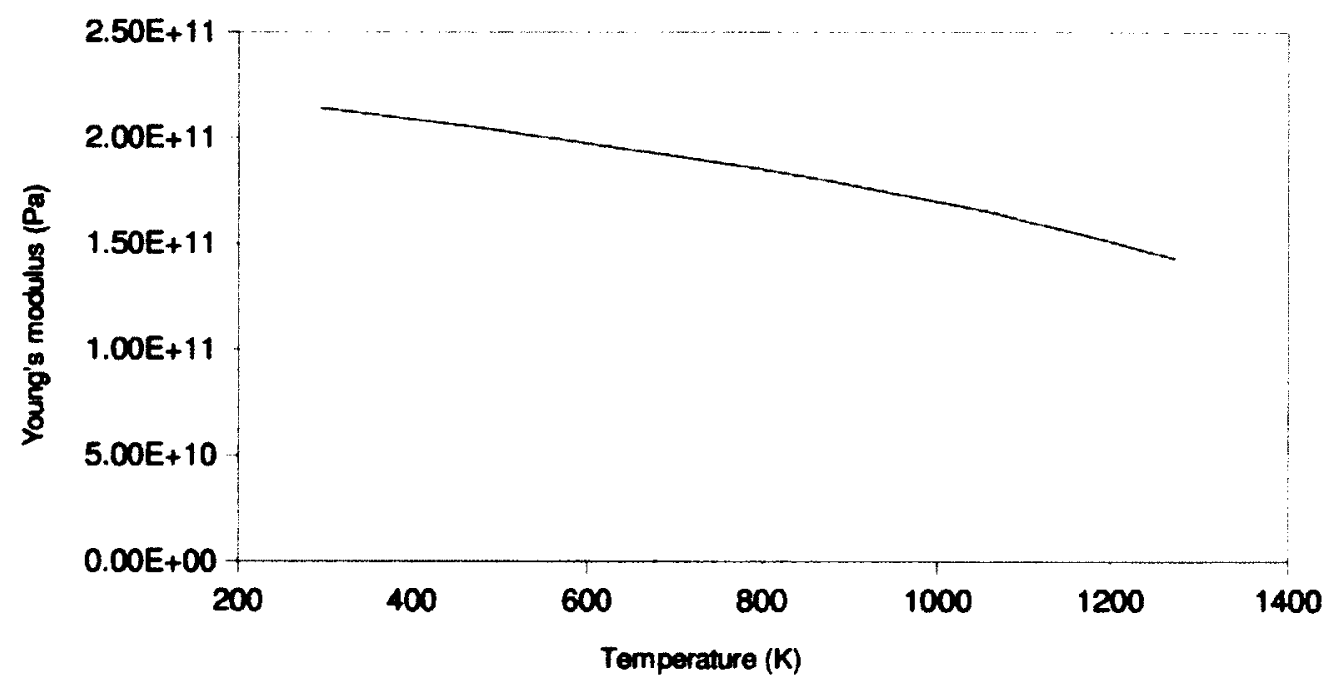

Figure A.1: Young's modulus versus temperature after VrSuite [6]. 


\section{A.0.2 Yield Stress}

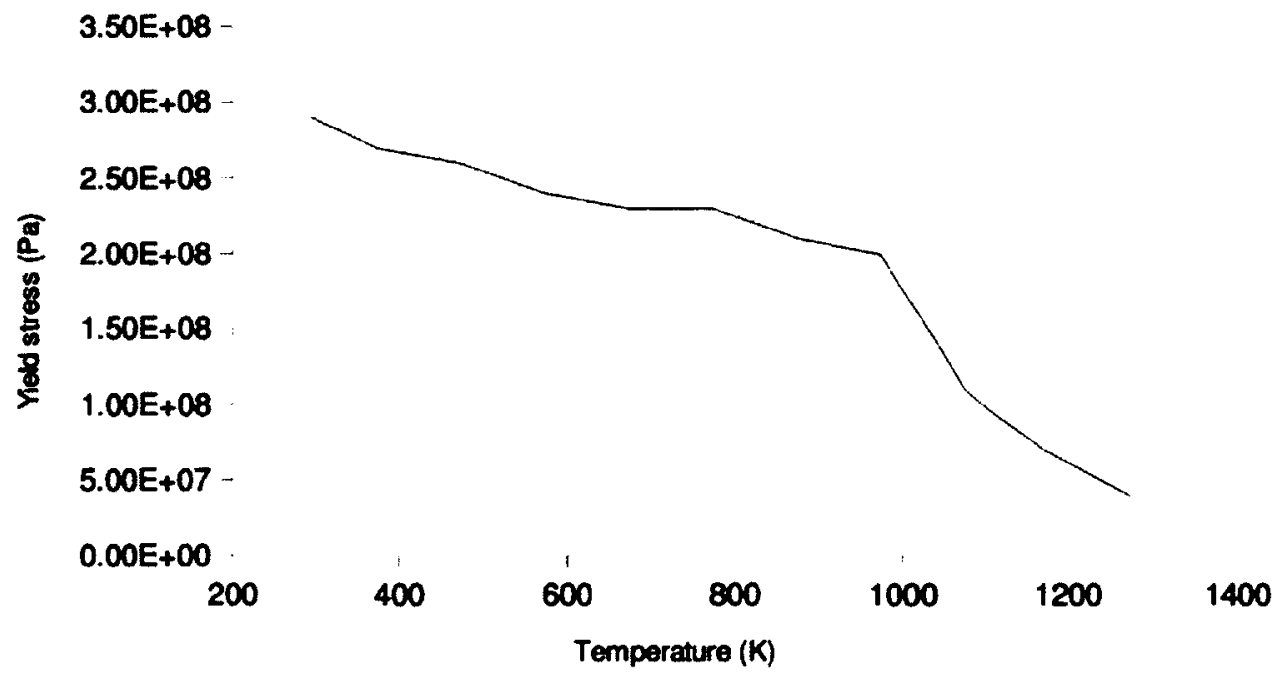

Figure A.2: Yield stress versus temperature for Inconel 600 after VrSuite [6].

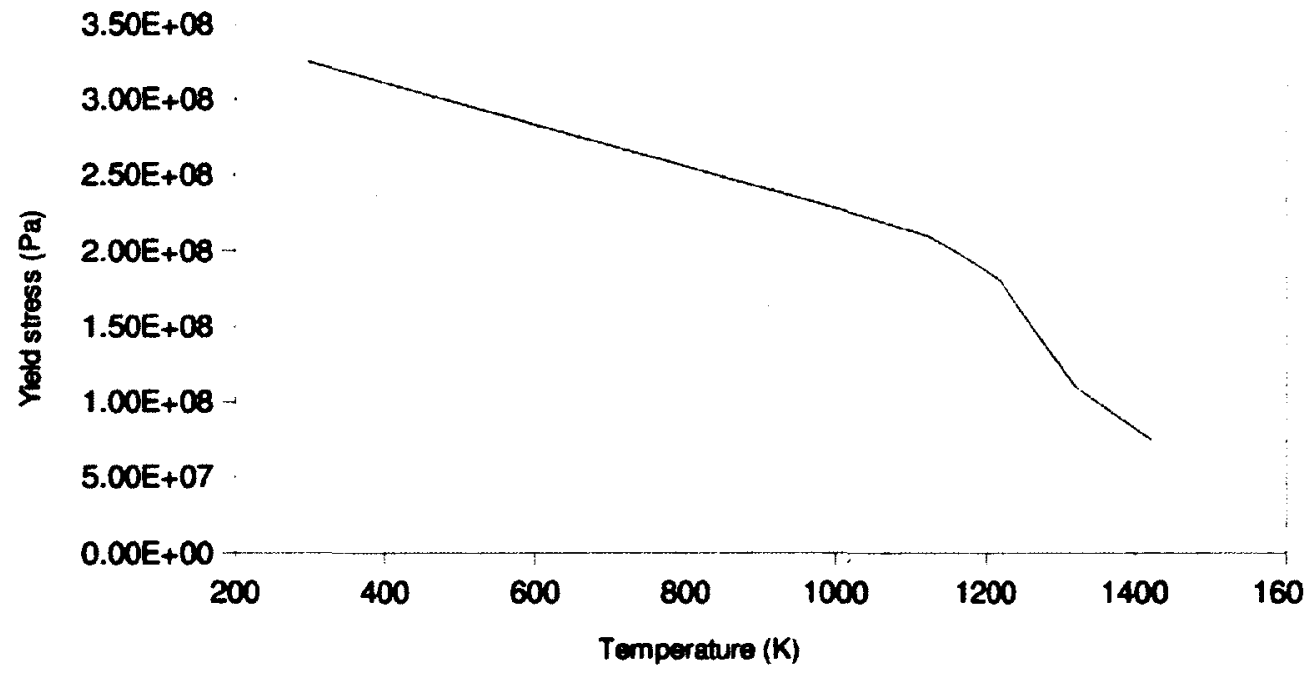

Figure A.3: Yield stress versus temperature for FM82 after Chen et al. [7]. 


\section{A.0.3 Viscosity}

Values for viscosity is exhibited during rate dependent plastic deformation is limited thus it is set as constant even though in reality it is likely to be temperature dependent.

$$
\mu=1 \times 10^{9}
$$

\section{A.0.4 Thermal Conductivity}

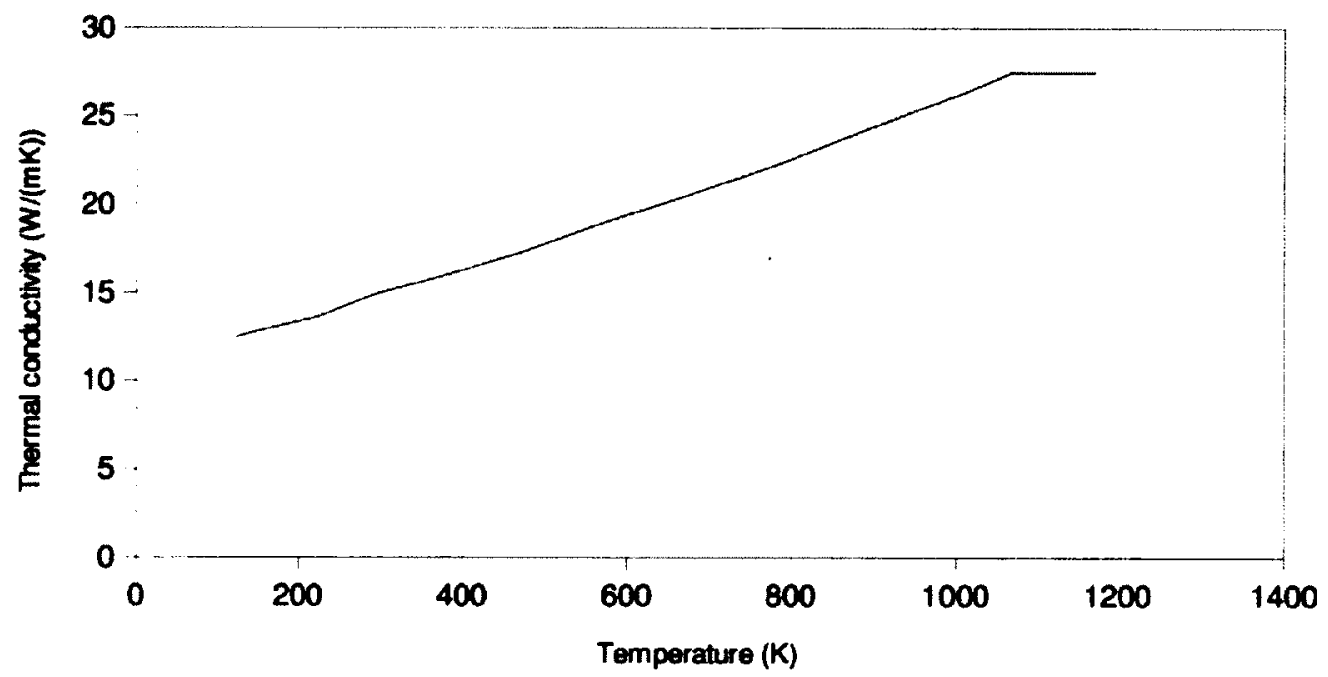

Figure A.4: Thermal conductivity versus temperature after VrSuite [6].

\section{A.0.5 Composition}

The composition was not directly used in the CWM analysis but the ductility curve was obtained from the work of Matsuda et al. [4] for the a material with the composition specified in Table A.1. 
Table A.1: Composition by weight percentage of alloying elements added to the nickel-based Inconel 600 after Matsuda et al. [4].

\begin{tabular}{|c|c|}
\hline Element & Weight \% \\
\hline Carbon (C) & 0.003 \\
\hline Silicon (Si) & 0.28 \\
\hline Manganese (Mn) & 0.33 \\
\hline Phosphorus (P) & 0.005 \\
\hline Sulfur (S) & 0.002 \\
\hline Chromium (Cr) & 15.37 \\
\hline
\end{tabular}

Table A.2: Composition by weight percentage of alloying elements for FM82 after Collins et al. [5].

\begin{tabular}{|c|c|}
\hline Element & Weight \% \\
\hline Carbon $(\mathrm{C})$ & 0.04 \\
\hline Silicon $(\mathrm{Si})$ & 0.12 \\
\hline Manganese $(\mathrm{Mn})$ & 2.86 \\
\hline Phosphorus $(\mathrm{P})$ & 0.007 \\
\hline Sulfur $(\mathrm{S})$ & 0.01 \\
\hline Chromium $(\mathrm{Cr})$ & 20.1 \\
\hline Iron $(\mathrm{Fe})$ & 1.18 \\
\hline Sulfur $(\mathrm{S})$ & 0.01 \\
\hline Copper $(\mathrm{Cu})$ & 0.09 \\
\hline Titainium $(\mathrm{Ti})$ & 0.37 \\
\hline Niobium $+\mathrm{Tantalum}$ & 2.3 \\
\hline (Nb $+\mathrm{Ta})$ & \\
\hline Lead $(\mathrm{Pb})$ & 0.004 \\
\hline Cobalt $(\mathrm{Co})$ & 0.05 \\
\hline Nickel $(\mathrm{Ni})$ & 72.75 \\
\hline
\end{tabular}




\section{Appendix B}

\section{Governing Equations}

The governing equations available to conduct welding simulation are heat and stress.

\section{B.1 Thermal}

The heat equation is based on the conservation of energy principle.

$$
\begin{aligned}
\dot{h}+\nabla \cdot q+Q_{\text {input }} & =0 \\
q & =-\kappa \nabla T \\
d h & =c_{p} d T
\end{aligned}
$$

where $h$ is enthalpy $(\mathrm{J}), \kappa$ is the heat conduction coefficient (matrix) $\left(\mathrm{W} \mathrm{m}^{-1} \mathrm{~K}^{-1}\right), q$ is the surface flux $\left(\mathrm{W} \mathrm{m}^{-2}\right), Q_{\text {input }}$ is heat input rate $\left(\mathrm{J} \mathrm{s}^{-1}\right)$ and $T$ is the temperature $(\mathrm{K})$.

$$
Q=\eta I V
$$

where $\eta$ is arc efficiency, $I$ is current (A) and $V$ is voltage (V). 


\section{B.2 Stress}

The equations used for stress relies on principles of conservation of momentum, the constitutive equation, and the relationship between strain and displacement. The constitutive equation relates stress to strain. VrWeld solves this partial differential equation for a visco-thermo-elasto-plastic stress-strain relationship.

$$
\begin{aligned}
\nabla \cdot \sigma+b & =0 \\
\sigma & =D \varepsilon \\
\varepsilon & =\left(\nabla u+(\nabla u)^{T}+(\nabla u)^{T} \nabla u\right) / 2
\end{aligned}
$$

where $b$ is body force $\left(\mathrm{N} \mathrm{m}^{-3}\right), \varepsilon$ is Green-Lagrange strain tensor, $\rho$ is density (Kg $\mathrm{m}^{-3}$ ), $u$ is displacement $(\mathrm{m})$ and $D$ is elasticity or visco-elasto-plastic tensor (as a $6 \times 6$ matrix) 


\section{Appendix C}

\section{Effect of Welding Speed on Hot Cracking Susceptibility}

In order to illustrate the effect of increasing welding speed on susceptibility to hot cracking, observing the temperature and stress fields over the entire domain is beneficial. Increasing welding speed has been shown to decrease the risk of hot cracking in the work of Chihoski [12]. This is explained by that the area behind the weld pool is subject to a tensile strain from solidification and thermal shrinkage. The deformation pattern, hence the location of the tensile strain, is affected by the welding speed. Increasing the welding speed can increase the distance between the tensile strain and the weld pool. Moving the tensile strain beyond the susceptible temperature range greatly reduces the risk of hot cracking [12].

The welding speed was increased from $2 \mathrm{~mm} / \mathrm{s}$ to $5 \mathrm{~mm} / \mathrm{s}$ with constant power per unit length. The dimensions of heat source were altered to keep the dimensions of weld pool and the maximum temperature approximately the same. The temperature and stress fields for each welding speed is shown when the heat source reaches the same location along the weld path. This is at a time of $40 \mathrm{~s}$ with a $2 \mathrm{~mm} / \mathrm{s}$ welding speed and at $16 \mathrm{~s}$ with a $5 \mathrm{~mm} / \mathrm{s}$ welding speed. Increasing the weld speed has increased the

size of the region within the susceptible temperature range at any given time. The 
region at temperatures within the range susceptible to DDC is significantly larger, as shown in Figures C.1 and C.2. On the other hand, the increase in the size of region susceptible to solidification cracking is only slightly larger, as shown in Figures C.3 and C.4.

Increasing the welding speed has moved the tensile region further behind the weld pool where temperatures are lower. If the tensile stress region can be moved to temperatures outside of the BTR region, then hot cracking would be avoided. Moving the tensile stress region to lower temperatures is observed for both the stress transverse and longitudinal to the welding direction. Regarding the susceptibility to DDC, the increase in the size of the temperatures region susceptible to DDC (DTR) increases with welding speed as the the tensile region moves farther away from the weld pool. Increasing the welding speed may at first appear to have increased the likelihood of DDC. However, the susceptibility to DDC was reduced by decreasing the magnitude and rate of the strain increment on region in the susceptible temperature region. In the case of solidification cracking, increasing the welding speed, has moved the tensile region outside the susceptible temperature (BTR) region. Based on this observation, the risk of solidification cracking has been reduced. 


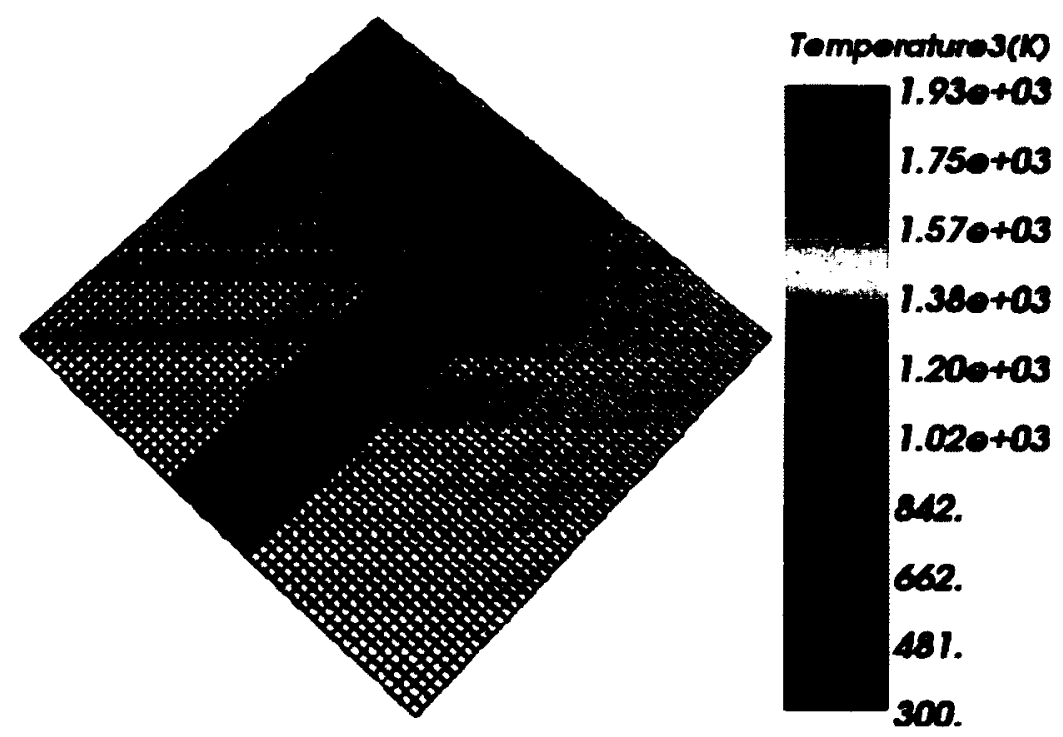

Figure C.1: Welding speed test: temperature distribution and DTR iso-therms with a $2 \mathrm{~mm} / \mathrm{s}$ welding speed, at $\mathrm{t}=40 \mathrm{~s}$.

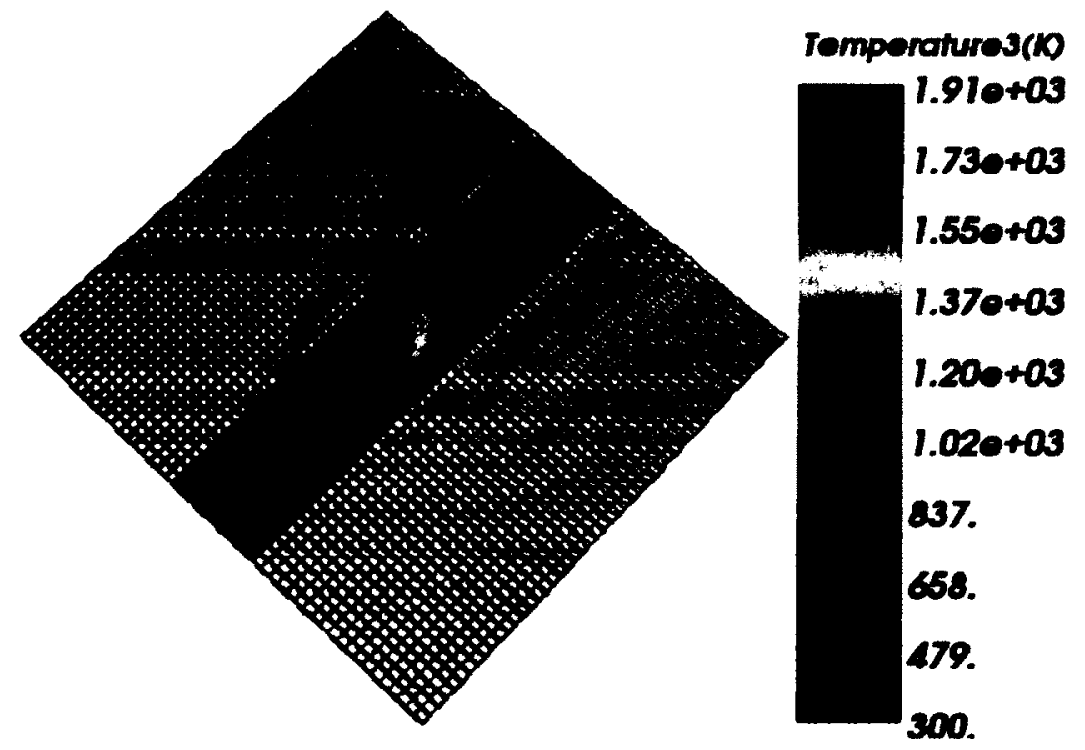

Figure C.2: Welding speed test: temperature distribution and DTR iso-therms with a $5 \mathrm{~mm} / \mathrm{s}$ welding speed, at $\mathrm{t}=16 \mathrm{~s}$. 


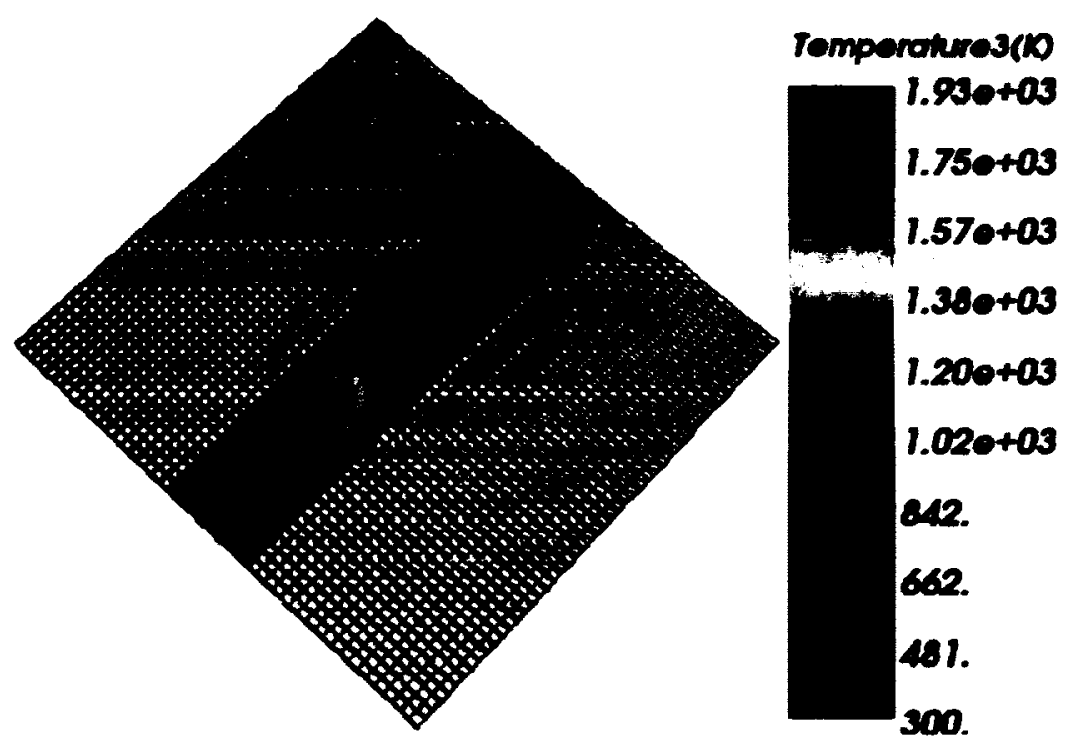

Figure C.3: Welding speed test: temperature distribution and BTR iso-therms with a $2 \mathrm{~mm} / \mathrm{s}$ welding speed, at $\mathrm{t}=40 \mathrm{~s}$.

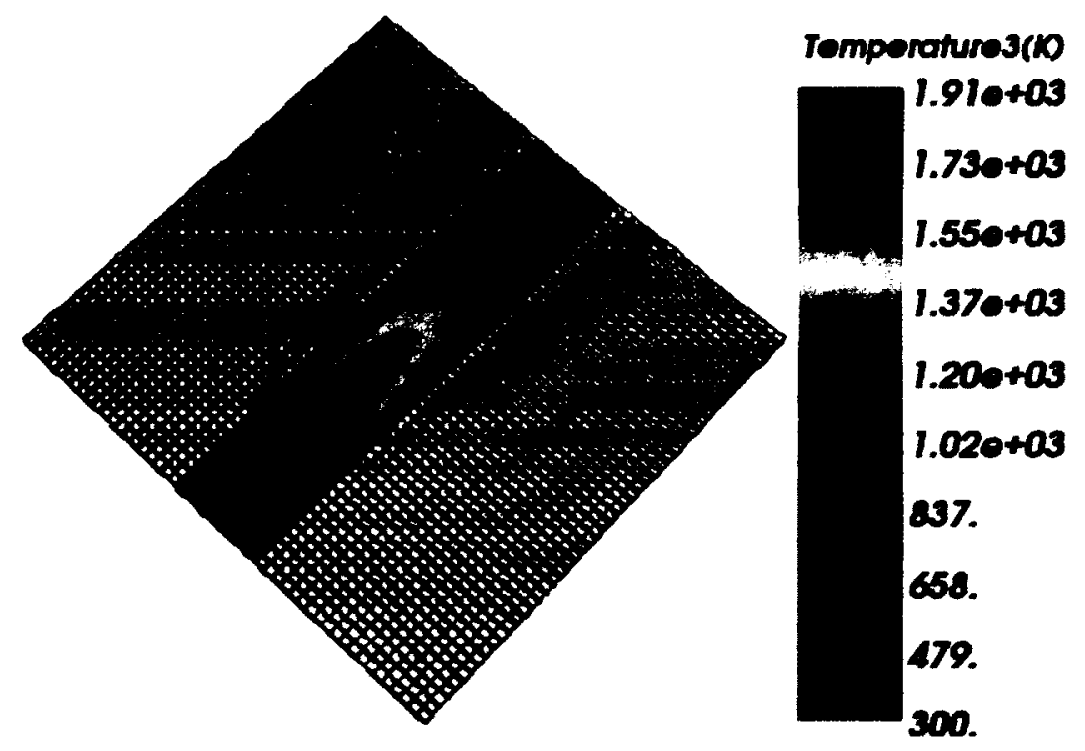

Figure C.4: Welding speed test: temperature distribution and BTR iso-therms with a $5 \mathrm{~mm} / \mathrm{s}$ welding speed, at $\mathrm{t}=16 \mathrm{~s}$. 


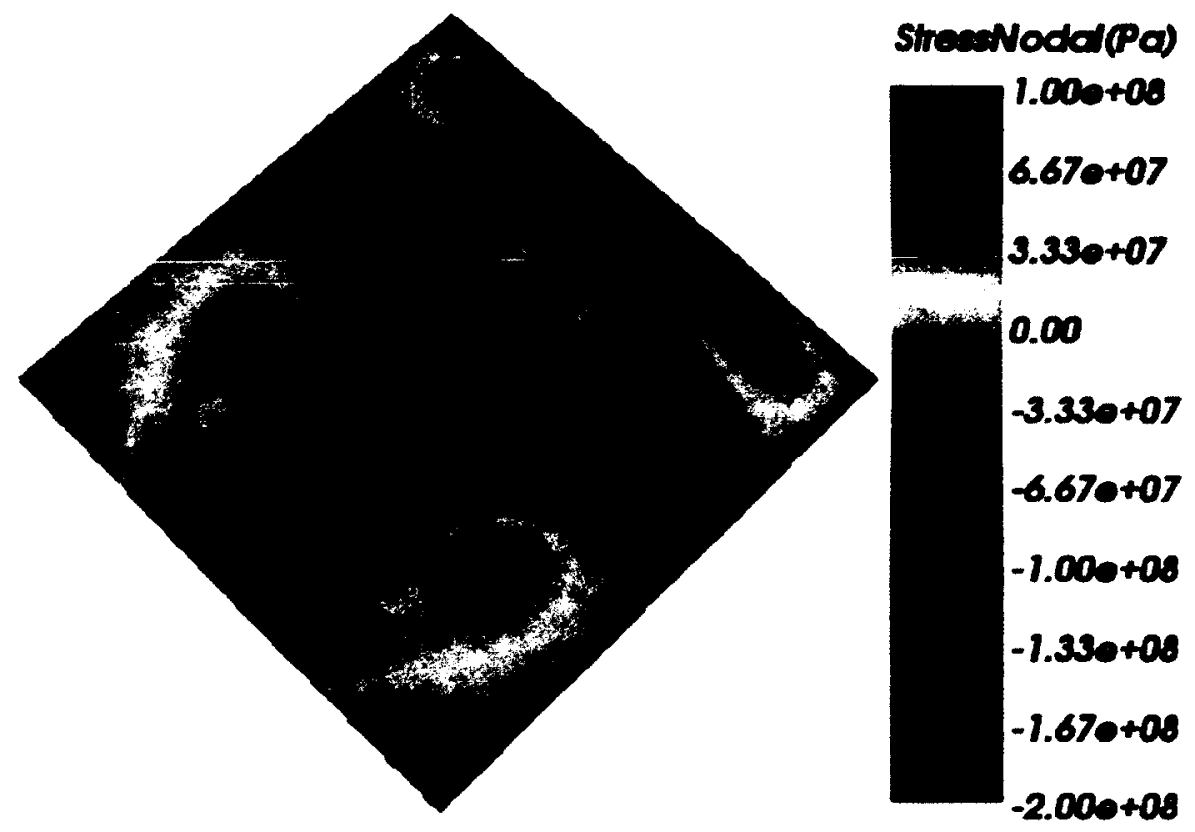

Figure C.5: Welding speed test: stress XX (transverse to weld path) field with a 2 $\mathrm{mm} / \mathrm{s}$ welding speed, at $\mathrm{t}=40 \mathrm{~s}$.

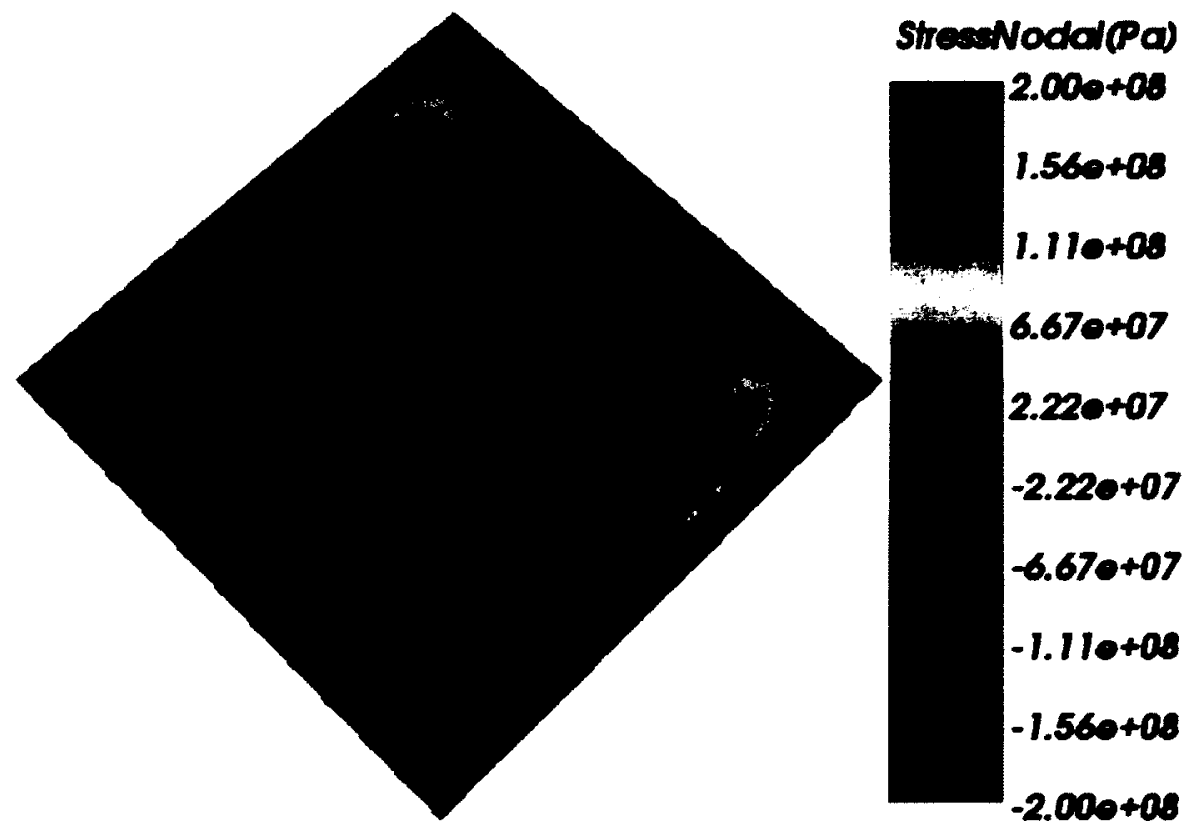

Figure C.6: Welding speed test: stress ZZ (longitudinal to weld path) field with a $2 \mathrm{~mm} / \mathrm{s}$ welding speed, at $\mathrm{t}=40 \mathrm{~s}$. 


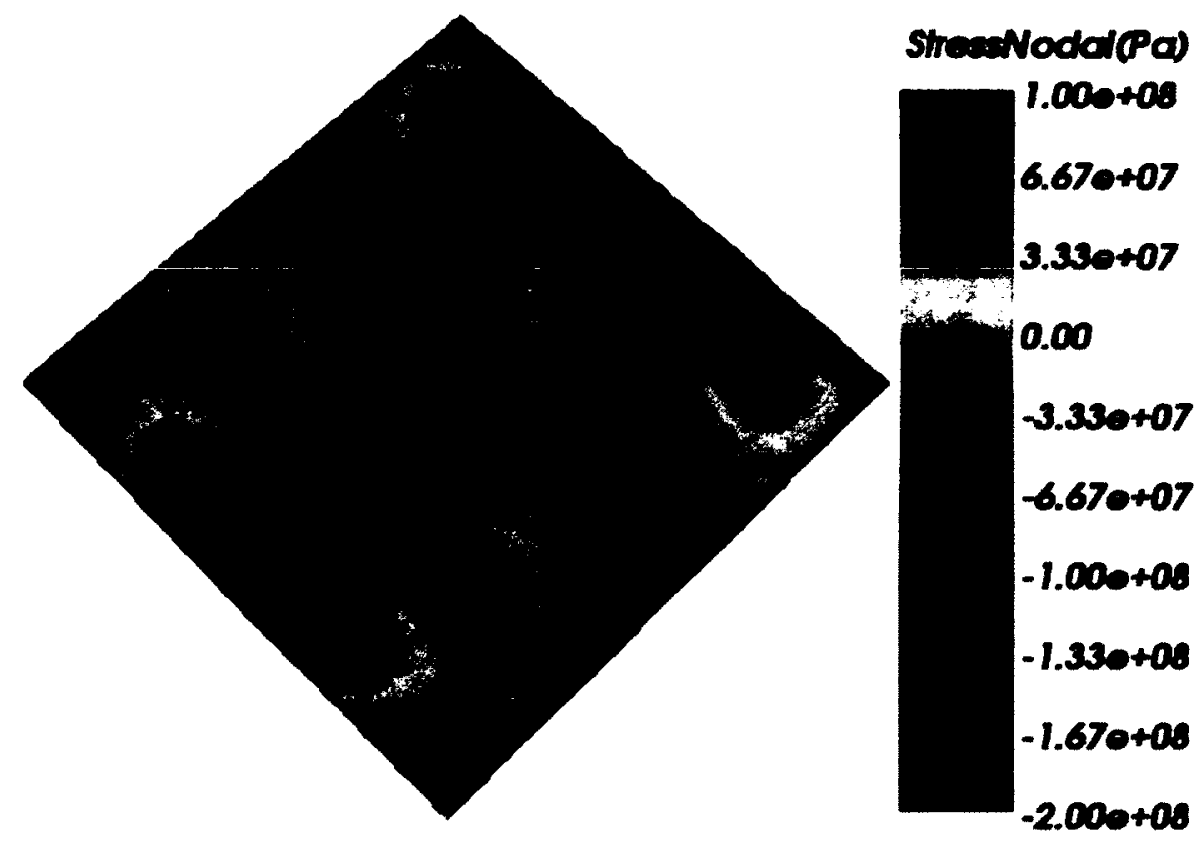

Figure C.7: Welding speed test: stress XX (transverse to weld path) field with a 5 $\mathrm{mm} / \mathrm{s}$ welding speed, at $\mathrm{t}=16 \mathrm{~s}$.

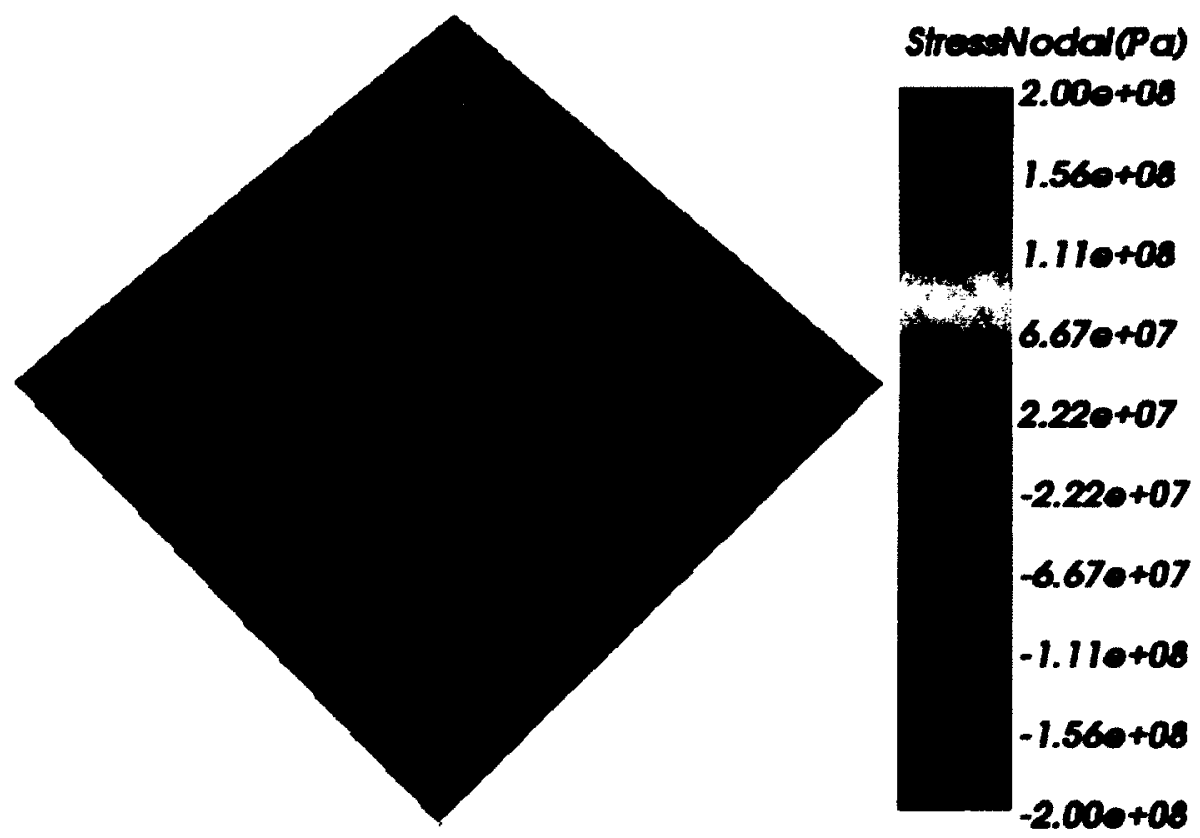

Figure C.8: Welding speed test: stress ZZ (longitudinal to weld path) field with a $5 \mathrm{~mm} / \mathrm{s}$ welding speed, at $\mathrm{t}=16 \mathrm{~s}$. 


\section{Appendix D}

\section{Viscous Behaviour}

The most common engineering view is that a material behaves as a linear elastic material at stresses below the yield value but in fact, material does not follow this idealistic behaviour precisely. During the simulation of material response to an applied stress/strain, limited plastic deformation that occurs below yield stress often can be ignored. Rate independent plasticity requires a yield stress function. Plastic deformation is considered to occur only when the stress state tries to go above the yield stress. The yield condition assumes that below the yield stress, deformation will be completely elastic [44]. A yield condition does not represent plastic deformation exhibited during creep or fatigue when plastic deformation occurs below the rate independent yield stress [44]. The yield condition is applied in the simulation of welding conducted in this thesis, since the time frame is limited for this application.

\section{D.1 Yield}

In rate dependent plasticity, viscous behaviour is also exhibited when stress exceeds the yield surface. An applied stress greater than the yield value results in a distinct change of material behaviour. Yield stress is perceived as the value beyond which deformation is rate-dependent and non-recoverable [45]. The stress level relaxes to 
the yield surface with time, when a material is subject to stress beyond the yield surface. In rate dependent plasticity, the measurement for the relaxation rate, can be related to the viscosity $[19$, p. 51-52]. Rate dependent plasticity and creep are two different phenomena.

\section{D.2 Creep}

Plastic deformation can occur once a stress, even if it is lower than the yield value, is applied to a material over time. This phenomena, called creep, reveals that the rate of plastic deformation depends on material creep properties, stress and time. Materials' resistance to rate dependent plastic deformation is quantified by a viscosity, $\mu$, as shown in Equation D.1. The value for viscosity is material specific and dependent on temperature, history and strain rate. The underlying physics behind viscous behaviour is not yet fully understood in detail, as a result, macroscopic viscous behaviour is best represented by analytical models.

$$
\sigma=\mu \dot{\varepsilon}
$$

A variation of the Norton-Bailey creep power law, shown in equation D.2, can be used to relate creep strain rate to stress, time and material creep properties [46, p. 271]. The creep power law is valid only for primary and secondary creep [47]. Even though the creep power law does not have an explicit term for temperature, the material's creep parameters, $A, n$ and $m$, are temperature dependent. These properties can be obtained by performing multiple creep tests, e.g., the uniaxial creep test. This should be followed by converting the equation into a logarithmic form, as shown in Equation D.3 and conducting multiple regression analyses [48].

$$
\dot{\varepsilon}^{c r e e p}=A \sigma^{n} t^{m}
$$




$$
\log \left(\dot{\varepsilon}^{\text {creep }}\right)=\log (A)+n \cdot \log (\sigma)+m \cdot \log (t)
$$

An expression for the viscosity exhibited can be determined by rearranging Equation D.2. The expression for viscosity, shown in equation D.4, is a function of the creep material, properties, stress and time.

$$
\begin{gathered}
\dot{\varepsilon}^{\text {creep }}=A t^{m} \sigma^{n-1} \sigma \\
\sigma=\frac{1}{A \sigma^{n-1} t^{m}} \dot{\varepsilon} \\
\mu=\frac{1}{A \sigma^{n-1} t^{m}}
\end{gathered}
$$

Many analytical representations for viscous deformation have been published. The accuracy of individual models depends on the material and application. A model developed by Anand [49] appears the most suitable to the elevated temperatures expected during welding, since the model was created for hot working of metals. Hot working could entail temperature between 0.5 and 0.9 of absolute melting temperature and strain rate between $10^{-4}$ and $10^{3} \mathrm{~s}^{-1}[50, \mathrm{p}$. 95]. This range is expected to encompass strain rates encountered during welding.

Anand [49] observed that plastic deformation occurs, without a definite yield surface, at constant strain rate and temperature. The absence of a yield condition would mean that plastic strain occurs with any magnitude of stress [51]. A model for rate dependent plasticity requires a quasi static 'yield surface' and at least three constitutive equations. Anand identified that the steady flow stress, $\tau$, can be determined by the Zener-Holloman parameter. Using equation D.5 the steady flow stress at high temperatures can be determined from moderate strain rates. 


$$
\tau=\tau_{0} \sinh ^{-1}\left[\left(\frac{Z}{\Gamma_{0}}\right)^{m}\right]
$$

where $\tau_{0}, \Gamma_{0}$ and $m$ are constants.

In order to allow the steady state relation to be applied to unsteady conditions for isotropic material in multiple dimensions the assumption shown in equation D.6 is made.

$$
\Gamma\left(\sqrt{J_{2}}, T, \kappa\right)=\Gamma_{0} e^{-\frac{C}{k T}}\left[\sinh \left(\frac{\sqrt{J_{2}}}{\kappa}\right)\right]^{\frac{1}{m}}
$$

which is the same as:

$$
\dot{\varepsilon}=A e^{\frac{-Q}{R T}}[\sinh (\xi \sigma)]^{m}
$$

where $k$ is the Boltzmann constant $\left(\mathrm{m}^{2} \mathrm{~kg} \mathrm{~s}^{-2} \mathrm{~K}^{-1}\right), Q$ is the material specific activation energy for the deformation mechanism $(\mathrm{J})$, which is close to the value for self-diffusion, $T$ is absolute temperature $(\mathrm{K})$ and $\xi$ is work hardening rate. $\kappa$ is determined from equation D.8.

$$
\dot{\kappa}=\xi(|s|, T, \kappa)=h_{0}\left|1-\frac{\kappa}{\hat{\kappa}}\right|^{a-1}\left(1-\frac{\kappa}{\hat{\kappa}}\right) \Gamma\left(\sqrt{J_{2}}, T, \kappa\right)
$$

where $a \geq 1$ and $\hat{\kappa}=\kappa_{0}\left[\left(\frac{\Gamma}{\Gamma_{0}}\right) e^{\frac{G}{k T}}\right], h_{0}$ and $\kappa_{0}$ are constants and $\hat{\kappa}$ is constant for fixed temperature and strain rate.

Therefore $\kappa$ saturates at fixed value $\hat{\kappa}$, where $\dot{\kappa}=0$ and $\sqrt{J_{2}}$ takes on saturation values, as determined by previous equations for $\Gamma\left(\sqrt{J_{2}}, T, \kappa\right) . \kappa$ in this model may be increasing or decreasing because $\hat{\kappa}$ may change with changing temperature and strain rate, thus changing the sign of the right hand side of Equation D.8 strain rate variation with imposed stress. 
A microscopic view is needed in order to understand the viscous behaviour exhibited in more detail. On a micro scale elastic deformation only allows the stretching of the bonds between atoms/molecules in a crystal lattice, which from the perspective of thermodynamics, is reversible. In contrast, plastic deformation, from the perspective of thermodynamics, is irreversible. Plastic behaviour is characterized by the changing relation between neighbouring atoms/molecules in a crystal lattice atoms/molecules change neighbouring partners as a dislocation moves or with grain boundary sliding.

Dislocation movement/sliding takes place by two mechanisms, both of which are temperature dependent. The two relevant mechanisms are dislocation creep and diffusional creep, both of which are affected by temperature. The velocity of a dislocation is directly proportional to local stress, which must exceed the Peierls stress. It is the stress necessary for a dislocation to overcome the energy barrier that prevents sliding. On the other hand, with diffusion creep, the increasing vibration of the lattice aids dislocation in overcoming the energy barrier when the local stress is insufficient. Short segments of the dislocation slide over the barrier and grow in opposite direction until the dislocation has shifted. According to temperature and local stress either of the two competing mechanisms becomes the driving force for dislocation movement [52, p. 22].

Equation D.7 is the functional form for the flow equation of the Anand model [49]. The hyperbolic sine function in Equation D.7 is expressed as Taylor series, seen in Equation D.9. In addition, temperature dependence is incorporated by the Arrhenius term, $e^{\frac{-Q}{R T}}$, which is the formula for the temperature dependence of a reaction rate [52, p. 22].

$$
\sinh (x) \approx x+\frac{x^{3}}{3 !}+\frac{x^{5}}{5 !}+\ldots
$$




$$
\begin{gathered}
\sinh (x) \approx x\left(1+\frac{x^{2}}{3 !}+\frac{x^{4}}{5 !}+\ldots\right) \\
\dot{\varepsilon}=A e^{-\frac{Q}{R T}}\left[\xi \sigma\left(1+\frac{(\xi \sigma)^{2}}{3 !}+\frac{(\xi \sigma)^{4}}{5 !}+\ldots\right)\right]^{m} \\
\dot{\varepsilon}=A e^{-\frac{Q}{R T}}\left[\xi\left(1+\frac{(\xi \sigma)^{2}}{3 !}+\frac{(\xi \sigma)^{4}}{5 !}+\ldots\right)\right]^{m} \sigma^{m-1} \sigma \\
\mu=\frac{1}{A e^{-\frac{Q}{R T}}\left[\xi\left(1+\frac{(\xi \sigma)^{2}}{3 !}+\frac{(\xi \sigma)^{4}}{5 !}+\ldots\right)\right]^{m} \sigma^{m-1}} \\
\mu=A^{-1} e^{\frac{Q}{R T}}\left[\xi\left(1+\frac{(\xi \sigma)^{2}}{3 !}+\frac{(\xi \sigma)^{4}}{5 !}+\ldots\right)\right]^{-m} \sigma^{1-m}
\end{gathered}
$$

where $\dot{\varepsilon}$ is plastic strain rate, $A$ is pre-exponential factor (material specific), $m$ is strain rate sensitivity (material specific), $\xi$ is multiplier of stress (material specific), $R$ is gas constant $\left(\mathrm{J} \mathrm{K}^{-1} \mathrm{~mol}^{-1}\right)$. 


\section{List of References}

[1] J. Chen and H. Lu. "Investigation on ductility dip cracking susceptibility of filler metal 82 in welding." Transactions of JWRI 39(2), 91-93 (2010).

[2] F. Matsuda, H. Nakagawa, K. Nakata, H. Kohmoto, and Y. Honda. "Quantitative evaluation of solidification brittleness of weld metal during solidification by means of in-stu observation and measurement (Report I)." Transactions of JWRI 12, 65-72 (1983).

[3] F. Matsuda, H. Nakagawa, H. Kohmoto, Y. Honda, and Y. Matsubara. "Quantitative evaluation of solidification brittleness of weld metal during solidification by means of in-stu observation and measurement (Report II)." Transactions of JWRI 12(1), 73-80 (1983).

[4] F. Matsuda, H. Nakagawa, and S. Tomita. "Quantitative evaluation of solidification brittleness of weld metal during solidification by means of in-stu observation and measurement (Report III)." Transactions of JWRI 15(2), 125-133 (1986).

[5] M. G. Collins, A. J. Ramirez, and J. C. Lippold. "An investigation of ductilitydip cracking in nickel-based weld metals - part III." Supplement to the Welding Journal 91, 39s-49s (2004).

[6] Goldak Technologies Inc. "VrSuite." software (2012).

[7] J. Chen, H. Lu, and W. Cui. "Study on ductility dip cracking susceptibility in filler metal 82 during welding." Material Science 5(2), 203-208 (2011).

[8] F. Matsuda, H. Nakagawa, and S. Tomita. "Quantitative evaluation of solidification brittleness of weld metal during solidification by means of in-stu observation and measurement (Report V)." Transactions of JWRI 19(1), 93-98 (1990).

[9] A. J. Ramirez, J. W. Sowards, and J. C. Lippold. "Improving the ductility-dip cracking resistance of ni-base alloys." Journal of Materials Processing Technology 179, 212-218 (2006). 
[10] K. Masubuchi. Analysis of Welded Structures: Residual Stresses, Distortion, and their Consequences. Number 33 in International Series on Materials Science and Technology. Pergamon, Oxford (1980).

[11] Z. Feng. Methodology for Quantifying the Thermal and Mechanical Conditions for Weld Metal Solidification Cracking. Ph.D. thesis, Ohio State University, Columbus (1993).

[12] R. A. Chihoski. "Understanding weld cracking in aluminum sheet is aided by studying a pattern of stresses and strains caused by a moving heat source like a welding arc." Welding Journal 25, 24-30 (1972).

[13] K. Nishimoto, T. O. I Woo and, and M. Shirai. "Factors affecting HAZ cracking susceptibility of laser welds. study of weldability of inconel 718 cast alloy (4th report)." Welding International 15(12), 965-972 (2001).

[14] F. Matsuda and S. Tomita. Quantitative evaluation of solidification brittleness of weld metal MISO technique. ASM, Materials Park (1993).

[15] V. Ploshikhin, A. Prikhodovsky, M. Makhutin, A. Ilin, and H. W. Zoch. "Integrated mechanical-metallurgical approach to modeling of solidification cracking in welds." In T. Böllinghaus and H. Herold, editors, "Hot Cracking Phenomena in Welds," pages 223-244. Springer Berlin - Heidelberg (2005).

[16] N. N. Prokhorov and N. N. Prokhorov. "Fundamentals of the theory for technological strength of metals while crystallising during welding." Transactions of Japan Welding Society 2(2), 109-117 (1971).

[17] K. Nishimoto, K. Saida, Y. Nomoto, and A. Taniguchi. "Prevention of microcracking in multipass welds of alloy 690 and dissimilar multipass welds of alloy 690 to type 3161 stainless steel." Technical report, Division of Material \& Manufacturing Science - Graduate School of Engineering - Osaka University, Osaka (2010).

[18] R. A. Chihoski. "Expansion and stress around aluminum weld puddles." Welding Journal, Research Supplementary 59, 263s 276s (1979).

[19] J. A. Goldak and M. Akhlaghi. Computational Welding Mechanics. Springer US, New York (2005).

[20] R. Blondeau. Metallurgy and Mechanics of Welding: Processes and Industrial Applications. International Scientific and Technical Encyclopedia (2008). 
[21] F. Matsuda, K. Nakata, and S. Harada. "Moving characteristics of weld edges during solidification in relation to solidification cracking in GTA weld of aluminum alloy thin sheet." Transactions of JWRI 9(2), 83-93 (1980).

[22] K. Easterling. Introduction to the Physical Metallurgy of Welding. Butterworths, London (1983).

[23] B. A. Graville. The Principles of Cold Cracking Control in Welds. Dominion Bridge Company, San Francisco (1975).

[24] J.-L. Chaboche. "Continuous damage mechanics - a tool to describe phenomena before crack initiation." Nuclear Engineering and Design 64, 87-105 (1981).

[25] A. J. Ramirez and J. C. Lippold. "Ductility dip cracking of Ni-base filler metals insight into the mechanism." In "Technical Sessions," American Welding Society (2003).

[26] H. Okauchi, Y. Nomoto, H. Ogiwara, K. Saida, and K. Nishimoto. "Metallurgical mechanism of ductilty-dip cracking in multipass welds of alloy 690." Transactions of JWRI 39(2), 221-223 (2010).

[27] G. A. Young, T. E. Capobianco, M. A. Penik, B. W. Morris, and J. J. McGee. "The mechanism of ductility dip cracking in nickel-chromium alloys." Welding Journal 87(2), 31s-43s (2007).

[28] S. Kou. "Solidification and liquation cracking issues in welding." JOM Journal of the Minerals, Metals and Materials Society 55, 37-42 (2003).

[29] S. Kou. "Hot cracking in welds of $\mathrm{Al}$ and $\mathrm{Mg}$ alloys." In "3rd International Hot Cracking Workshop," Columbus (2010).

[30] F. Matsuda and H. Nakagawa. "Some fractographic features of various weld cracking and fracture surfaces with scanning electron microscope - studies on fractography of welded zone (I)." Transactions of JWRI 6(1), 81-90 (1977).

[31] V. Ploshikhin, A. Prikhodovsky, A. Ilin, C. Heimerdinger, and F. Palm. "Mechanical-metallurgical approach for prediction of solidification cracking in welds." Mathematical Modelling of Weld Phenomena 8, 87-105 (2007).

[32] J. D. Verhoeven. Fundamentals of Physical Metallurgy. John Wiley \& Sons, New York (1975).

[33] S. Kou. Welding Metallurgy, volume 2. Wiley Interscience, New Jersey (2003). 
[34] F. Matsuda, H. Nakagawa, and K. Sorada. "Dynamic observation of solidification and solidification cracking during welding with optical microscope." Transactions of JWRI 11(2), 67-77 (1982).

[35] G. M. Goodwin. "Test methods for evaluating hot cracking: Review and perspective." United States-Japan Symposium on Advances in Welding Metallurgy 1, 59-78 (1990).

[36] J. C. Lippold. "Recent developments in weldability testing for advanced materials." In "International Conference on Joining of Advanced and Specialty Materials VII," ASM International. Conference Keynote (2004).

[37] C. L. M. da Silva and A. Scotti. "Performance assessment of the (trans) varestraint tests for determining solidification cracking susceptibility when using welding processes with filler metal." Measurement Science and Technology 15, 2215-2223 (2004).

[38] J. Goldak, A. Chakravarti, and M. Bibby. "A new finite element model for welding heat sources." Metallurgical Transactions B 15B, 299-305 (1984).

[39] F. Matsuda, H. Nakagawa, and S. Tomita. "Quantitative evaluation of solidification brittleness of weld metal during solidification by means of in-stu observation and measurement (Report IV)." Transactions of JWRI 16(2), 89-95 (1987).

[40] W. Zhang. personal communication (2011).

[41] "1st International Workshop, Hot Cracking Phenomena in Welds." Berlin (2004, 2007 and 2010).

[42] "2nd International Workshop on Hot Cracking." Berlin (2007).

[43] "3rd International Hot Cracking Workshop." Columbus (2010).

[44] J. Eftis, M. S. Abdel-Kader, and D. L. Jones. "Comparisons between the modified Chaboche and Bodner-Partom viscoplastic constitutive theories at high temperatures." International Journal of Plasticity 5, 1-27 (1989).

[45] H. A. Barnes. "The yield stress - a review or ' $\pi \alpha \nu \tau \alpha \rho \varepsilon \iota$ ' - everything flows?" Journal of Non-Newtonian Fluid Mechanics 81(1-2), 133-178 (1999).

[46] J. Betten. Creep Mechanics. Springer (2008). 
[47] A. Fehér, M. S. S. Linn, A. Scholz, and C. Berger. "An interactive approach to creep behavior modeling." Materials Science and Engineering A 510-511, 29-34 (2009).

[48] A. Tjan and Y. Adrian. "Analysis of creep properties of bituminous mixture with constant rate of load increment method." Proceedings of the Eastern Asia Society for Transportation Studies 4, 450-460 (2003).

[49] L. Anand. "Constitutive equations for hot-working of metals." International Journal of Plasticity 1, 213-231 (1985).

[50] T. W. Wright. The Physics and Mathematics of Adiabatic Shear Bands. Cambridge University Press, Cambridge (2002).

[51] N. Bai, X. Chen, and H. Gao. "Simulation of uniaxial tensile properties for leadfree solders with modified Anand model." Materials and Design 30, 122-128 (2009).

[52] V. V. Bulatov and W. Cai. Computer simulations of dislocations. Oxford University Press, Oxford (2006). 